\title{
CRITICAL SUCCESS FACTORS FOR DIFFERENT ORGANIZATIONS IN CONSTRUCTION PROJECTS
}

by

\section{ASFANDYAR INAYAT}

B.E., National University of Sciences and Technology, Pakistan, 2001

\section{A THESIS}

submitted in partial fulfillment of the requirements for the degree

\section{MASTER OF SCIENCE.}

Department of Civil Engineering

College of Engineering

\author{
KANSAS STATE UNIVERSITY \\ Manhattan, Kansas
}

2012

Approved by:

Dr. Hani Melhem 


\section{Copyright}

ASFANDYAR INAYAT

2012 


\begin{abstract}
Researchers have been compiling lists of key factors the presence or absence of which have determined the success or failure of projects. Early researches of critical success factors were largely theory based; subsequent researches employed the use of statistics and continuously refined methods like neural network and the analytical hierarchy process. Over the passage of time, the focus has narrowed down from broad generalization of 'projects' to 'project classes'.
\end{abstract}

The thesis can be broadly divided into three components.

\title{
First Component:
}

The first component (Chapter 1, 2, and 3) leads an insight into the basic concept of success factor studies, and the empirical frameworks adopted for identification of critical success factors. The second and the third component, comprises literature review and original research, respectively. These components pertain to success factor studies of construction projects, and are introduced as below.

\section{Second Component:}

The second component (Chapter 4: Review Component) sets out to choose from among a treasure of resources on construction projects, three such state of the art works that can best explain the progress in search of success factors over a period of the foregoing 25 years. After discussing each work in detail, the reader's attention is drawn to a collective discussion, and summary towards the end of the Review Component. The review includes the following works: (1) Pinto and Covin, 1989, (2) Ashley et al., 1987, and (3) Kog and Loh, 2011.

Pinto and Covin (1989) endeavored to set aside the convenient research trend of treating all project types (Manufacturing, R\&D, Construction etc.) as similar. It was felt that management practitioners considered the generalized project management prescriptions offered by researchers as mostly inapplicable to the unique situations posed by their respective classes of projects. Stepwise regression analysis was employed to seek separate sets of CSFs for construction and R\&D projects. The choice of these two project types was made as they apparently lied on opposite ends of the spectrum of characteristics. The phases of project lifecycle considered for 
determining CSFs were conceptualization, planning, execution, and termination. It was concluded that though identification of a set of general critical success factors has some benefits for both academics and practitioners, strict adherence to them would not necessarily ensure project success. It was proved that every project type offers its own set of problems, and that these vary over a project's lifecycle.

The review briefly touches upon the work of Ashley et al. (1987) so as to lead an insight into yet another methodology adopted by CSF researchers. This study views project success from the project managers' perspective for the owner and contractor organizations they works for, and does not take into consideration the view point of other professionals working for owner, contractor and consultant organizations. Hypothesis testing was employed to find those factors that exhibited strong statistical difference while going from average to outstanding projects.

Kog and Loh (2011) studied a possible dissimilarity between CSFs pertaining to different components of construction projects: (1) civil works, (2) architectural works, and (3) mechanical and electrical works. Using the Analytical Hierarchy Process the CSFs were compared separately for the objectives of budget, schedule, quality, and overall performance. They concluded that, on the whole, markedly distinct sets of factors were perceived as crucial by professionals associated with these three components. Apart from their varying job descriptions, the divergence in views of professionals was interpreted to be an outcome of the different frames of time that they mostly work in. While a major portion of civil and structural works would be undertaken in early project-life, mechanical and electrical works, and architectural works would be initiated later in the project's life. For the three components of construction projects ( $C \& S$ : civil \& structural, $M \& E$ : mechanical \& electrical, and architectural works), the highest correlation of views was seen to exist between the $C \& S$ and $M \& E$, while the lowest was always that between the M\&E and the architect. This trend remained the same whether the goal of overall performance or any of the three objectives were taken into consideration.

\section{Third Component:}

The thesis terminates with the original work (Research Component: Chapter 5) conducted by the author in the light of Chua et al. (1999) that had attempted, though very briefly, to distinguish between CSFs for different organizations involved in construction projects. Because the survey sample of Chua et al. (1999) was quite small, the researchers referred to their findings 
regarding organization-based CSFs as inconclusive. It was suggested that further research be conducted in this regard. Addressing these recommendations, the 'Research Component' has differentiated the CSFs based on organizational backgrounds of project participants: consultants, contractors, and project management organizations.

Spearman's test on overall rankings of 40 significant factors results in a highest level of correlation between the managers and contractor personnel ( $\mathrm{rs}=0.54)$, followed by that between the managers and the consultants $(\mathrm{rs}=0.50)$, and a least correlation between the contractor personnel and the consultants (rs=0.19). Managers not only maintain a significant presence on the site with the contractors, but also coordinate with the consultants regarding any designconstruction issues that arise more than often during project execution: No wonder why their pivotal position helps the managers to establish a higher understanding with both contractor personnel and consultants. The lowest correlation of views between the contractor personnel and the consultants arise from the spot on difference between their workspace environments. Whereas the contractor personnel operate in the field, the consultants are mostly restricted to their design offices. 


\section{Table of Contents}

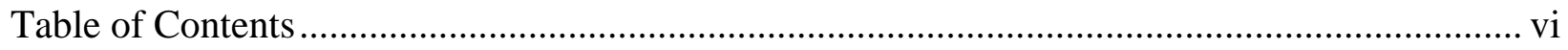

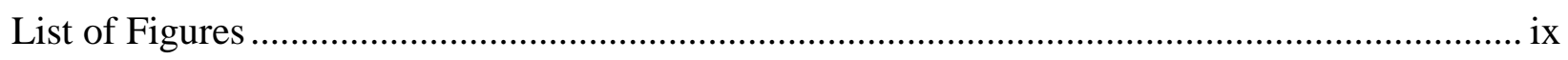

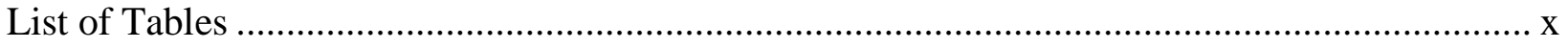

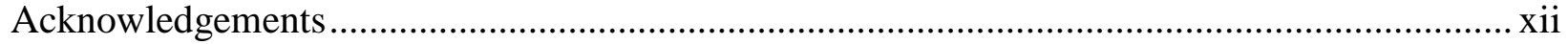

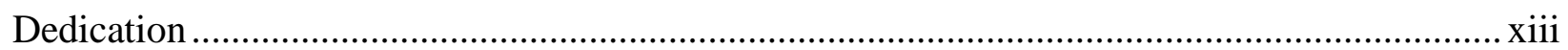

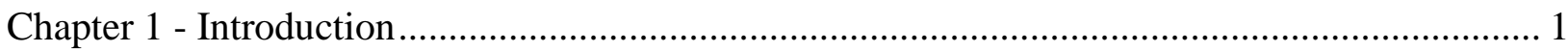

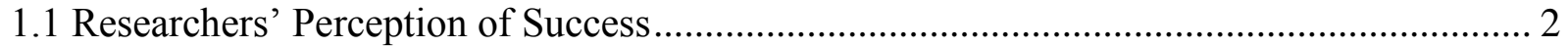

1.1.1 Tuman's Success Perception: Stakeholders and Objectives ................................... 3

1.1.2 Sanvido’s Success Perception: Stakeholders and Objectives ................................. 4

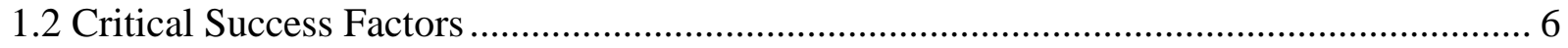

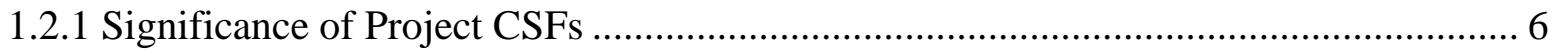

1.2.2 CSFs: Some Important Considerations .............................................................. 7

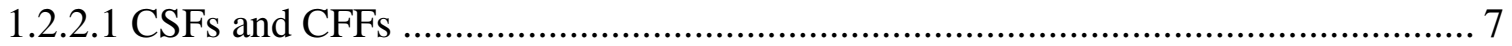

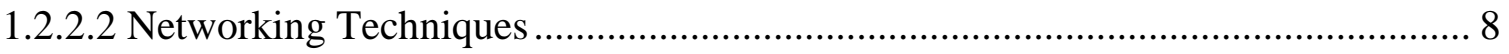

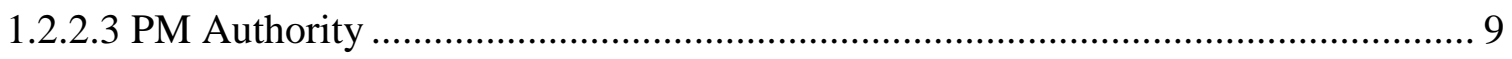

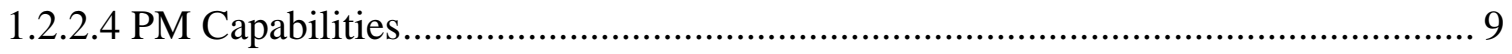

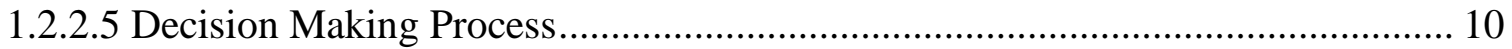

Chapter 2 - Approaches Employed in CSF-Research ....................................................... 12

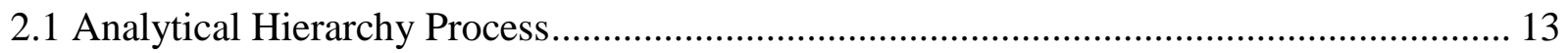

2.2 Illustration of Analytical Hierarchy Process ............................................................. 16

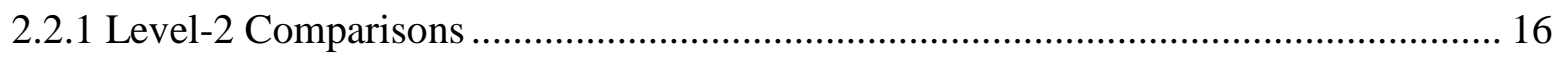

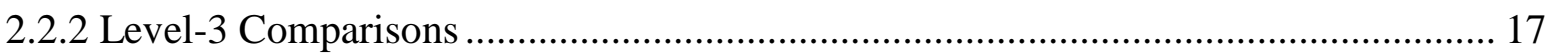

2.2.3 Relative Importance of Alternates for the Goal .................................................. 19

Chapter 3 - Statistical Approaches Used by Researchers .................................................... 20

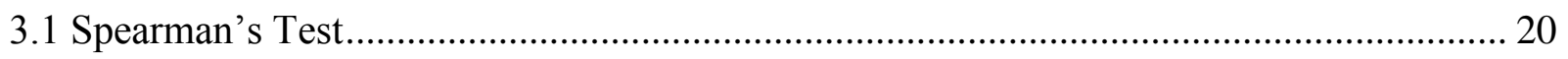

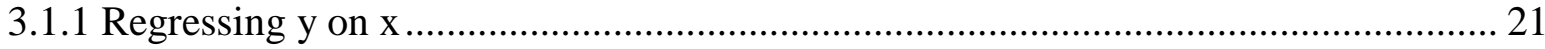

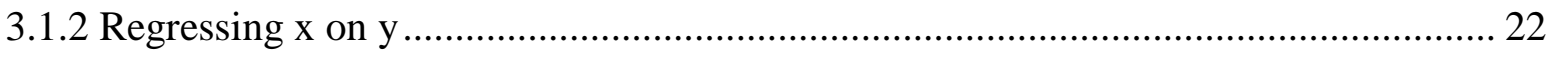

3.1.3 Pearsonian Coefficient of correlation .............................................................. 23

3.1.3.1 Spearman's Coefficient of Rank Concordance ................................................ 25 


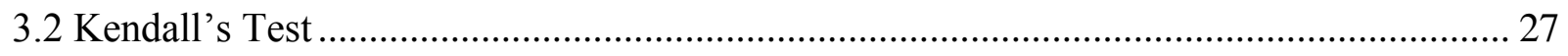

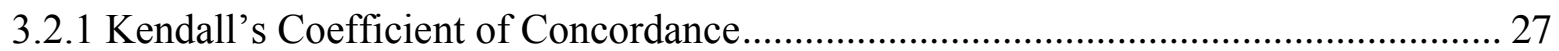

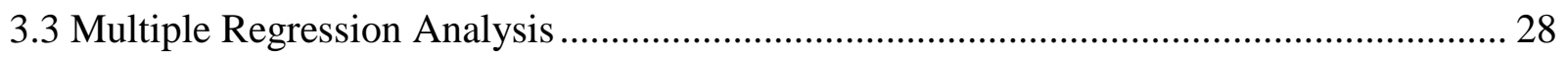

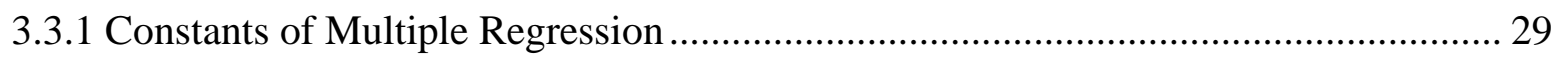

3.3.2 Coefficient of Multiple Correlation .............................................................................. 29

3.3.3 Coefficients of Partial Correlation ............................................................................. 31

3.3.4 Extension to n Variables ...................................................................................... 32

3.3.4.1 Coefficients of Partial Correlation ...................................................................... 32

3.3.4.2 Coefficient of Multiple Correlation ……………….......................................... 33

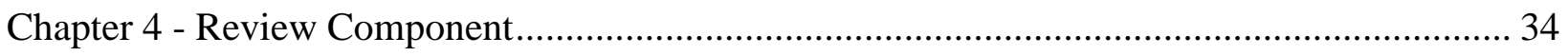

4.1 Work by Pinto and Covin ........................................................................................... 34

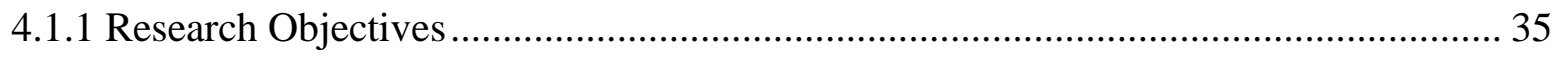

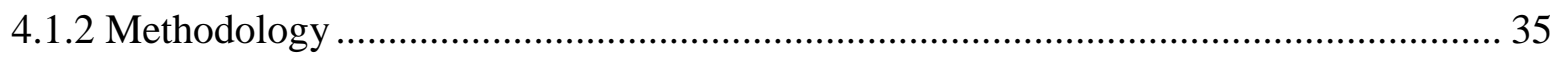

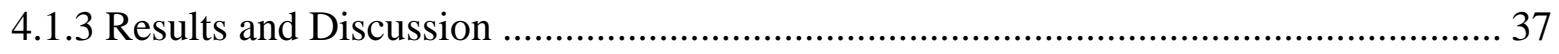

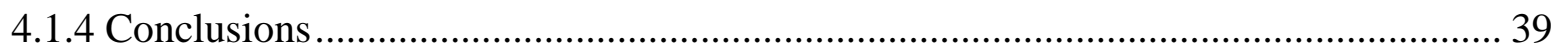

4.2 Work by Ashley et al ............................................................................................. 41

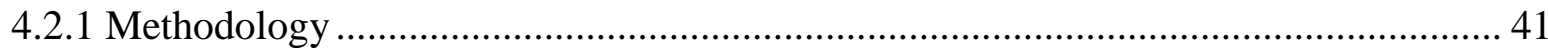

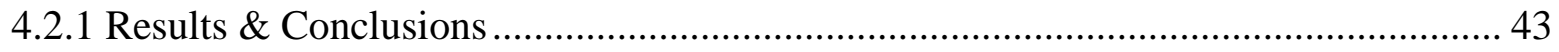

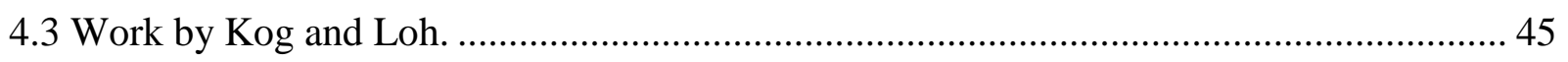

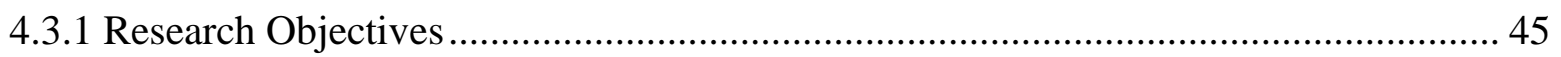

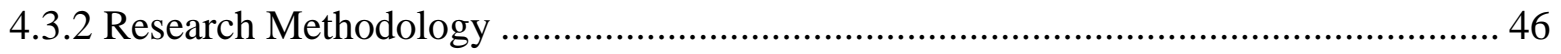

4.3.2.1 Preliminary Findings (Initial Results and Conclusions) ....................................... 50

4.3.3 Final Findings (Final Results and Conclusions) ........................................................ 53

4.3.3.1 Results: Grouping Based on Components ........................................................... 53

4.3.3.2 Results: Grouping Based on Objectives …………………………………..... 54

4.3.3.3 Conclusions and Discussion .......................................................................... 55

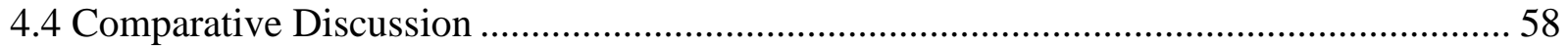

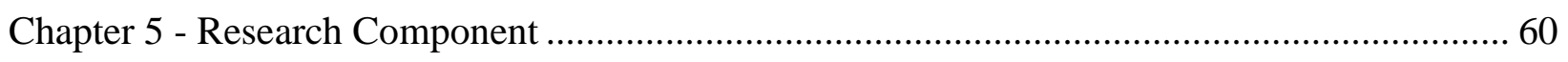

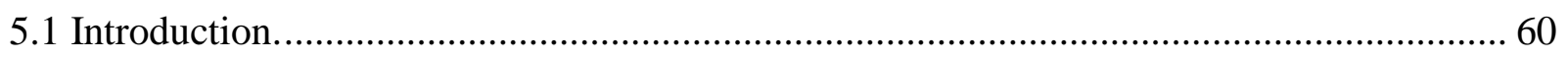

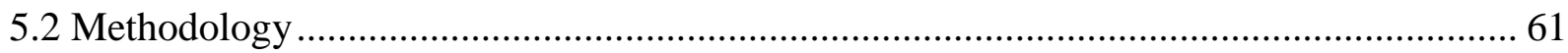

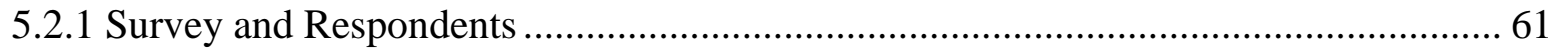




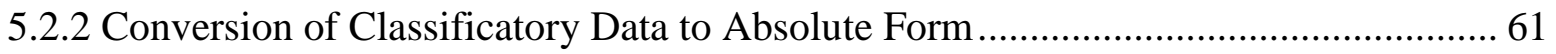

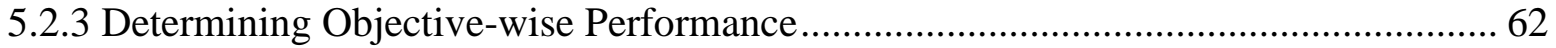

5.2.4 Determining Overall Project Performance....................................................... 63

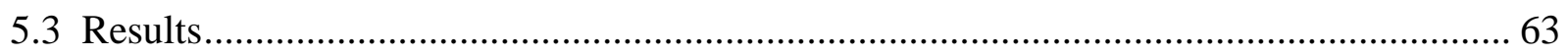

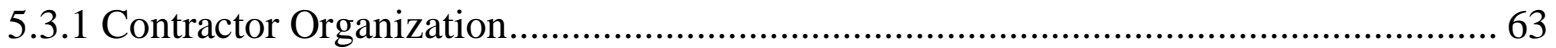

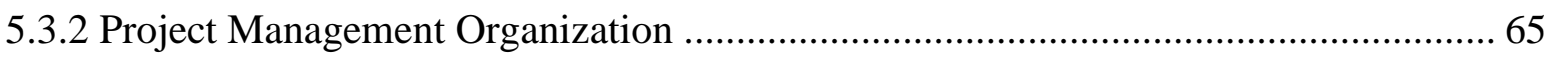

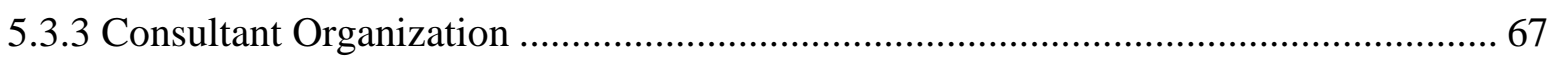

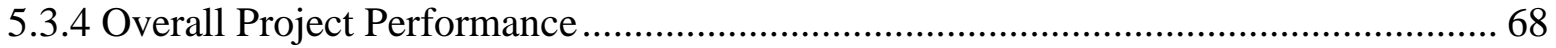

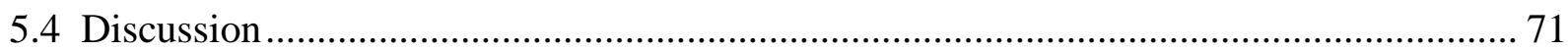

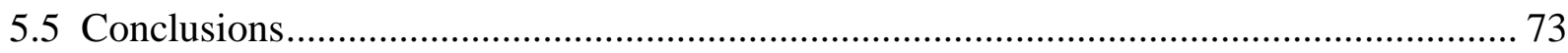

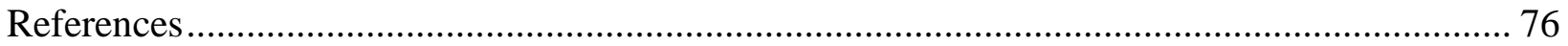




\section{List of Figures}

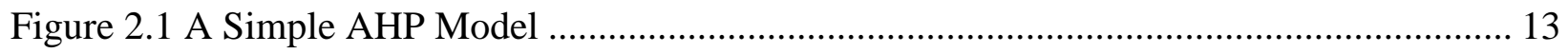

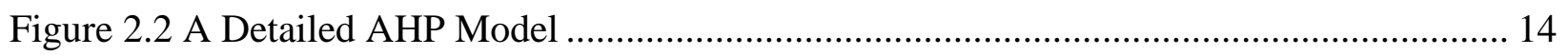

Figure 2.3 AHP Model for Illustrative Example ............................................................. 16

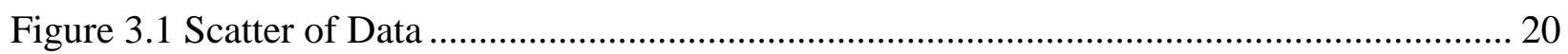

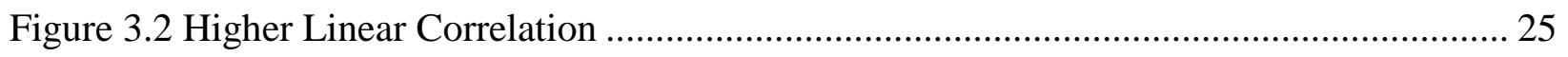

Figure 3.3 Lower Linear Correlation. ........................................................................... 26

Figure 4.1 Subjective Factor Rating by Owner and Contractor PMs [Jaselskis 1988]................ 42

Figure 4.2 Factor Significance Level for Average versus Outstanding Projects [Ashley et al.

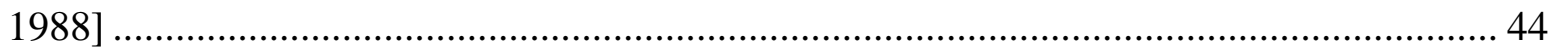

Figure 4.3 AHP Model for Construction Project Success [Chua et al. 1999] ............................ 47

Figure 4.4 Subhierarchy for Project Characteristics [Chua et al. 1999] ..................................... 47

Figure 4.5 Subhierarchy for Contractual Arrangements [Chua et al. 1999] .............................. 48

Figure 4.6 Subhierarchy for Project Participants [Chua et al. 1999]........................................ 48

Figure 4.7 Subhierarchy for Interactive Processes [Chua et al. 1999] ...................................... 49 


\section{List of Tables}

Table 1.1 Criteria for Measuring Success [Sanvido et al. 1992] ................................................ 5

Table 2.1 Fundamental Pairwise Comparison Scale [Saaty 2006] ........................................... 14

Table 2.2 Saaty's Random Consistency Index [Saaty 1980] ................................................ 15

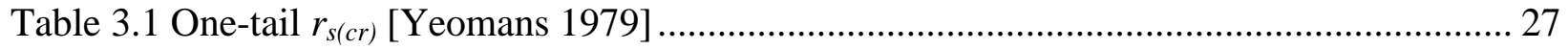

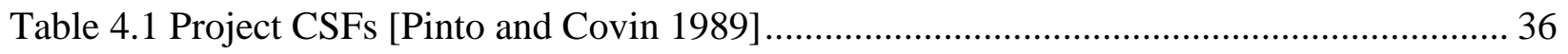

Table 4.2 Comparison of CSFs in Each Stage of Project Lifecycle (Construction and R\&D)

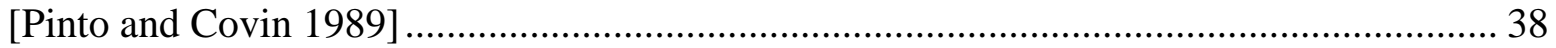

Table 4.3 Selected Major Success Factors [Jaselskis 1988] ................................................. 43

Table $4.4 r_{s}$ Between Different Expertise Level (Schedule Performance) [Kog and Loh 2011] . 51

Table 4.5 $r_{s}$ Between Different Expertise Level (Budget Performance) [Kog and Loh 2011] .... 51

Table 4.6 $r_{s}$ Between Different Expertise Level (Quality Performance) [Kog and Loh 2011] .... 51

Table $4.7 r_{s}$ Between Different Expertise Level (Overall Performance) [Kog and Loh 2011] ... 51

Table $4.8 r_{s}$ Between Different Professions (Schedule Performance) [Kog and Loh 2011] ....... 57

Table $4.9 r_{s}$ Between Different Professions (Budget Performance) [Kog and Loh 2011] ........... 57

Table 4.10 $r_{s}$ Between Different Professions (Quality Performance) [Kog and Loh 2011] ......... 57

Table 4.11 $r_{s}$ Between Different Professions (Overall Performance) [Kog and Loh 2011] ......... 57

Table 5.1 Fundamental Pairwise Comparison Scale [Saaty 2006] .......................................... 62

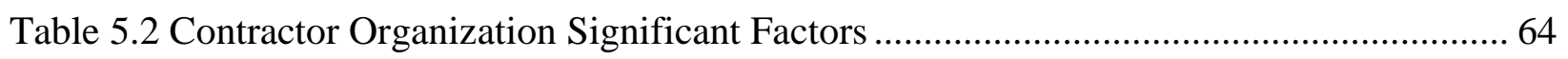

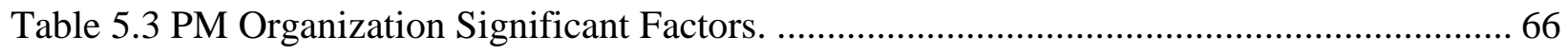

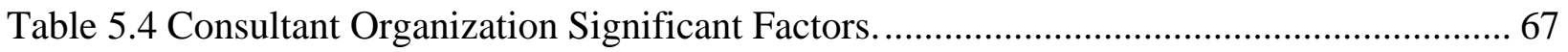

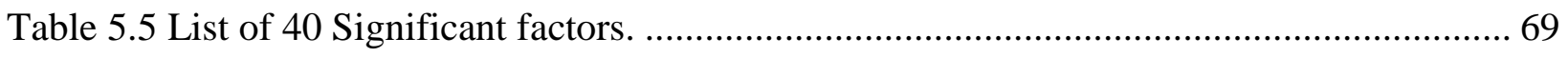

Table 5.6 CSFs for Overall Project Success. ...................................................................... 70

Table A.1 Strong Failure Factors [Murphy et al. 1974] .......................................................... 79

Table A.2 Strong Success Factors [Murphy et al. 1974] .......................................................... 80

Table A.3 Strong Common Factors [Murphy et al. 1974] ...................................................... 81

Table B.1 List of 67 Potential Factors Considered in the Study [Kog and Loh 2011] ................ 82

Table B.2 Ranking of CSFs for C\&S Works [Kog and Loh 2011] ....................................... 83

Table B.3 Ranking of CSFs for M\&E Works [Kog and Loh 2011] ...................................... 83

Table B.4 Ranking of CSFs for Architectural Works [Kog and Loh 2011] ............................. 84 
Table B.5 Ranking of CSFs for QS Works [Kog and Loh 2011] .......................................... 84

Table B.6 Ranking of CSFs for Schedule Performance [Kog and Loh 2011] ........................... 85

Table B.7 Ranking of CSFs for Quality Performance [Kog and Loh 2011] ............................ 86

Table B.8 Ranking of CSFs for Budget Performance [Kog and Loh 2011] ............................. 87

Table B.9 Ranking of CSFs for Overall Performance [Kog and Loh 2011] ............................ 88

Table C.1 List of 53 Potential Factors Considered in the Study............................................ 89

Table C.2 Explanation of Important Factors.................................................................... 90 


\section{Acknowledgements}

I would like to express my indebtedness to my Major Advisor Dr. Hani G. Melhem without whose continued support many errors and ambiguities would have gone unnoticed. Credit goes to him for encouraging me to pursue a research topic that is innovative and not a continuation of the research activities at the department of Civil Engineering at Kansas State University.

Sincere acknowledgement is due to Dr. Hayder Rasheed and Dr. Asad Esmaeily for serving on my committee. While I was taking courses in structural design and analysis instructed by them I was mentored into the importance that research plays in the development of a nation's infrastructure.

Thanks to all those experts who spared their time to fill in the surveys that forms the crux of the analysis in the last part of this study. Special thanks to my father (M.S. in Traffic and Highway Engineering) and fellows who requested their references to dedicate their time for the research. Professionals hailing from London Borough of Newham, MS Mohindeseen-e-Masud Builders of Pakistan, MS Saudi BinLaden Group, and other firms from Canada and the UAE are applauded for their valuable contributions.

Last, but no means least, I thank the Fulbright Commission for honoring me with their prestigious scholarship to pursue my academic goals and be a proud alumni of Kansas State University. 


\section{Dedication}

To my parents. 


\section{Chapter 1 - Introduction}

A project is a costly and high risk undertaking that needs to be accomplished by a certain date, for a certain amount of money and within some expected level of performance. Important aspects of a project includes "inputs" in the form of men, money, materials, and plans, and "outputs" in the form of activities, products, or services. Project management is the name given to assessing the time-based needs of a project followed by adequate resource allocation and ensuring optimum utilization of the allocated resources. In other words, management of a project is a chain cycle of well-defined monitoring, information, and control systems without which the project-implementation would be a hodge-podge of poorly related elements [PMH 1983].

Characteristics like high cost, riskiness and complexity of large projects are bound to become "more pronounced in the future as inflation, government regulations and interdependencies of economies all work to produce an environment of dynamic uncertainty [PMH 1983]." It would not be inappropriate to say that the current slump in construction activities around the world was fuelled by a recession that had its roots in the US economy: unfavorable economic environments decrease the feasibility or success probability of construction projects. Another environmental factor affecting the success probability of construction projects is the extent of political stability - a primary concern for undertakings in third world countries where a shift in government policies may not augur well for any of the various stakeholders involved in construction projects.

"Success of construction projects" is a relative conglomeration of words; a more appropriate alternative phrase would perhaps be "perceived success of construction projects [PMH 1983]." It is, however, important to emphasize that a project perceived as successful by the financer (i.e. owner) may be seen as a failure by the end user and vice versa; a project perceived as successful by the developer and consultant may not produce benefits as were initially expected by its constructor. All participants, besides having common stakes, have their own unique sets of stakes involved in a construction project [Sanvido et al. 1992].

Owing to the non-absolute nature of the success, not surprisingly, efforts to describe it quite often led to rather some difficult to comprehend definitions. To quote an example, Ashley et al. (1987) define success as having "results much better than expected or normally observed in terms of cost, schedule, quality, safety, and participant satisfaction." 
Continuous contributions by researchers, did however, yield some meaningful success definitions. de Wit (1986) considers a project as an overall success if it meets the technical performance specifications and/or mission to be performed, and if there is a high level of satisfaction concerning the project outcome among key people in the parent organization, key people in the project team, and key users or clientele of the project effort. de Wit (1986), however, concludes that a project can simultaneously be a disaster for one stakeholder and a success for another. This conclusion further testifies the following findings:

(1) "Any study of success and failure in projects must before long decide what is meant by success: for whom? Using what criteria? And over what time period? [Morris 1983]."

(2) "One stakeholder's view of success can differ from another stakeholder's view of success [Cleland 1986].”

\subsection{Researchers' Perception of Success}

A researcher's perception of success is shaped by the characteristics of a particular study; the characteristics of study being a combination of performance criteria, project participants (direct stakeholders), and likely consideration of project phases.

Performance criteria, often referred to as objectives or success criteria, are the different perspectives that success may be looked upon. These include, but are not limited to, schedule performance, budget performance, quality performance, functionality, marketability, constructability, aesthetics, and safety [Sanvido et al. 1992].

Project Participants are the individuals or groups who have direct stakes involved in the project. These direct stakes are inputs to the project in the form of money, men, materials, equipment, and time. Participants of a project include the developer, financer, consultant, constructor, and end-user [PMH 1983]. Any combination of participants engaged by the researcher would result in consideration of a separate set of objectives.

A researcher may also like to include the consideration of project lifecycle phases in success studies. The phases considered by a researcher may include the conceptualization, planning (including design), execution, and termination. From the perspective of a project management organization, these phases may be defined as follows [Pinto and Covin 1989]: 
Conceptualization: Realization of needs followed by suggestions for development of a project. This phase includes establishment of goals, implementation plans, and the resources needed for project implementation.

Planning: $\quad$ This phase includes preparation of detailed plans regarding accomplishment of established goals, and establishment of budgets to provide direction to the plans.

Execution: This phase involves procurement of resources to carry out the project on ground.

Termination: $\quad$ Project is handed over to the intended user, and project team members and unused resources are assigned to other running or new projects undertaken by the organization.

\subsubsection{Tuman's Success Perception: Stakeholders and Objectives}

Selection of performance criteria depends on the set of stakeholders that are considered for a study. Tuman (1986) categorized the various stakeholders involved in a construction project as follows:

Project Champions: Include those who have a reason for the project to come into being. Private developers and investors, government agencies and taxpayers, and politicians as recommenders of public projects are examples of project champions. The objectives important to project champions are good return on investment and fame.

Project Participants: Include those who have a role to play in project implementation. The consultant, contractor, suppliers and regulators working within the framework of a project are examples of project participants [Tuman 1986]. The term "consultant" can refer to the project management team exclusively, as well as in combination with associated civil, architectural, mechanical and electrical designers. The term "project management team" refers to the "parent organization" (hierarchy above the level of project managers) in combination with the "project team" (including the project manager) for a certain project [PMH 1983]. The objectives important to project participants include budget, schedule, quality, safety performance and fulfilling other stakeholders' objectives. 
Community Participants: Special groups like religious groups, political groups, and environmentalist groups. The objectives important to them include minimizing negative impacts on the community.

Parasitic Participants: Opportunists seeking self-fulfillment either philosophically or materially.

\subsubsection{Sanvido’s Success Perception: Stakeholders and Objectives}

Sanvido et al. (1992) considered three stakeholders among the project team which included the owner/financer, designer/consultant, and contractor. The term "project team", as used by Sanvido et al., was not limited only to the employees of the project management organization but rather as an alternative term to "all stakeholders".

Table 1.1 shows the objectives that are important to the individual stakeholders. It can be seen that where objectives may be common between the stakeholders, the reasons for their consideration may well be different: The owner may want an on time and on budget completion of a project to avoid possible effects of inflation and to reap on maximum possible benefits of the investment (Maximum and fastest return on investment); the consultant and contractor may be concerned with meeting budget and schedule to maintain their own cash flows and for timely allocation of organizational resources to other projects. The common objectives of schedule performance, budget performance, quality performance, and client satisfaction originate not only from the reality of doing business but also from the realization of professional responsibility. Absence of any legal claims on a project (and also client satisfaction) is another common desirable outcome recognized by all the three stakeholders. This means that absence of legal claims serves a major criteria for defining and hence determining project success from the viewpoint of the stakeholders considered by Sanvido et al. (1992).

The objective of marketability is common for different reasons to the owner than to the designer: Whereas the owner is looking for a good return on investment, the designer aspires marketability of a project for professional recognition among peers, and for staying in the good books of the client. The objective of constructability is common for the designer and contractor as both aspire minimal or no surprises during the project implementation [Sanvido et al. 1992]. 
Table 1.1 Criteria for Measuring Success [Sanvido et al. 1992]

\begin{tabular}{|c|c|c|c|}
\hline & Owner's Objectives & $\begin{array}{c}\text { Designer/Consultant's } \\
\text { Objectives }\end{array}$ & Contractor's Objectives \\
\hline \multirow{5}{*}{ 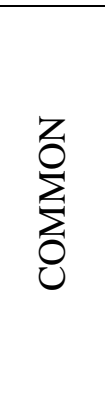 } & On schedule & Meeting project schedule & Meeting project schedule \\
\hline & On budget & Meeting project budget & $\begin{array}{l}\text { Under budget (profit for self } \\
\text { and/or owner) }\end{array}$ \\
\hline & Quality (workmanship) & Meeting quality specifications & Meeting quality specifications \\
\hline & $\begin{array}{c}\text { Client satisfaction } \\
\text { (Reputation with users) }\end{array}$ & $\begin{array}{c}\text { Client satisfaction } \\
\text { (Reputation with owners) }\end{array}$ & $\begin{array}{c}\text { Client satisfaction } \\
\text { (Reputation with owners and } \\
\text { consultants) }\end{array}$ \\
\hline & Absence of legal claims & Absence of legal claims & Absence of legal claims \\
\hline \multirow{3}{*}{ 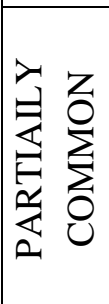 } & $\begin{array}{c}\text { Marketability } \\
\text { (Return on investment) }\end{array}$ & $\begin{array}{c}\text { Marketability } \\
\text { (Image with peers and client) }\end{array}$ & - \\
\hline & - & Constructability & Constructability \\
\hline & - & Payments by client & Payments by client \\
\hline \multirow{4}{*}{ 岁 } & Aesthetics & - & - \\
\hline & Functionality & - & - \\
\hline & - & Professional Staff Fulfillment & - \\
\hline & - & - & Safety \\
\hline
\end{tabular}

Some objectives are seen to be uniquely important to the stakeholders considered. The Objective of professional staff fulfillment, referring to development of new skills by employees from every project, is considered important only by the designers/consultants. The objective of safety has a higher importance for the contractor as compared to the other two stakeholders: contractor's staff is more vulnerable to construction accidents owing to its continuous on-site presence. Similarly, functionality of a project is uniquely important to the owner as it ensures the intended use and minimizes maintenance works [Sanvido et al. 1992]. 


\subsection{Critical Success Factors}

Consensus exists among researchers that most reasons for project success can be attributed to the presence or absence of certain project characteristics: comprising organizational rules, executive procedures, and environmental conditions [Pinto and Covin 1989]. These project characteristics, referred to as critical success factors (CSFs), require special attention from the management owing to their impact on project performance. CSFs are predictors of project success that may be positive or negative in their influence, and hence the key to project success lies in enhancing those which are positive, and reducing those which are negative in nature. The term critical success factors was introduced to the field of project management by Rocart in 1982 who defined it as, "Those few areas of activities in which favorable results are absolutely necessary for a particular manager to reach his or her goals [Sanvido et al. 1992].”

It is an established fact that the efficiency of an organization largely depends on successful implementation of the projects it undertakes [Pinto and Covin 1989]. It follows, therefore, that CSFs need to be employed by an organization if it was to avoid missed opportunities and unpleasant surprises. Boynton and Zmund (1984) defined critical success factors as, "Those few things that must go well to ensure success to a manager or organization, and therefore they represent those managerial or enterprise areas that must be given special and continual attention to bring about high performance [Sanvido et al. 1992]."

\subsubsection{Significance of Project CSFs}

A project is a costly, complex and high risk undertaking that needs to be completed within some expected levels of performance, and has limitations of time and money attached to it. Management of a project involves allocation of only those resources to the project that are felt essential at a particular time, and to ensure that the allocated resources are utilized to the optimum level [PMH 1983]. A knowledge of CSFs pertinent to the project type provides the means to better deploy valuable resources on relevant areas so as to achieve much better objectives and hence a successful project.

The complexity associated with the implementation of a project is bound to increase because ever changing government regulations and increasing interdependence of national economies would always produce an environment of dynamic uncertainties. In particular, construction projects involve carrying out a combination of events and interactions with 
changing participants and processes in a rapidly changing environment; the diversity of workatmosphere, in turn, making the job of project manager more challenging with each day of the project. While performing duties associated with planning, scheduling, budgeting, accounting, and evaluating, the project manager integrates information obtained from the various functional departments, and reports it to top management in the form of progress reports and exception reports so as to aid project control decisions. This indeed is a difficult task and becomes more demanding when it comes to managing megaprojects or dealing with multiple companies over the same project. CSF studies highlights the need for a well-defined control and information system, tailor-stitched to the needs of the project and its manager. CSF researchers iterate that without such a control and information system in place, achieving success on large projects would be no more than wishful thinking [PMH 1983, Sanvido et al. 1992].

\subsubsection{CSFs: Some Important Considerations}

Sanvido et al. (1992) pointed out that the set of factors that contribute to the success of one type of project may not, in its entirety, be deterministic of success for another project type. Pinto and Covin (1989), as will be discussed later in detail, concluded that there exist distinct lists of factors that are responsible for the success of construction, and research and development (R\&D) projects; some factors, however, were seen to be critical for the success of both types of projects. Nevertheless, literature pertaining to management in fields other than construction management often provides a good preliminary source for extracting potential factors solely for CSF studies in the construction field.

In search for reasons of project success and failure, Murphy et al. (1974) collectively studied 670 projects related to construction, manufacturing, and R\&D. Though the findings of the study were not specific to construction projects, reference to it is made with the intent of explaining as to what may comprise CSFs. The study generated three separate lists of factors, that may be named as: (1) strong failure factors, (2) strong success factors, and (3) strong common factors (common to success and failure).

\subsubsection{CSFs and CFFs}

It is obvious that factors that have a positive correlation with project success will have the same negative correlation with project failure; similarly those that have a negative correlation with project success will have the same positive correlation with project failure. Intuition would 
have us believe that the inverses of all CSFs shall essentially constitute the list of critical failure factors (CFFs); however, such an understanding would only hold true if statistical analysis of the factors was not preceded by segregating the sample of projects into successful and unsuccessful projects.

Based on input from project participants, the 670 projects studied by Murphy et al. (1974) were, first of all, divided into three categories: (1) successful projects - those whose success was rated in the upper third, (2) average projects - those whose success was rated in the middle third, and (3) unsuccessful projects - those whose success was rated in the lower third. This was followed by subjecting the rated-factors to stepwise regression analysis separately for the group of successful and unsuccessful projects resulting in the following three sets of critical factors:

- Strong failure factors [Table A.1]: factors highly correlated with project failure only. Their absence shall not be presumed to ensure project success.

- Strong success factors [Table A.2]: factors highly correlated with project success only. They partly contribute to project CSFs.

- Strong common factors [Table A.3]: Their presence increases chances of project success and decreases chances of project failure. They partly contribute to project CSFs.

Combining the second and third list groups all the CSFs together, and combining the first list and the inverses of third list would form the CFFs. It is interesting to note that good budget and schedule performance could neither make up to the list of strong success factors nor to the list of strong common factors; similarly budget and schedule overrun could not show up in the list of strong failure factors. This apparent dichotomy can be understood from the realization that the 670 projects were studied after their completion: Budget and schedule considerations are considered extremely important during the course of a project, but are overweighed by other factors in a post-completion frame of time.

\subsubsection{Networking Techniques}

Networking techniques such as Critical Path Method (CPM) and Program Evaluation Review Technique (PERT) are generally considered being synonymous with project management. However, Murphy et al. (1974) discovered that 'overuse of CPM/PERT' actually 
reduces the chances of project success: Simultaneously implying it is the 'judicious use of CPM/PERT' that would result in a higher probability of project success. Explaining this point, the researchers refer to a military satellite program that was hindered due to reliance on a network covering four walls of a large conference room. Fortunately, owing to its confidentiality, someone ordered placement of curtains to cover it. "Once the curtains went up, they were never drawn again and the program proceeded as planned [Murphy et al. 1974]." Murphy and his colleagues referred to the complexity and time consumption associated with maintaining long networks of projects as being responsible for hampering their success; this finding may not hold true nowadays due to the advent of computerization.

\subsubsection{PM Authority}

Most organizational structures do not delegate authority to a project manager (PM) to a level commensurate with the demanding nature of this position. Generally the PM does not have any control on the employees with regard to deciding their salaries and bonuses, evaluating their performances, and assigning future responsibilities. At the most, the PM may be able to decide the employees' paid overtime, but even this is often subjected to strict scrutiny by the accounts section. In the event that the organizational rules allow the PM to evaluate the employees, the evaluations are forwarded for validation to the functional managers (FM), who may or may not agree with the PM's assessment of employees. Two reasons offered by organizations for this modus operandi are that (1) functional employees are only temporarily assigned to a PM during the course of project, and upon project termination, the employees are re-assigned to other running or new projects (While the employees work under different PMs, they always remain administratively attached to the same FM), and (2) within the same time frame, a functional employee may be working with multiple PMs but one FM (Sharing of Key Personnel). In such a scenario employees find it difficult to perceive themselves working for the PM who, by default, is not authorized to control the strings of their pockets; The PM, in turn, finds it difficult to motivate temporarily assigned employees for the objective of avoiding project failure [PMH $1983]$.

\subsubsection{PM Capabilities}

Murphy et al. (1974) determined that avoidance of failure requires three essential PM skills. Stated in a falling order of preference these are: 
- Technical skills.

- Influence.

- Administrative skills.

Influence, also referred to as interpersonal skills, must be distinguished from authority. Whereas authority is the power officially delegated to an individual to control his subordinates and to perform his duties effectively, influence is a capability possessed by an individual that can be used to solicit support from others for a desired result. In the absence of sufficient direct authority delegated by the top management, the PM can still assert himself on the employees using the following interpersonal skills [PMH 1983]:

- Formal Authority: Ability to solicit support from the employees because of their acceptance that a certain amount of authority has been delegated by the top management to the PM.

- Expert Power: Ability to gain support from the employees because of their recognition that PM possesses skills which they lack.

- Work Challenge: lobbying support from the employees because they would like future identification by the role they played in a challenging project.

- Reward Power: lobbying support from the employees because they recognize that the PM can either directly or indirectly allot the privileges that they enjoy.

- Referent power: Also referred to as friendship power is the means of obtaining support from the employees because they feel personally attracted to either the project or the PM.

\subsubsection{Decision Making Process}

It is the responsibility of the client organization to take the parent organization and project team in confidence while establishing clearly defined goals (success criteria) for a project. In case of in-house projects this responsibility of defining the project objectives shifts to the parent organization. Having established the goals upfront, except for extraordinary situations, the 'internal decision making process' must be left at the discretion of the project team.

Most client and parent organizations wrongly believe that the closer they monitor a project and interfere in its internal decisions the higher are the chances of its success. Such a trend is usually followed by an organization when a project is considered as critical for elevating 
its status. Many of the failed projects examined by Murphy et al. (1974) had the distinctive feature of a lower say of the project team in decision making. It is important to clarify that the role of the client and parent organizations should be close and supportive rather than being meddling or interfering. Whereas good coordination and good relations were found to be the key to success, meddling intervention from the parent and client organization were seen to be counterproductive. 


\section{Chapter 2 - Approaches Employed in CSF-Research}

It is the combination of performance criteria, project participants, and likely consideration of project phases that distinguishes one research from another. As explained in Section 1.1, selection of objectives actually depends on the set of stakeholders that are considered for a study; after having decided the stakeholders and objectives, a researcher sets to the task of generating the CSFs. Of the different methods employed for CSF identification, 'soliciting expert opinion' is worth mentioning. 'Expert opinion' has been employed with the following distinct approaches:

- Approach-1 (Expert opinion): Respondents are asked to identify a set number of factors that they consider critical to project success, and then indicate their relative importance. This is followed by a two pronged task by expert professionals: (1) Interpreting the essence of the factors as the same factor may have been stated quite distinctly by different respondents, and (2) Extract those factors as CSFs that have been stated with the highest frequency of respondents. Since it is not easy to read the mind of the respondents with a good degree of accuracy, it would rather be too much to expect that the experts would have understood the nomenclature and scope of the factors identified by the respondents [Pinto and Slevin 1987].

- Approach-2 (Expert opinion): Factors are extracted from available past literature and then shortlisted based on in-depth interviews with experts from the profession to which the research relates-The shortlisting results in what is commonly referred to as 'potential factors'. A survey questionnaire, essentially comprising potential factors and objectives is then presented for assessment to professionals from the related field. The completed questionnaires form a database that is analyzed for the CSFs. Researchers seek the assessment in the following two ways:

(a) The experts can be asked to rank the potential factors based on a predetermined scale [Chan and Kumaraswamy 1997]. 
(b) The experts may be asked to conduct a pair-wise comparison of all possible pairs of factors so that a database for the Analytical Hierarchy Process can be generated [Chua et al. 1999].

As an equivalent to the above mentioned approach-2(b) of 'soliciting expert opinion,' some researchers have used quantitative measures of various factors to identify the CSFs [Ashley and Jaselsky 1991]; however, this equivalent approach is inapplicable to intangible factors. The Analytical Hierarchy Process, which qualifies equally for both tangible and intangible factors, is hence considered worth explaining in the remaining part of this chapter.

\subsection{Analytical Hierarchy Process}

Based on mathematics and psychology, the Analytical Hierarchy Process (AHP) is a technique used for organizing complex decision-making problems. Developed by T.L. Saaty in 1970, and refined continuously to date, the AHP first of all breaks down the main problem into more comprehensible sub-problems - The AHP model. The AHP model is a tree diagram, which in its simplest form, consists of a goal at the top, a set of alternates for reaching the goal at the lowest level, and a set of criteria connecting the alternates to the goal (Figure 2.1 ).

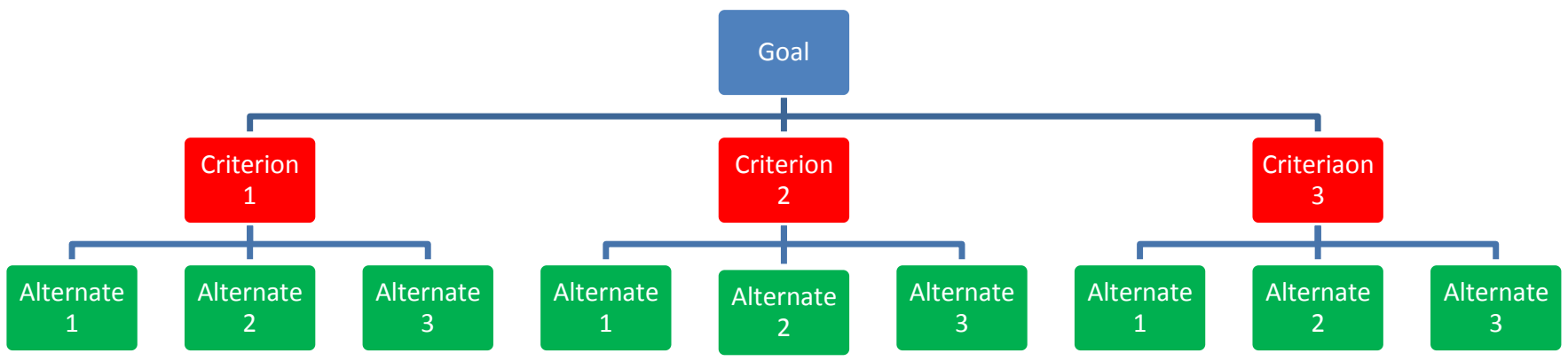

Figure 2.1 A Simple AHP Model

The criteria can be broken down to subcriteria, which can be further broken down to subsubcriteria, and so on depending on the levels required by the problem at hand. Each level increases the grasp of the assessors so that they develop more and more understanding of the problem (Figure 2.2). The goal, criteria, subcriteria, and alternates are represented by nodes on the AHP hierarchy; a node connected to two or more nodes below it is referred to as the parent node. At each level, the assessor compares the children nodes in a pairwise fashion with respect 


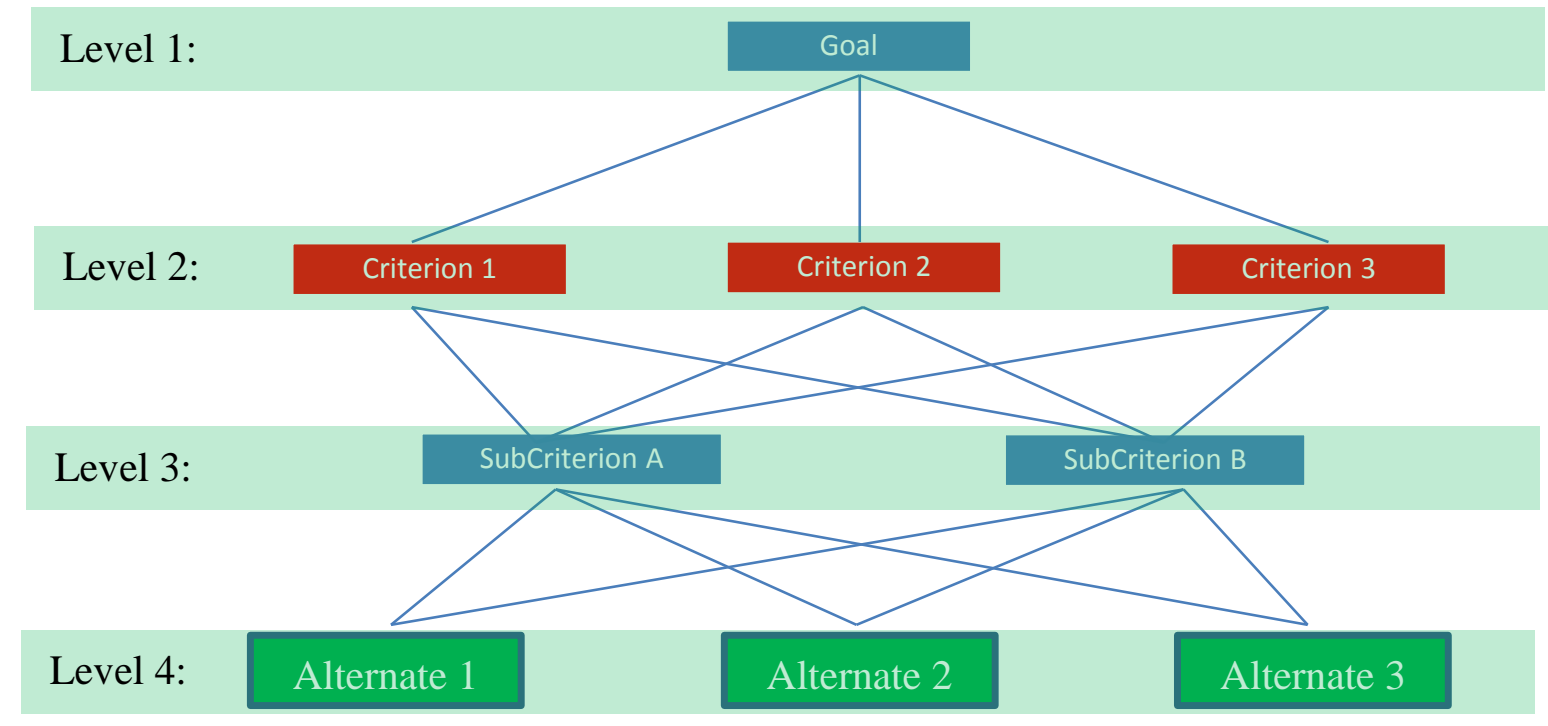

Figure 2.2 A Detailed AHP Model

Table 2.1 Fundamental Pairwise Comparison Scale [Saaty 2006]

\begin{tabular}{|c|l|l|}
\hline $\begin{array}{l}\text { Level of } \\
\text { Importance }\end{array}$ & Definition & Explanation \\
\hline 1 & Equal importance & The two nodes contribute equally to the parent \\
\hline 3 & Moderate importance & Judgment moderately favors the strong over the weak \\
\hline 5 & Strong importance & Judgment strongly favors the strong over the weak \\
\hline 7 & $\begin{array}{l}\text { Very strong demonstrated } \\
\text { importance }\end{array}$ & $\begin{array}{l}\text { The stronger node's importance over the weaker is } \\
\text { demonstrated very strongly in practice. }\end{array}$ \\
\hline 9 & $\begin{array}{l}\text { Extremely strong } \\
\text { demonstrated importance }\end{array}$ & $\begin{array}{l}\text { Extremely strong evidence exists for favoring the } \\
\text { stronger over the weaker node. }\end{array}$ \\
\hline \multicolumn{2}{|l|}{ Values 2,4,6,8 can be used for intermediate intensities between above-stated levels of importance } \\
\hline
\end{tabular}

to their importance for the parent node; prior to this, the assessor determines which of the two children nodes is weaker, assigns it a value of 1 , and then assigns a value between 1 to 9 for the stronger node based on Table 2.1. 
As will be illustrated in Section 2.2, pairwise comparison of ' $n$ ' nodes is followed by the following steps:

- Form an $n \times n$ 'comparison matrix $\left(\mathbf{A}_{(n \times n)}\right)$.' This is essentially a reciprocal matrix with the diagonal elements as 1 , and all non-diagonal elements satisfying $\mathrm{a}_{\mathrm{ij}}=1 / \mathrm{a}_{\mathrm{ji}}$.

- For each column of the comparison matrix, compute column-summation. Let the resulting row vector be denoted by $\mathbf{r}_{(1 \times n)}$.

- Normalize the columns of the comparison matrix with respect to column summations. The resultant matrix is $\mathbf{A}_{\text {norm }}$.

- Compute the row-averages of the normalized comparison matrix: The resulting column vector, denoted by $\mathbf{w}_{(n \times 1)}$, is the 'principal Eigen vector' referred to as 'priority vector.' The priority vector (with its rows always summing up to 1) gives the relative importance of all the nodes with respect to the parent node.

- According to Saaty, a comparison matrix would be perfectly consistent if $\mathrm{a}_{\mathrm{ij} .} \mathrm{a}_{\mathrm{jk}}=\mathrm{a}_{\mathrm{ik}}$ for all values of $i, j$ and $k$. Moreover, if the 'consistency ratio' is less than $10 \%$, the inconsistency is said to be within the acceptable limits. The consistency ratio is calculated by following the underlying steps:

$$
\begin{aligned}
& \text { Principal Eigen Value }=\lambda_{\max }=\mathbf{r}_{(1 \mathrm{x} n)} \cdot \mathbf{w}_{(n \times 1)} \\
& \text { Consistency Index }=C I=\frac{\lambda_{\max }-n}{n-1} \\
& \text { Random Consistency Index }=R C I \text { (Table 2.2) } \\
& \text { Consistency Ratio }=C R=\frac{C I}{R C I}
\end{aligned}
$$

Table 2.2 Saaty's Random Consistency Index [Saaty 1980]

\begin{tabular}{|c|c|c|c|c|c|c|c|c|c|c|}
\hline $\mathrm{n}$ & 1 & 2 & 3 & 4 & 5 & 6 & 7 & 8 & 9 & 10 \\
\hline $\mathrm{RCI}$ & 0.00 & 0.00 & 0.58 & 0.90 & 1.12 & 1.24 & 1.32 & 1.41 & 1.45 & 1.49 \\
\hline
\end{tabular}




\subsection{Illustration of Analytical Hierarchy Process}

The AHP can be best explained in the form of an example. Consider a situation where a developer has to construct an impressive wood structure by solely using maple, pine and oak. The

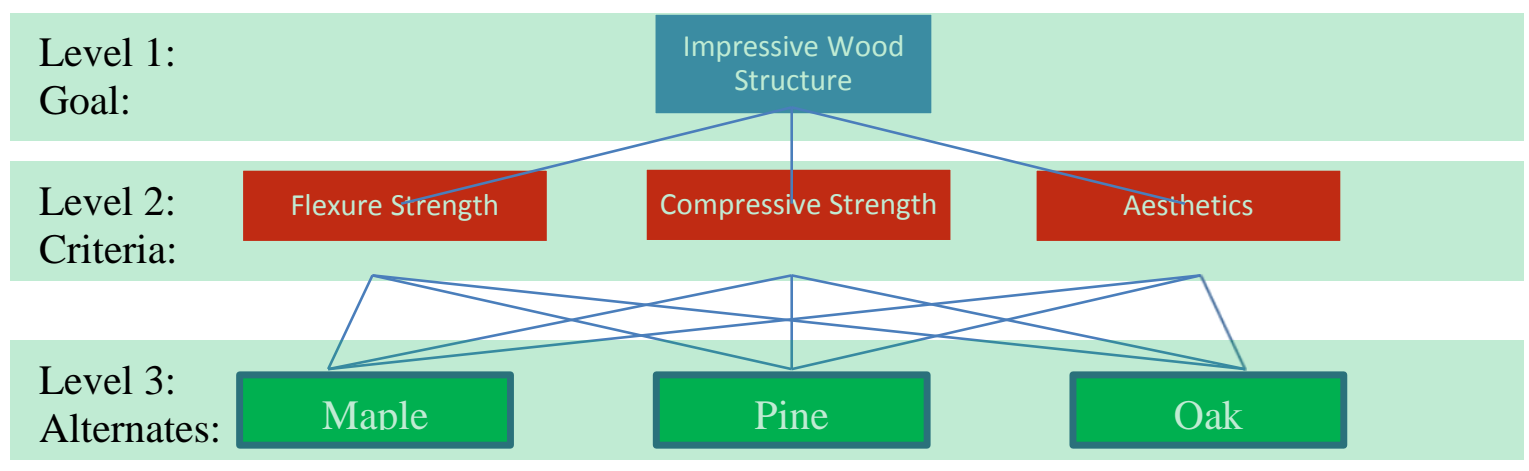

Figure 2.3 AHP Model for Illustrative Example

developer would need to compute the relative importance of maple, pine and oak woods. Say the criteria that the firm considers for computing the importance are dry flexure strength, dry compressive strength (perpendicular to grain), and aesthetics (other criteria like durability and cost are not considered here for the purpose of simplicity). The AHP hierarchy for this case study would be as shown in .

\subsubsection{Level-2 Comparisons}

Pairwise Comparison of Criteria w.r.t. Goal: For the three nodes at level 2, suppose a member of the board of directors has the following opinion:

- Flexure strength is weakly important over compressive strength: importance level $=2$.

- Flexure strength cannot be neglected, but it can be catered for in the structural design. Since the goal is to construct a 'state of the art wood structure,' aesthetics is strongly favored over flexure strength: importance level $=5$.

- For the same reason as stated above, aesthetics is strongly favored over compressive strength: importance level $=5$. 
The following A, r, $\mathbf{A}_{\text {norm }}, \mathbf{w}, \lambda_{\max }, C I, R C I$, and $C R$ (all explained in Section 2.1) results from the pairwise comparison of criteria:

\begin{tabular}{l|ccc|} 
A= Flex Str. & 1 & 2 & $1 / 5$ \\
Comp. Str. & $1 / 2$ & 1 & $1 / 5$ \\
Aesthetics & 5 & 5 & 1
\end{tabular}

$$
\begin{aligned}
& \text { Flex Str. Comp. Str. Aesthetics } \\
& \begin{array}{l|lll|l|l|}
\mathbf{A}_{\text {norm }}=\begin{array}{l}
\text { Flex Str. } \\
\text { Comp. Str. }
\end{array} & 0.154 & 0.250 & 0.143 & \mathbf{W}_{2}=\text { Flex Str. } & 0.182 \\
\text { Aesthetics } & 0.769 & 0.625 & 0.714 & \text { Comp. Str. } & 0.115 \\
& 0.125 & 0.143 & \text { Aesthetics } & 0.703
\end{array} \\
& \lambda_{\max }=\mathbf{r}_{(1 \times n)} \cdot \mathbf{w}_{(n \times 1)}=3.088 \\
& C I=\frac{\lambda_{\max }-n}{n-1}=0.044 \\
& \text { RCI (From Saaty's table of RCI, Table 2.2) }=0.58 \\
& C R=\frac{C I}{R C I}=0.076<0.1==>\text { Judgment is consistent }
\end{aligned}
$$

\subsubsection{Level-3 Comparisons}

Pairwise Comparison of Alternates w.r.t. Aesthetics: For the comparison of the three woods (level 3) corresponding to aesthetics (level 2), follow the same steps as in Section 2.2.1. Suppose we arrive at the following comparison matrix and its resulting calculations:

\begin{tabular}{l|ccc|}
$\mathbf{A}=$ Maple & Maple & Pine & Oak \\
Pine & 1 & 3 & $1 / 5$ \\
Oak & $1 / 3$ & 1 & $1 / 7$ \\
& 5 & 7 & 1
\end{tabular}




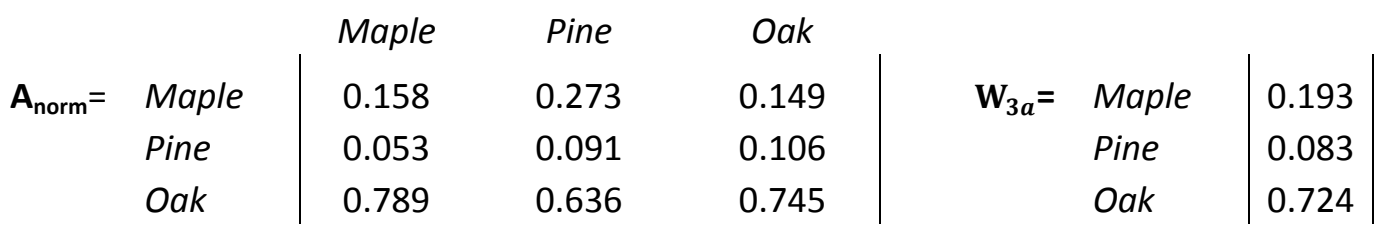

$$
\begin{aligned}
& \sum \text { check }=1.000 \\
& \lambda_{\max }=\mathbf{r}_{(1 \times n)} \cdot \mathbf{w}_{(n \times 1)}=3.111 \\
& C I=\frac{\lambda_{\max }-n}{n-1}=0.056 \\
& \text { RCI (From Saaty's table of RCI, Table 2.2) }=0.58 \\
& C R=\frac{C I}{R C I}=0.096<0.1==>\text { Judgment is consistent }
\end{aligned}
$$

Comparison of Alternates w.r.t. Flexural Strength: It is not recommended to use expert

\begin{tabular}{|c|c|c|c|c|c|}
\hline Maple & 1495 & normalizing w.r.t. $\sum$ str & $\mathbf{W}_{3 b}=$ & Maple & 0.329 \\
\hline Pine & 1438 & 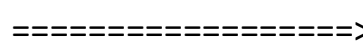 & & Pine & 0.317 \\
\hline Oak & 1610 & & & Oak & 0.354 \\
\hline Estr.= & 4543 & & & $\sum=$ & 1.000 \\
\hline
\end{tabular}
judgment to compare the three alternates at level 3 with respect to flexure strength. This is because flexural strength is a measurable criterion. If the flexural strength of maple, pine and oak are 1495 psi, 1438 psi and 1610 psi, respectively, we can easily compute the priority vector as follows:

\begin{tabular}{|c|c|c|c|c|c|}
\hline Maple & 410 & normalizing w.r.t. $\sum$ str. & $\mathbf{W}_{3 c}=$ & Maple & 0.335 \\
\hline Pine & 223 & $==================>$ & & Pine & 0.182 \\
\hline Oak & 590 & & & Oak & 0.482 \\
\hline Estr.= & 1223 & & & $\Sigma=$ & 1.000 \\
\hline
\end{tabular}

Comparison of Alternates w.r.t. Compressive Strength: Since compressive strength also is measurable, use of expert judgment shall be avoided to compare the three alternates at level 3 with respect to it. If the compressive strength of maple, pine and oak are 410 psi, 223 psi and 590 psi, respectively, the priority vector is computed as follows:

Level-3 Priority Matrix: The three priority vectors at level-3 (i.e. $\mathbf{W}_{3 a}, \mathbf{W}_{3 b}$, and $\mathbf{W}_{3 c}$ ) can now be entered into a single priority matrix: 


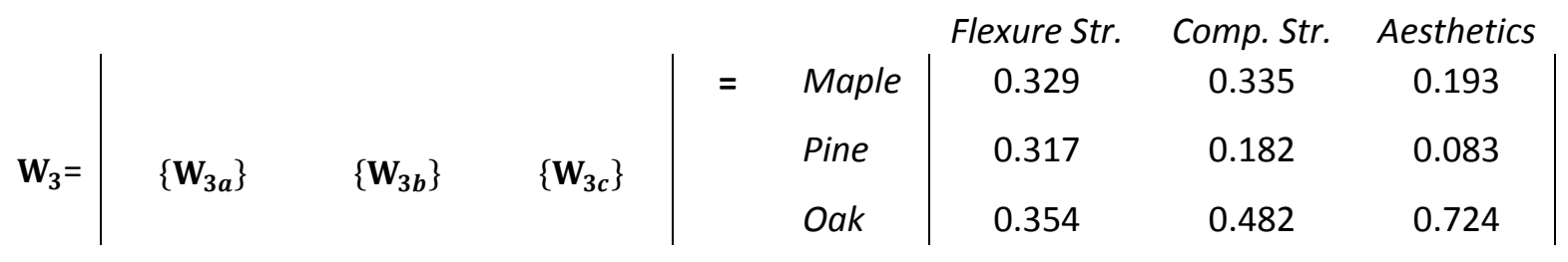

\subsubsection{Relative Importance of Alternates for the Goal}

The relative importance of the alternates w.r.t. criteria (level 3 w.r.t. level 2), and of the criteria w.r.t. goal (level 2 w.r.t. level 1) have been determined as $\mathbf{w}_{3}$ and $\mathbf{w}_{2}$ respectively. The ultimate aim of the AHP, finding the relative importance of the alternates w.r.t. the goal (level 3 w.r.t. level 1), can now be fulfilled. The final priority vector $\left(\mathbf{w}_{\text {final }}\right)$ for level 3 w.r.t. level 1 is obtained simply by matrix multiplication of $\mathbf{w}_{3}$ and $\mathbf{w}_{2}$ :

$$
\begin{aligned}
& \text { Flexure Str. Comp. Str. Aesthetics }
\end{aligned}
$$

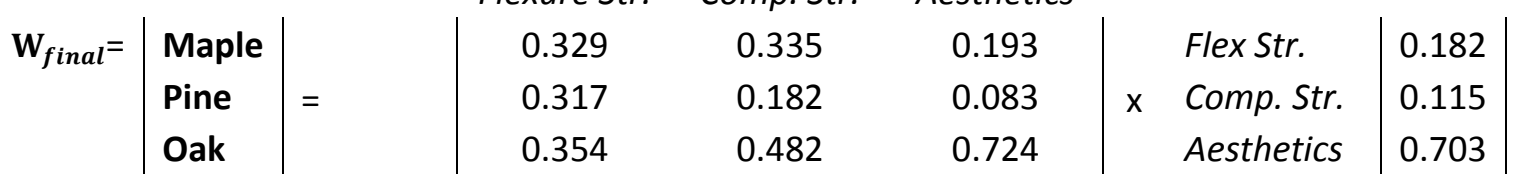

$$
\begin{aligned}
& =\left|\begin{array}{l}
0.234 \\
0.137 \\
0.629
\end{array}\right| \\
& \sum \text { check }=\quad 1.000
\end{aligned}
$$

Interpreting the $\mathbf{w}_{\text {final }}$, it can now be stated that while collectively considering all the three criteria of flexure strength, compressive strength, and aesthetics :

- Oak is the best choice (relative importance of 0.629), followed by maple (relative importance of 0.234 ), followed by pine (relative importance of 0.137 ). Hence, the three alternates may be ranked as

AHP Ranking $=\left|\begin{array}{l}\text { Maple } \\ \text { Pine } \\ \text { Oak }\end{array}\right|=\mid \begin{aligned} & 2 \\ & 3 \\ & 1\end{aligned}$

- Oak is approximately 2.75 times a better choice as compared to maple, the later being 1.75 times a better choice as compared to pine. 


\section{Chapter 3 - Statistical Approaches Used by Researchers}

\subsection{Spearman's Test}

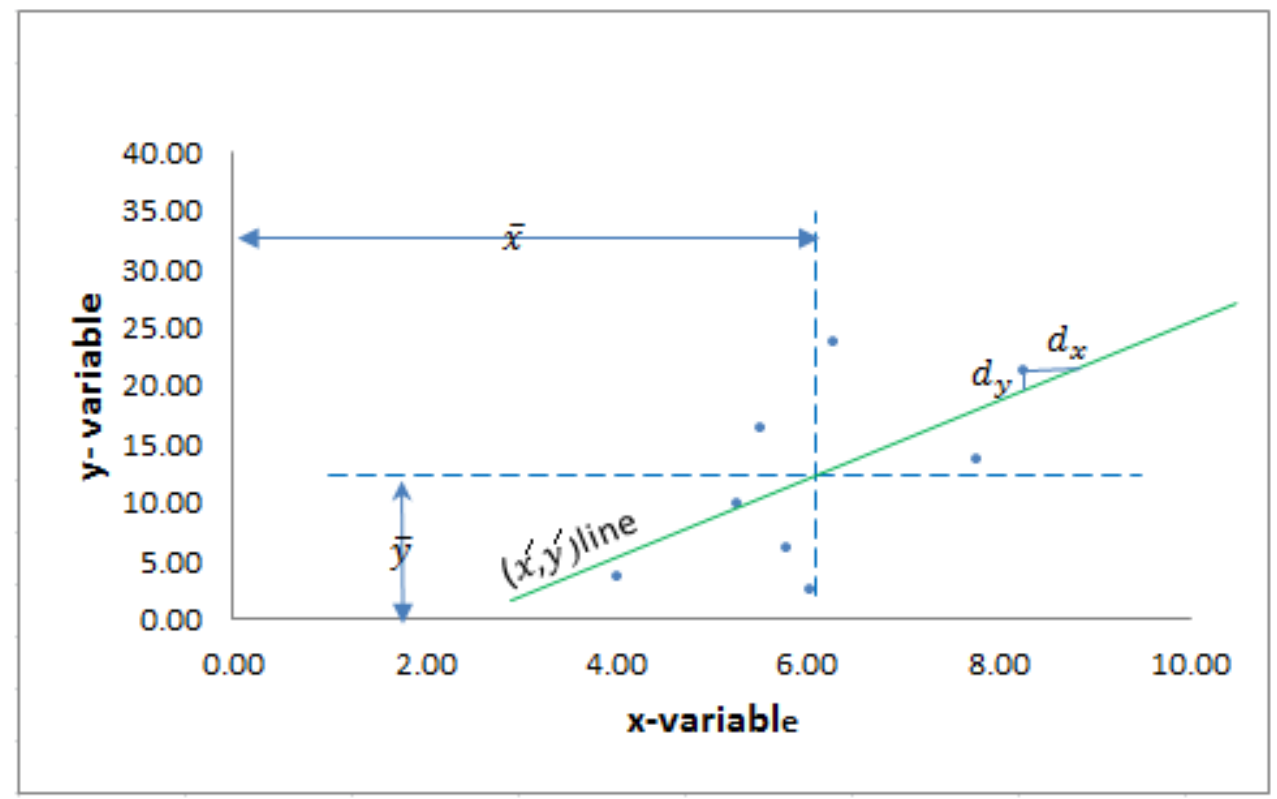

\section{Figure 3.1 Scatter of Data}

Let $(x, y)$ be the data set representing two variables $x$ and $y$ plotted in Figure 3.1. A straight line passing through a point $(\bar{x}, \bar{y})$ defined by the means of the variables would divide the data points in two equal sets. Let $\left(x^{\prime}, y^{\prime}\right)$ represent points on the line under consideration, then the summation of deviations of the data points from the line, along the $\mathrm{y}$-axis and $\mathrm{x}$-axis would always be as below:

$$
\begin{aligned}
& \Sigma \mathrm{d}_{y}=\Sigma\left(y-y^{\prime}\right)=0 \\
& \Sigma \mathrm{d}_{x}=\Sigma\left(x-x^{\prime}\right)=0
\end{aligned}
$$

The summation of squares of deviations of $y$ from $y^{\prime}$ referred to as unexplained variation of the $y$-variable is given as follows:

$$
\text { Unexplained Variation of } y=\Sigma\left(d_{y}\right)^{2}=\Sigma\left(y-y^{\prime}\right)^{2}
$$

The summation of squares of deviations of $x$ from $x^{\prime}$ referred to as unexplained variation of the $x$-variable is given as follows: 


$$
\text { Unexplained Variation of } x=\Sigma\left(d_{x}\right)^{2}=\Sigma\left(x-x^{\prime}\right)^{2}
$$

An infinite number of lines passing through $(\bar{x}, \bar{y})$ would all satisfy Eq (1) and Eq (2), yet all can have distinct values for the unexplained variations (summation of deviation-squares) defined by $\mathrm{Eq}(3)$ and $\mathrm{Eq}(4)$. The line that most appropriately represents the relation between the variables $\mathrm{y}$ and $x$ is one that not only passes through $(\bar{x}, \bar{y})$ but also results in the least value of the summation of deviation-squares. It follows, therefore, that there are always two best fit lines

(regression lines): first for which $\Sigma\left(\mathrm{d}_{y}\right)^{2}$ is minimum, and second for which $\Sigma\left(\mathrm{d}_{x}\right)^{2}$ is minimum, the process of determining each being respectively referred to as 'regression of $y$ on $x$ ', and 'regression of $x$ on $y$ '.

The least squares methods explained below in Section 3.1.1, and Section 3.1.2 pertains to linear regression. Using these methods, a linear best fit line may be wrongly sought between two variables that do not actually correlate linearly. The Spearman's test explained in Section 3.1.3.1 provides a tool to determine if at all a linear correlation exists between two variables.

\subsubsection{Regressing $y$ on $x$}

Knowing,

$$
y^{\prime}=m_{y} x+c_{y}
$$

where,

$m_{y}=$ Slope of a fitting line, the subscript referring to the variable to be regressed, and $c_{y}=y$-intercept of a fitting line, the subscript referring to the variable to be regressed. The un-explained variation of $y$-variable defined in Eq (3) for all the fitting lines may be rewritten as:

$$
\begin{aligned}
& \Sigma \mathrm{d}_{y}{ }^{2}=\Sigma\left(y-y^{\prime}\right)^{2} \\
& =\Sigma\left[y-\left(m_{y} x+c_{y}\right)\right]^{2} \\
& =\Sigma\left(y^{2}+m_{y}{ }^{2} x^{2}+c_{y}{ }^{2}+2 m_{y} x c_{y}-2 y m_{y} x-2 y c_{y}\right) \\
& =\Sigma y^{2}+\Sigma\left(m_{y}{ }^{2} x^{2}\right)+\Sigma c_{y}{ }^{2}+\Sigma\left(2 m_{y} x c_{y}\right)-\Sigma\left(2 y m_{y} x\right)-\Sigma\left(2 y c_{y}\right) \\
\Sigma \mathrm{d}_{y}{ }^{2} & =\Sigma y^{2}+m_{y}{ }^{2} \Sigma x^{2}+c_{y}{ }^{2} n+2 m_{y} c_{y} \Sigma x-2 m_{y} \Sigma(y x)-2 c_{y} \Sigma y
\end{aligned}
$$


Since we are interested in determining the equation of a line that gives least value of $\Sigma\left(\mathrm{d}_{y}\right)^{2}$, let us first equate the partial differentiation of $\mathrm{Eq}(5)$ with respect to ' $m_{y}$ ' to zero, and then equate the partial differentiation of $\mathrm{Eq}(5)$ with respect to ' $c{ }_{y}$ ' to zero.

Differentiating Eq (5) w.r.t. ' $m_{y}$ ', (' $c_{y}$ ' being constant):

$$
\begin{aligned}
\frac{d}{d m_{y}} \Sigma \mathrm{d}_{y}{ }^{2} & =0+2 m_{y} \Sigma x^{2}+0+2 c_{y} \Sigma x-2 \Sigma(y x)-0 \\
& =2 m_{y} \Sigma x^{2}+2 c_{y} \Sigma x-2 \Sigma(y x)
\end{aligned}
$$

Putting $\frac{d}{d m_{y}} \sum \mathrm{d}_{y}{ }^{2}=0$ in Eq (6):

$$
0=2 m_{y} \Sigma x^{2}+2 c_{y} \Sigma x-2 \Sigma(y x)
$$

Differentiating Eq (5) w.r.t. ' $c y$ ', (' $m_{y}$ ' being constant):

$$
\begin{aligned}
\frac{d}{d c_{y}} \Sigma \mathrm{d}_{y}{ }^{2} & =0+0+2 c_{y} n+2 m_{y} \Sigma x-0-2 \Sigma y \\
& =2 c_{y} n+2 m_{y} \Sigma x-2 \Sigma y
\end{aligned}
$$

Putting $\frac{d}{d c_{y}} \sum \mathrm{d}_{y}{ }^{2}=0$ in Eq (8):

$$
0=2 c_{y} n+2 m_{y} \Sigma x-2 \Sigma y
$$

Solving Eq (7) \& Eq (9) simultaneously for ' $m_{y}$ ' and ' $c_{y}$ ', would give us the slope and intercept parameters of the best-fit line pertinent to the regression of $y$ on $x$ :

$$
\begin{aligned}
& c_{y}=\frac{\Sigma y \Sigma x^{2}-\Sigma(x y) \Sigma x}{\mathrm{n} \Sigma x^{2}-(\Sigma x)^{2}} \\
& m_{y}=\frac{\Sigma y\left[n \Sigma x^{2}-(\Sigma x)^{2}\right]-n\left[\Sigma y \Sigma x^{2}-\Sigma(x y) \Sigma x\right]}{\Sigma x\left[n \Sigma x^{2}-(\Sigma x)^{2}\right]}
\end{aligned}
$$

\subsubsection{Regressing $x$ on $y$}

Knowing,

$$
y=m_{x} x^{\prime}+c_{x}
$$

where, 
$m_{x}=$ Slope of a fitting line, the subscript referring to the variable to be regressed, and

$c_{x}=y$-intercept of a fitting line, the subscript referring to the variable to be regressed.

The un-explained variation of $x$-variable defined in Eq (d) for all the fitting lines may be rewritten as:

$$
\begin{gathered}
\Sigma \mathrm{d}_{x}{ }^{2}=\Sigma\left(x-x^{\prime}\right)^{2} \\
\Sigma \mathrm{d}_{x}{ }^{2}=\Sigma\left[x-\frac{\left(y-c_{x}\right)}{m_{x}}\right]^{2}
\end{gathered}
$$

Following the same steps as in Section 3.1.1 we would arrive at two equations for the unknowns $c_{x}$ and $m_{x}$, solving which yields the slope and intercept parameters of the best-fit line pertinent to the regression of $x$ on $y$ :

$$
\begin{aligned}
c_{x} & =\frac{\Sigma \mathrm{x} \Sigma y^{2}-\Sigma(x y) \Sigma y}{\mathrm{n} \Sigma y^{2}-(\Sigma y)^{2}} \\
m_{x} & =\frac{\Sigma x\left[n \Sigma y^{2}-(\Sigma y)^{2}\right]-n\left[\Sigma x \Sigma y^{2}-\Sigma(x y) \Sigma y\right]}{\Sigma y\left[n \Sigma y^{2}-(\Sigma y)^{2}\right]}
\end{aligned}
$$

\subsubsection{Pearsonian Coefficient of correlation}

It is always possible to obtain a linear best-fit line for two variables even though they may better correlate non-linearly. Moreover, linear-regressions of $y$ on $x$, and $x$ on $y$ can be conducted irrespective of the spread of the data set $(x, y)$. This gives rise to the need of a tool that can be used to judge the extent of linear association that actually exists between the variables in question. One such tool is provided by 'covariance' which is defined as the average of the products of the variable-deviations from their respective means.

Hence,

$$
\text { Covariance }=\frac{\Sigma(x-\bar{x})(y-\bar{y})}{n}
$$

It can be seen that covariance of a bivariate dataset is absolute in nature as it does not take into account the spread of the variables around their respective means. A more relative tool for measuring linear correlation is the 'Pearsonian or product moment coefficient of correlation $(r)$ ' that is obtained by dividing the covariance by the standard deviations of both the variables in the dataset. Hence the Pearsonian Product moment formula: 


$$
r=\frac{\sum(x-\bar{x})(y-\bar{y})}{n S_{x} S_{y}}
$$

But,

$$
\begin{aligned}
S_{x} & =\sqrt{\frac{\sum\left(x-\bar{x}^{2}\right)}{n}}=\sqrt{\frac{\sum\left(x^{2}+\bar{x}^{2}-2 x \bar{x}\right)}{n}}=\sqrt{\frac{\sum x^{2}+n \bar{x}^{2}-2 \bar{x} \Sigma x}{n}} \\
& =\sqrt{\left(\frac{\sum x^{2}}{n}+\frac{n}{n} *\left(\frac{\Sigma x}{n}\right)^{2}-2 \frac{\sum x}{n} * \frac{\Sigma x}{n}\right)}=\sqrt{\frac{\Sigma x^{2}}{n}+\left(\frac{\Sigma x}{n}\right)^{2}-2\left(\frac{\Sigma x}{n}\right)^{2}} \\
& =\sqrt{\frac{\sum x^{2}}{n}-\left(\frac{\Sigma x}{n}\right)^{2}}=\sqrt{\frac{n \sum x^{2}-(\Sigma x)^{2}}{n^{2}}}
\end{aligned}
$$

And Similarly,

$$
S_{y}=\sqrt{\frac{\Sigma\left(y-\bar{y}^{2}\right)}{n}}=\sqrt{\frac{n \Sigma y^{2}-(\Sigma y)^{2}}{n^{2}}}
$$

Therefore Eq (14) transforms as:

$$
\begin{aligned}
& r=\frac{\sum(x y-x \bar{y}-\bar{x} y+\bar{x} \bar{y})}{n \sqrt{\frac{n \sum x^{2}-\left(\sum x\right)^{2}}{n^{2}} * \frac{n \Sigma y^{2}-(\Sigma y)^{2}}{n^{2}}}} \\
& =\frac{\sum(x y)-\bar{y} \Sigma x-\bar{x} \Sigma y+n \bar{x} \bar{y}}{\frac{1}{n} * \sqrt{\left[n \Sigma x^{2}-(\Sigma x)^{2}\right] *\left[n \Sigma y^{2}-(\Sigma y)^{2}\right]}} \\
& =\frac{\Sigma(x y)-\frac{\Sigma y}{n} * \Sigma x-\frac{\Sigma x}{n} * \Sigma y+n \frac{\Sigma x}{n} * \frac{\Sigma y}{n}}{\frac{1}{n} * \sqrt{\left[n \Sigma x^{2}-(\Sigma x)^{2}\right] *\left[n \Sigma y^{2}-(\Sigma y)^{2}\right]}} \\
& =\frac{\sum(x y)-\frac{\sum x \Sigma y}{n}}{\frac{1}{n} * \sqrt{\left[n \Sigma x^{2}-\left(\sum x\right)^{2}\right] *\left[n \Sigma y^{2}-(\Sigma y)^{2}\right]}} \\
& =\frac{n \Sigma(x y)-\Sigma x \Sigma y}{\sqrt{\left[n \Sigma x^{2}-(\Sigma x)^{2}\right] *\left[n \Sigma y^{2}-(\Sigma y)^{2}\right]}}
\end{aligned}
$$




\subsubsection{Spearman's Coefficient of Rank Concordance}

The bivariate dataset considered so far can contain any real values. If, on the other hand, the variables $x$ and $y$ in a dataset were to only take values of the first $n$ integers (as in case of ordinal measurements of ranked data), the 'Pearsonian product moment formula' would reduce to the following form:

$$
r_{s}=1-\frac{6 \Sigma(x-y)^{2}}{n\left(n^{2}-1\right)}
$$

where,

$$
r_{s}=\text { Spearman's Coefficient of Rank Concordance }
$$

Depending upon the dispersion of the bivariate dataset, the value of $r_{S}$ (like $r$ ) varies between -1 and +1 . The lower the dispersion, the lower would be the acute angle between the two least-square lines, and the closer would be the magnitude of $r_{s}$ (like $r$ ) to 1 (Figure 3.2); A higher dispersion is characterized by an acute angle closer to $90^{\circ}$ and a magnitude of $r_{s}$ (like $r$ ) closer to 0 (Figure 3.3).

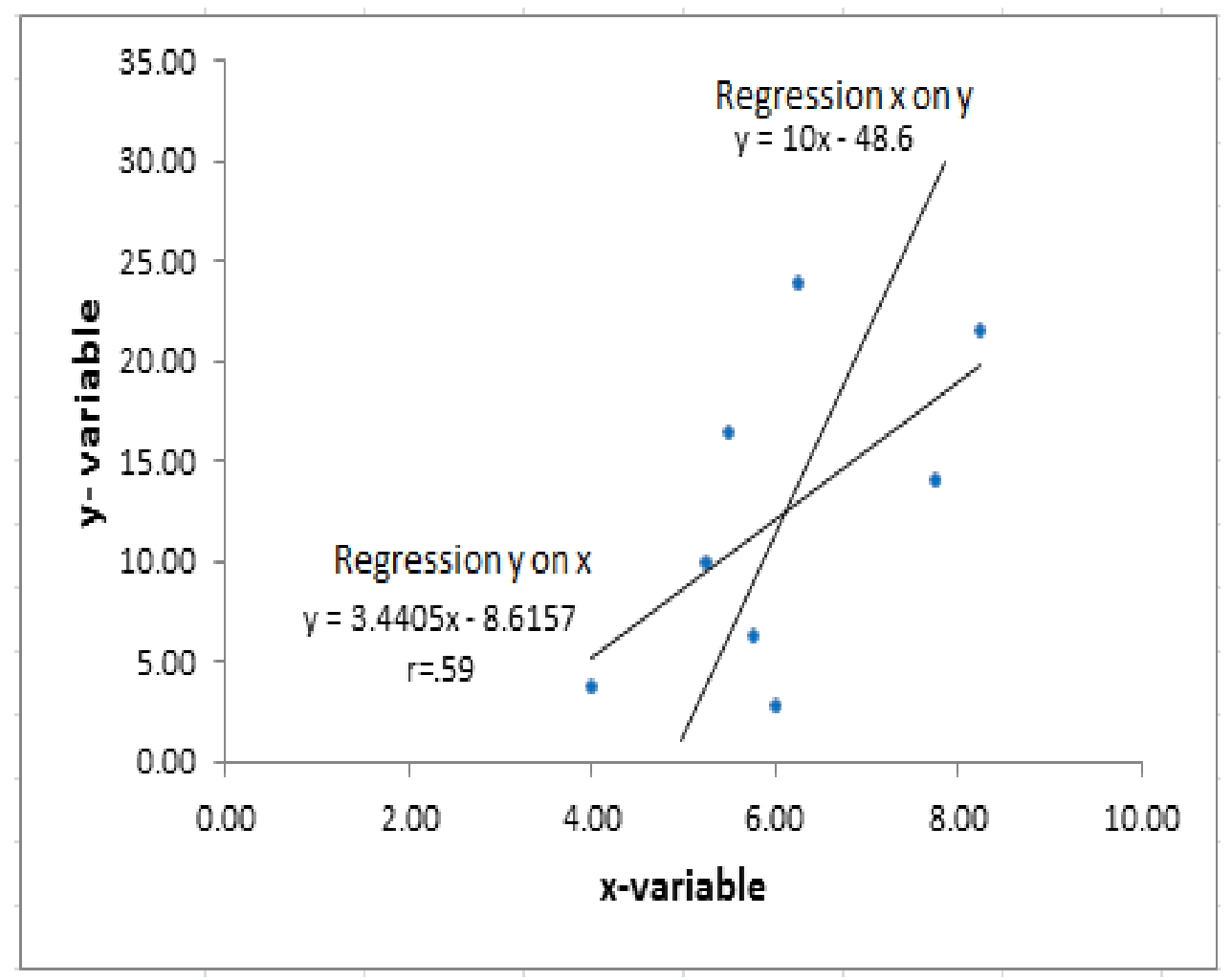

Figure 3.2 Higher Linear Correlation 


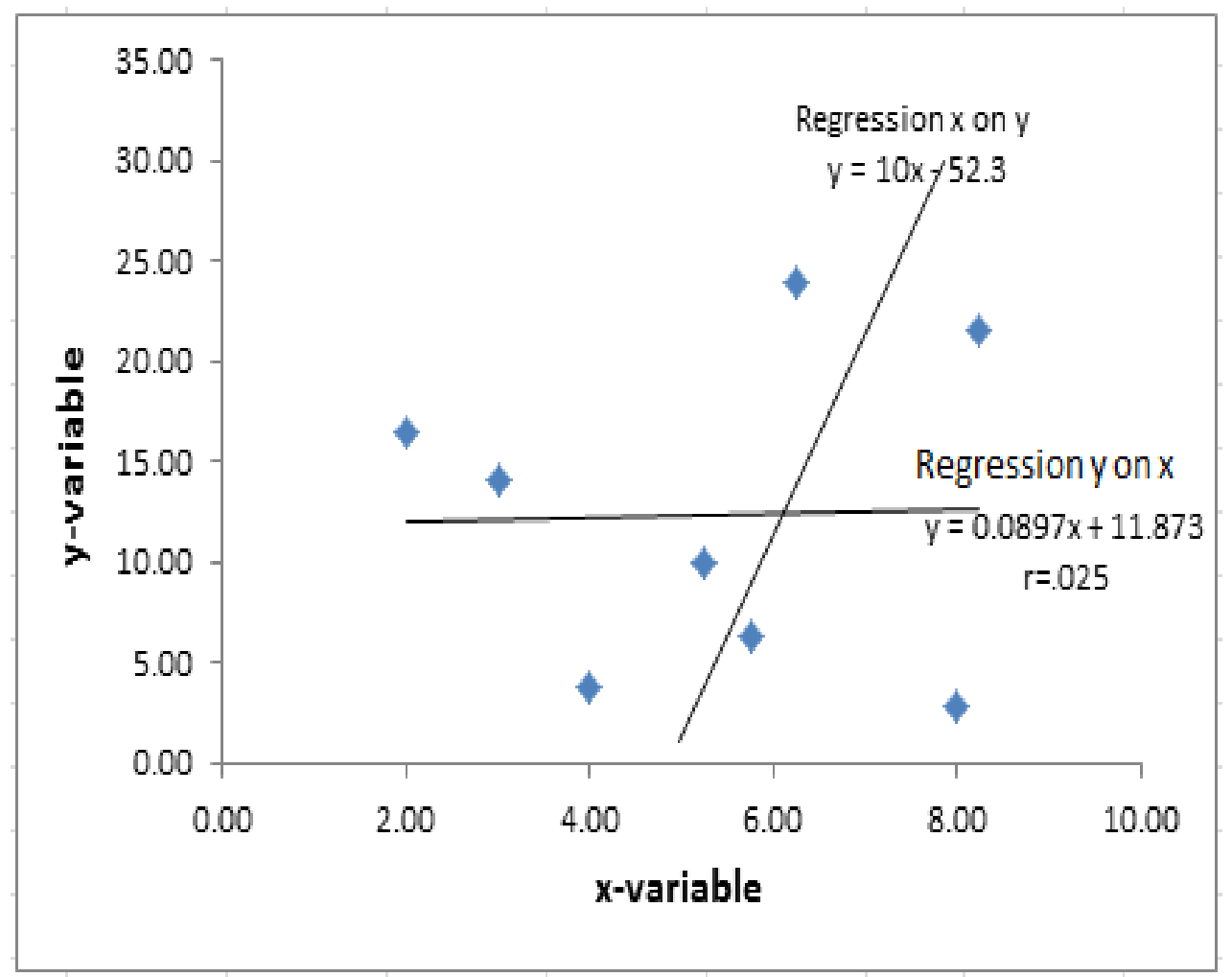

Figure 3.3 Lower Linear Correlation.

In the event of occurrence of ties in one or both the series (variables), the tied observations are given the mean value of the ranks that they cover and a correction is introduced to avoid the increase in $r_{s}$ that would otherwise occur. The correction involves addition of $\left(t^{3}-t\right) / 12$ for each set of ties (in any of the two variables) to the numerator of the second coefficient of Eq (16), where $t$ is the number of tied observations for each set of ties.

For any extent of ranking (i.e. $n$ ), the sampling distribution of $r_{S}$ can be determined by considering $n !\left(={ }_{n}^{n} P\right)$ possible permutations of the ranking. After determining the standard error of the 'sampling distribution of $r_{s}$ ', the 'critical value of $r_{s}$ ' (i.e. $r_{s(c r)}$ ) for a one-tail-test can be determined based on a given level of significance (generally $1 \%$ or $5 \%$ ). Having done that, the relative location of $r_{s(c a l c)}$ w.r.t. $r_{s(c r)}$ on the 'sampling distribution of $r_{s}$ ' can be used to check if $r_{s(c a l c)}$ is significantly more than zero at the given level of significance. Using this procedure, the $r_{s(c r)}$ for ranking-extents from 4 to 30 have been calculated and presented in Table 3.1 
Table 3.1 One-tail $r_{s(c r)}$ [Yeomans 1979]

\begin{tabular}{|c|c|c|}
\hline \multirow{2}{*}{$\boldsymbol{n}$} & \multicolumn{2}{|c|}{$\boldsymbol{r}_{\boldsymbol{s}(\boldsymbol{c r})}$} \\
\cline { 2 - 3 } & Significance Level=0.05 & Significance Level=0.01 \\
\hline 4 & 1 & 1 \\
\hline 5 & 0.9 & 1 \\
\hline 6 & 0.829 & 0.943 \\
\hline 7 & 0.714 & 0.893 \\
\hline 8 & 0.643 & 0.833 \\
\hline 9 & 0.6 & 0.783 \\
\hline 10 & 0.564 & 0.746 \\
\hline 12 & 0.506 & 0.712 \\
\hline 14 & 0.456 & 0.645 \\
\hline 16 & 0.425 & 0.601 \\
\hline 18 & 0.399 & 0.564 \\
\hline 20 & 0.377 & 0.534 \\
\hline 22 & 0.359 & 0.508 \\
\hline 24 & 0.343 & 0.485 \\
\hline 26 & 0.329 & 0.465 \\
\hline 28 & 0.317 & 0.448 \\
\hline 30 & 0.306 & 0.432 \\
\hline
\end{tabular}

\subsection{Kendall's Test}

\subsubsection{Kendall's Coefficient of Concordance}

When more than two sets of ranks are to be checked for an overall agreement, one possible discourse available to a statistician is to compute $r_{s}$ for all possible pairs of series and average them out. If we have $k$ number of series, the $r_{s}$ needs to be computed ${ }_{2}^{k} C$ times-The resulting $\frac{2 \Sigma r_{s}}{k(k-1)}$ of this procedure provides a quite acceptable check of the overall agreement between the $k$ number of series.

Alternately, the 'Kendall's coefficient of rank concordance $(W)$, differing from $\frac{2 \Sigma r_{s}}{k(k-1)}$ but linearly related to it, may be determined using the following formula:

$$
W=\frac{12 \Sigma(\text { RRank }-\overline{\Sigma R a n k s})^{2}}{k^{2} n\left(n^{2}-1\right)}
$$


where,

$n=\#$ of data points $=$ Extent of Ranking

$\Sigma$ Rank $=$ Summation of ranks across all sets for a given observation.

$\overline{\Sigma R a n k s}=$ Average of $\Sigma R a n k$ for all observations.

In the event of occurrence of ties in one or both the series (variables), the tied observations are given the mean value of the ranks that they cover and a correction is introduced to avoid the decrease in $r_{S}$ that would otherwise occur. The correction involves subtraction of $\left(t^{3}-t\right) / 12$ for each set of ties (in any of the two variables) from the numerator of Eq (17), where $t$ is the number of tied observations for each set of ties.

The test for significance of $W$ is based upon the sum of squared deviations of $\Sigma$ Rank

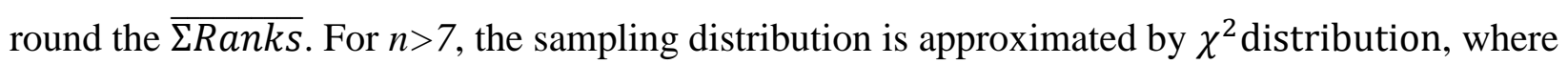
$\chi_{(\text {calc })}^{2}$ is found as below:

$$
\chi_{(\text {calc })}^{2}=\frac{12 \Sigma\left(\sum R a n k-\overline{\Sigma R a n k s}\right)^{2}}{k n(n+1)}
$$

\subsection{Multiple Regression Analysis}

Before Multiple Regression Analysis is explained, it would be useful to briefly discuss the 'limitations and reservations' pertaining to the Two-variable Linear Regression Model (TVLRM) determined in Section 3.1.3. Firstly, if the coefficient of linear correlation is too low, it shall not be concluded out of hand that no relationship exists between the two variables; the possibility of a non-linear association shall always be checked as a first step by plotting a scatter diagram. The second reservation concerns the TVLRM assumption that the dependent variable can be completely explained in terms of a single independent variable; the regression equation might well be better defined by including in it two or even more independent variables. The process that deals with identifying all possible independent variables that collectively reduce the un-explained variation in the dependent variable to a least value is referred to as Multiple Regression Analysis. 


\subsubsection{Constants of Multiple Regression}

For purpose of simplicity a total of three variables, two being independent, are being considered here. Let $y_{1}{ }^{\prime}$ be the dependent, and $x_{2}{ }^{\prime}\left(=x_{2}\right)$ and $x_{3}{ }^{\prime}\left(=x_{3}\right)$ be the two independent variables. The multiple regression model for the three variables is a plane defined by the following equation:

$$
y_{1}{ }^{\prime}=a_{1.23}+b_{12.3} x_{2}+b_{13.2} x_{3}
$$

where the constants of multiple regression namely $a_{1.23}, b_{12.3}$ and $b_{13.2}$ are defined as below:

$b_{12.3}=$ change in $y_{1}{ }^{\prime}$ for a unit change in $x_{2}$ while $x_{3}$ is kept constant

$b_{13.2}=$ change in $y_{1}{ }^{\prime}$ for a unit change in $x_{3}$ while $x_{2}$ is kept constant

$a_{1.23}=y-$ intercept of the plane defining the equation

Applying the least square method for determining the best fit plane by partially differentiating $\Sigma\left(y_{1}-y_{1}^{\prime}\right)^{2}$ w.r.t $a_{1.23}, b_{12.3}$ and $b_{13.2}$, and equating to zero yields the following three equations:

$$
\begin{aligned}
& \Sigma y_{1}=n a_{1.23}+b_{12.3} \Sigma x_{2}+b_{13.2} \Sigma x_{3} \\
& \Sigma y_{1} x_{2}=a_{1.23} \Sigma x_{2}+b_{12.3} \Sigma x_{2}{ }^{2}+b_{13.2} \Sigma x_{2} x_{3} \\
& \Sigma y_{1} x_{3}=a_{1.23} \Sigma x_{3}+b_{12.3} \Sigma x_{2} x_{3}+b_{13.2} \Sigma x_{3}{ }^{2}
\end{aligned}
$$

where:

$$
n=\# \text { of data points }
$$

With known values of $n, \Sigma y_{1}, \Sigma x_{2}, \Sigma x_{3}, \Sigma y_{1} x_{2}, \Sigma y_{1} x_{3}, \Sigma x_{2} x_{3}, \Sigma x_{2}{ }^{2}$ and $\Sigma x_{3}{ }^{2}$, the above three equations can be solved simultaneously for the constants of regression $a_{1.23}, b_{12.3}$ and $b_{13.2}$.

\subsubsection{Coefficient of Multiple Correlation}

The coefficient of multiple determination, $C_{d}$, and the coefficient of multiple correlation can, $R_{1.23}$, can be found as described below:

$$
C_{d}=\frac{\text { Explained Variation }}{(\text { Total Variation })}=\frac{\Sigma\left(y_{1}{ }^{\prime}-\bar{y}_{1}\right)^{2}}{\Sigma\left(y_{1}-\bar{y}_{1}\right)^{2}}=\frac{\Sigma\left({y_{1}^{\prime}}^{2}+\bar{y}_{1}{ }^{2}-2 y_{1}^{\prime} \bar{y}_{1}\right)}{\Sigma\left(y_{1}{ }^{2}+\bar{y}_{1}{ }^{2}-2 y_{1} \bar{y}_{1}\right)}
$$




$$
\begin{aligned}
& =\frac{\Sigma y_{1}^{\prime 2}+\mathrm{n} \bar{y}_{1}^{2}-2 \bar{y}_{1} \Sigma y_{1}^{\prime}}{\Sigma y_{1}^{2}+n \bar{y}_{1}^{2}-2 \bar{y}_{1} \Sigma y_{1}}=\frac{\Sigma y_{1}^{\prime 2}+n \frac{\left(\Sigma y_{1}\right)^{2}}{\mathrm{n}^{2}}-2 \frac{\Sigma y_{1}}{\mathrm{n}} \Sigma y_{1}}{\Sigma y_{1}^{2}+n \frac{\left(\Sigma y_{1}\right)^{2}}{\mathrm{n}^{2}}-2 \frac{\Sigma y_{1}}{\mathrm{n}} \Sigma y_{1}} \\
& =\frac{\Sigma y_{1}^{\prime 2}+\frac{\left(\Sigma y_{1}\right)^{2}}{n}-2 \frac{\left(\Sigma y_{1}\right)^{2}}{\mathrm{n}}}{\Sigma y_{1}^{2}+\frac{\left(\Sigma y_{1}\right)^{2}}{n}-2 \frac{\left(\Sigma y_{1}\right)^{2}}{\mathrm{n}}}=\frac{\Sigma y_{1}^{\prime 2}-\frac{\left(\Sigma y_{1}\right)^{2}}{\mathrm{n}}}{\Sigma y_{1}^{2}-\frac{\left(\Sigma y_{1}\right)^{2}}{\mathrm{n}}}
\end{aligned}
$$

But using Eq (19),

$$
\begin{aligned}
& y_{1}{ }^{\prime}=a_{1.23}+ b_{12.3} x_{2}+b_{13.2} x_{3} \\
& y_{1}^{\prime 2}=a_{1.23}{ }^{2}+\left(b_{12.3} x_{2}\right)^{2}+\left(b_{13.2} x_{3}\right)^{2}+2 a_{1.23} b_{12.3} x_{2}+2 a_{1.23} b_{13.2} x_{3} \\
&+2 b_{12.3} b_{13.2} x_{2} x_{3} \\
& \Sigma y_{1}^{\prime 2}=n a_{1.23}{ }^{2}+b_{12.3}^{2} \Sigma x_{2}^{2}+b_{13.2}{ }^{2} \Sigma x_{3}^{2}+2 a_{1.23} b_{12.3} \Sigma x_{2}+2 a_{1.23} b_{13.2} \Sigma x_{3} \\
&+2 b_{12.3} b_{13.2} \Sigma x_{2} x_{3} \\
& \Sigma y_{1}^{\prime 2}=a_{1.23}\left(n a_{1.23}+b_{12.3} \Sigma x_{2}+b_{13.2} \Sigma x_{3}\right)+b_{12.3}\left(a_{1.23} \Sigma x_{2}+b_{12.3} \Sigma x_{2}{ }^{2}+b_{13.2} \Sigma x_{2} x_{3}\right) \\
& \quad+b_{13.2}\left(a_{1.23} \Sigma x_{3}+b_{12.3} \Sigma x_{2} x_{3}+b_{13.2} \Sigma x_{3}{ }^{2}\right) \\
&=a_{1.23} \Sigma y_{1}+b_{12.3} \Sigma y_{1} x_{2}+b_{13.2} \Sigma y_{1} x_{3}
\end{aligned}
$$

Therefore Eq (23) transforms as:

$$
C_{d}=\frac{a_{1.23} \Sigma y_{1}+b_{12.3} \Sigma y_{1} x_{2}+b_{13.2} \Sigma y_{1} x_{3}-\frac{\left(\Sigma y_{1}\right)^{2}}{\mathrm{n}}}{\Sigma y_{1}{ }^{2}-\frac{\left(\Sigma y_{1}\right)^{2}}{\mathrm{n}}}
$$

The coefficient of multiple correlation, $R_{1.23}$, can now be found as:

$$
R_{1.23}=\sqrt{C_{d}}=\sqrt{\frac{a_{1.23} \Sigma y_{1}+b_{12.3} \Sigma y_{1} x_{2}+b_{13.2} \Sigma y_{1} x_{3}-\frac{\left(\Sigma y_{1}\right)^{2}}{\mathrm{n}}}{\Sigma y_{1}{ }^{2}-\frac{\left(\Sigma y_{1}\right)^{2}}{\mathrm{n}}}}
$$

Let $r_{12}$ be the simple correlation between $y_{1}$ and $x_{2}$, and $r_{13}$ be the simple correlation between $y_{1}$ and $x_{3}$. If $R_{1.23}$ is more than both $r_{12}$ and $r_{13}$, it is a sufficient indication that the variability of $y_{1}$ is better explained by $x_{2}$ and $x_{3}$ together rather than by any one of them alone. 
In other words a higher definition of the regression equation is achieved by incorporating in it both independent variables as compared to when only one of them is used.

\subsubsection{Coefficients of Partial Correlation}

Coefficients of partial correlation are analogous in interpretation to their respective coefficients of partial estimation. For instance $r_{12.3}$ (analogous to $b_{12.3}$ ) is the correlation between $y_{1}$ and $x_{2}$ while $x_{3}$ is held constant at its mean value of $\bar{x}_{3}$; Similarly $r_{13.2}$ is the correlation between $y_{1}$ and $x_{3}$ while $x_{2}$ is held constant at its mean value of $\bar{x}_{2}$.

By definition $r_{13.2}{ }^{2}$ is the ratio between: the change in explained variation of $y_{1}$ brought about by including $x_{3}$ in the regression equation to the unexplained variation in the absence of $x_{3}$. Let $r_{12}$ be the simple correlation between $y_{1}$ and $x_{2}$, and $r_{13}$ be the simple correlation between $y_{1}$ and $x_{3}$, then :

Change in explained variation due to $x_{3}=R_{1.23}{ }^{2}-r_{12}^{2}$

Unexplained variation in absence of $x_{3}=1-r_{12}^{2}$

$$
\begin{aligned}
& r_{13.2}^{2}=\frac{\text { Change in explained variation due to } x_{3}}{\text { Unexplained variation in absence of } x_{3}} \\
& r_{13.2}^{2}=\frac{R_{1.23}{ }^{2}-r_{12}^{2}}{1-r_{12}^{2}}=\frac{\left(r_{13}-r_{12} r_{32}\right)^{2}}{\left(1-r_{12}^{2}\right)\left(1-r_{32}^{2}\right)}
\end{aligned}
$$

Similarly,

$$
r_{12.3}^{2}=\frac{R_{1.23}{ }^{2}-r_{13}^{2}}{1-r_{13}^{2}}=\frac{\left(r_{12}-r_{13} r_{23}\right)^{2}}{\left(1-r_{13}^{2}\right)\left(1-r_{23}^{2}\right)}
$$

It must be mentioned here that even if $r_{12}$ is less than $R_{1.23}$, it does not always mean that it would be less than $r_{12.3}$; Similarly if $r_{13}$ is less than $R_{1.23}$, it does not always mean that it would be less than $r_{13.2}$. This is particularly true because some independent variables assert their importance on the dependent variable not only through their direct interaction with it, but also indirectly through another independent variable. In such a case holding the second independent variable constant would definitely have the effect of reducing the coefficient of partial correlation. 


\subsubsection{Extension to $n$ Variables}

\subsubsection{Coefficients of Partial Correlation}

For a three variable case the coefficients like $r_{12.3}$ and $r_{13.2}$ (first order coefficients of partial correlation) requires prior computation of $r_{12}$ and $r_{13}$ (zero order coefficients of correlation). For a four variable case the coefficient like $r_{12.34}$ (second order coefficients of partial correlation) requires prior computation of $r_{12.3}, r_{14.3}$ and $r_{24.3}$ (first order coefficients of correlation). Hence the following useful generalizations can be made:

(1) An $n$ variable case requires computation of coefficients of partial correlation to the order of $n-2$.

(2) Determination of coefficients of partial correlation of any order requires prior computation of one lower order of coefficients of partial correlation.

$\mathrm{Eq}$ (26) and $\mathrm{Eq}$ (27) were obtained based on a three variable case. A generalized form of the two equations for $\mathrm{n}$ variables would be as follows:

$$
\begin{array}{cc}
r_{12.3 \ldots n}=\frac{r_{12.3 \ldots n-1}-r_{1 n .3 \ldots n-1} r_{2 n .3 \ldots n-1}}{\sqrt{\left(1-r_{1 n .3 \ldots n-1}^{2}\right)\left(1-r_{2 n .3 \ldots . n-1}^{2}\right)}} \\
r_{13.24 \ldots . . n}=\frac{r_{13.24 \ldots n-1}-r_{1 n .24 \ldots .1} r_{3 n .24 \ldots n-1}}{\sqrt{\left(1-r_{1 n .24 \ldots . . .1}^{2}\right)\left(1-r_{3 n .24 \ldots . . n-1}^{2}\right)}} \\
. . & . . \\
. . & . . \\
. . & . .
\end{array}
$$

Further generalizing for $n$ variables, the equations above can be represented by a single equation as follows:

$$
r_{a b .(\text { all but } a \& b)}=\frac{r_{a b .(\text { all but } a, b \& n)}-r_{a n .(\text { all but } a, b \& n)} r_{b n .(\text { all but } a, b \& n)}}{\sqrt{\left(1-r_{\text {an.(all but } a, b \& n)}^{2}\right)\left(1-r_{b n .(\text { all but } a, b \& n)}^{2}\right)}}
$$

where $a$ and $b$ represent any 2 integer values between 1 and $n-1$ (both inclusive) such that $a \neq b$. 


\subsubsection{Coefficient of Multiple Correlation}

Eq (25) used for computation of 'coefficient of multiple correlation' of 3 variables can be further extended up to a case of more than three variables. This however would require computation of the 'constants of regression', whose number and order would keep on increasing with an increase in the number of independent variables. A generalized, but still cumbersome alternate to computation of 'coefficient of multiple correlation' for any number of variables is given by the following equation:

$R_{1.2 \ldots n}$

$=\sqrt{r_{12}^{2}+r_{13.2}^{2}\left(1-r_{12}^{2}\right)+r_{14.23}^{2}\left(R_{1.23}^{2}\right)+r_{15.234}^{2}\left(R_{1.234}^{2}\right)+\ldots r_{1 n .23 \ldots .(n-1)}^{2}\left(R_{1.2 \ldots(n-1)}^{2}\right)}$

The complexity of computations associated with the determination of $n$th order of 'coefficient of multiple correlation' would be clear from a glance at the enormity of Eq (29) and Eq (30): It requires prior computations of all 'coefficients of multiple correlation' and 'coefficients of partial correlation' up to the $(n-1)$ th order. 


\section{Chapter 4 - Review Component}

\subsection{Work by Pinto and Covin}

As mentioned in Chapter 2, CSF identification based on expert opinion has been mostly conducted using two distinct approaches. The basic difference between these approaches is the way they are initiated. The first approach employs extraction and shortlisting of potential factors from past literature, and presenting a survey questionnaire, essentially comprising objectives and the potential factors, to expert professionals for rating purpose. The second approach involves identification of a set number of factors considered critical to project success by respondents, indication of the subjective importance of the factors selected by each respondent, and a conclusive assessment of all responses by expert professionals [Chua et al. 1999, Pinto and Slevin 1987].

Due to the theoretical or predominantly conceptual base of the first approach, Pinto and Slevin (1987) rather decided to adopt the second approach which, according to them, was more empirically grounded. Blank cards were distributed among a group of respondents who had served on projects during the past two years. They were asked to consider a project that they had served on during the last two years, and briefly describe the project and their involvement in it. Picking the first card, the respondents were required to write down something that could have helped improve implementation of the project. The process of picking card and providing input was repeated 5 times by each respondent. Following this, two experts were individually tasked to gauge the cards. Each expert sorted the responses across 10 categories in accordance with their own assessments. The total of 20 categories or factors concluded by the experts were finally reduced to 10 after having eliminated duplications.

Employing the process explained in the foregoing paragraph, Pinto and Slevin (1987) also extracted a list of 14 factors that provided the foundation for the research of Pinto and Covin (1989). The later research's effort to study the effect of project lifecycle on CSFs was, in essence, influenced by an earlier research of Pinto and Perscot (1988): "Variations in critical success factors over the stages in project lifecycle." Hence, Pinto and Covin (1989) forms the cream of research contributions by the first author. The research entitled "Critical factors for project implementation: a comparison of construction and R\&D projects" is considered for review in the following four subsections. 


\subsubsection{Research Objectives}

General project-management researchers initially perceived a common set of factors to be critical to the success of all project types (Manufacturing, R\&D, Construction etc.). "In other words, for the purpose of project management research, the implicit view of many academics could be represented by the axiom 'a project is a project is a project.' Indeed it could be argued that many academic researchers lost the sight of the individual trees by focusing too broadly on the larger forest [Pinto and Covin 1989]."

On the contrary, management practitioners (principally project managers) felt that the generalized project management prescriptions were mostly inapplicable to the unique situations posed by their respective classes of projects. Consequently the conclusions of theoreticians were often ignored by the practitioners. The need for this particular research arose from the realization of the serious dichotomy that existed in researches on project management and the implementation of projects in organizations. The basic objective of this study was to determine if generalized CSFs have the same importance for distinct types of projects; additionally it was felt necessary to see if the generalized CSFs varied over a project's lifecycle.

\subsubsection{Methodology}

The two types of project considered for comparison were construction, and research and development $(\mathrm{R} \& \mathrm{D})$. The reason for selection of these project types was the apparently vast difference of characteristics between them. It is important to mention that while construction projects involve building a physical facility, R\&D projects involve creation, evaluation or refinement of a product or service. Besides, the researchers believed that as compared to $R \& D$ projects, construction projects were more routine, less innovative, and more predictable.

A survey comprising 72 questions pertaining to $14 \mathrm{CSFs}$ was prepared and presented to members of the Project Management Institute, Canada. The response-ratio of construction managers to R\&D project managers was 184:151. A total of 13 objectives comprising the survey questionnaire included adherence to schedule and budget, perceived quality and utility of the completed project, and client satisfaction with the project. The 14 CSFs used in this this study, obtained from a previous research [Pinto and Slevin 1987], are briefly explained in Table 4.1. 
Table 4.1 Project CSFs [Pinto and Covin 1989]

\begin{tabular}{|c|c|c|}
\hline 1 & Mission & Initial clarity of goals and general directions. \\
\hline 2 & Top Management Support & $\begin{array}{l}\text { Willingness of top management to provide necessary } \\
\text { resources and authority/power for project success. }\end{array}$ \\
\hline 3 & Project Schedule/Plans & $\begin{array}{l}\text { A detailed specification of individual action steps required } \\
\text { for project implementation. }\end{array}$ \\
\hline 4 & Client Consultation & $\begin{array}{l}\text { Communication, consultation, and active listening to all } \\
\text { impacted parties. }\end{array}$ \\
\hline 5 & Personnel & $\begin{array}{l}\text { Recruitment, and training of necessary personnel for the } \\
\text { project team. }\end{array}$ \\
\hline 6 & Technical Tasks & $\begin{array}{l}\text { Availability of required technology and expertise to } \\
\text { accomplish the specific technical action steps. }\end{array}$ \\
\hline 7 & Client Acceptance & The act of 'selling' the final project to its ultimate users. \\
\hline 8 & Monitoring and Feedback & $\begin{array}{l}\text { Timely provision of comprehensive control information at } \\
\text { each stage in the implementation process (Monitoring } \\
\text { followed by information/feedback for control purposes). }\end{array}$ \\
\hline 9 & Communication & $\begin{array}{l}\text { The provision of an appropriate network and necessary data } \\
\text { to all key actors in the project implementation. }\end{array}$ \\
\hline 10 & Trouble-shooting & $\begin{array}{l}\text { The ability to handle unexpected crisis and deviation from } \\
\text { the plan. }\end{array}$ \\
\hline 11 & Characteristics of Project Team Leader & $\begin{array}{l}\text { Authority and Competence (administrative, inter personal } \\
\text { and admin) of project leader. }\end{array}$ \\
\hline 12 & Power and Politics & $\begin{array}{l}\text { The degree of political activity within the organization and } \\
\text { the perception of the project furthering an organization } \\
\text { member's self-interests. }\end{array}$ \\
\hline 13 & Environmental Effects & $\begin{array}{l}\text { The likelihood of external organizational or environmental } \\
\text { factors impacting on the operations of project team. }\end{array}$ \\
\hline 14 & Urgency & $\begin{array}{l}\text { The perception of importance of the project or the need to } \\
\text { implement the process as soon as possible. }\end{array}$ \\
\hline
\end{tabular}

The project managers were asked to consider an ongoing project or a recently completed one while completing the questionnaire. They were asked to classify their projects as residing in conceptualization, planning, execution or termination stage (stages explained in Section 1.1) The project implementation profile [Pinto and Slevin 1986] was used to assess the 72 questions, covering 14 CSFs, on a seven-point Likert (ordinal) scale. Besides answering the questions pertaining to the factors with respect to the 13 objectives, the managers were required to mention the importance of each objective towards the ultimate goal of project success in the particular lifecycle stage that their project resided in. The level of a project's success was measured as an aggregate of the responses of its project manager towards the relation between success and the 13 stated objectives. Finally, stepwise regression analysis was conducted to identify the most important CSFs during the four stages of construction and R\&D projects. 


\subsubsection{Results and Discussion}

The results of stepwise regression analysis are summarized in Table 4.2. It is evident that distinct lists of factors are responsible for the success of construction and R\&D projects. A clearly stated mission is the only CSF that is perceived to be important in all four stages of construction as well as $\mathrm{R} \& \mathrm{D}$ projects.

For construction projects, during the conceptual stage $54 \%$ of variation in project success is explained by the lone significant factor of mission. During the planning stage, three significant CSFs of mission, power and politics, and technical tasks collectively explain $84 \%$ of variation in project success. Mission, schedule, client consultation, and client acceptance are significant CSFs during the execution stage and have a cumulative R-square of $70 \%$. In the termination stage, $54 \%$ of variation in project success is collectively explained by technical tasks, mission, communication, and trouble-shooting.

For the R\&D projects, mission client consultation, personnel, and urgency are significant CSFs during the conceptual stage and have a cumulative R-square of 92\%. Mission, environmental effects, schedule, monitoring and feedback, and client acceptance are significant during the planning stage and collectively explain $63 \%$ of variation in project success. During the execution stage, the three CSFs of mission, technical tasks, and top management support collectively explain 54\% of the variation in project success. Finally during the termination stage, mission, schedule, client acceptance, technical tasks, and personnel collectively explain $72 \%$ of the variation in project success.

A comparative explanation of why certain CSFs appear more important for construction projects while others more important for R\&D projects is as follows:

- Overt Risk: Risk is defined as the likelihood of encountering potentially severe project-development and implementation difficulties [Narasimhan and Schroeder 1979]. The causes of risks prevalent in R\&D projects include uncertain client expectation, loss of project support, uncertain resource requirements, technical problems, and lack of experience project team members. In case of construction projects most uncertainties regarding client expectation, resource procurement (project funding), and procedural concerns are removed long before the actual work is initiated on the site. 
Table 4.2 Comparison of CSFs in Each Stage of Project Lifecycle (Construction and R\&D) [Pinto and Covin 1989]

\begin{tabular}{|c|c|c|c|c|c|c|}
\hline \multirow[b]{2}{*}{$\begin{array}{l}\text { Stage of } \\
\text { project } \\
\text { lifecycle }\end{array}$} & \multicolumn{3}{|c|}{ Construction } & \multicolumn{3}{|c|}{ R\&D } \\
\hline & $\begin{array}{c}\text { Number } \\
\text { of } \\
\text { projects }\end{array}$ & Factors & $(\mathrm{Cum}-\mathrm{R})^{2}$ & $\begin{array}{l}\text { Number } \\
\text { of } \\
\text { projects }\end{array}$ & Factors & $\begin{array}{c}(\mathrm{Cum}- \\
\mathrm{R})^{2}\end{array}$ \\
\hline \multirow[t]{4}{*}{ Conceptual } & \multirow[t]{4}{*}{17} & \multirow[t]{4}{*}{ Mission } & \multirow[t]{4}{*}{0.54} & \multirow[t]{4}{*}{14} & Mission & 0.67 \\
\hline & & & & & Client Consultation & 0.81 \\
\hline & & & & & Personnel & 0.87 \\
\hline & & & & & Urgency & 0.92 \\
\hline \multirow[t]{5}{*}{ Planning } & \multirow[t]{5}{*}{24} & Mission & 0.71 & \multirow[t]{5}{*}{30} & Mission & 0.30 \\
\hline & & Power \& Politics & 0.82 & & Environmental Effects ${ }^{a}$ & 0.38 \\
\hline & & \multirow[t]{3}{*}{ Technical Tasks } & \multirow[t]{3}{*}{0.84} & & Schedule & 0.50 \\
\hline & & & & & Monitoring \& Feedback ${ }^{\mathrm{a}}$ & 0.54 \\
\hline & & & & & Client Acceptance & 0.63 \\
\hline \multirow[t]{4}{*}{ Execution } & \multirow[t]{4}{*}{82} & Mission & 0.57 & \multirow[t]{4}{*}{81} & Mission & 0.46 \\
\hline & & Schedule & 0.66 & & Technical Tasks & 0.51 \\
\hline & & Client Consultation & 0.69 & & Top Management Support & 0.54 \\
\hline & & Client Acceptance & 0.70 & & & \\
\hline \multirow[t]{5}{*}{ Termination } & \multirow[t]{5}{*}{61} & Technical Tasks & 0.35 & \multirow[t]{5}{*}{26} & Mission & 0.42 \\
\hline & & Mission & 0.50 & & Schedule & 0.48 \\
\hline & & Communication $^{\mathrm{a}}$ & 0.53 & & Client Acceptance $^{\mathrm{a}}$ & 0.56 \\
\hline & & Trouble-shooting & 0.54 & & Technical Tasks & 0.61 \\
\hline & & & & & Personnel $^{\mathrm{a}}$ & 0.72 \\
\hline
\end{tabular}

- Project Team Personnel: R\&D projects are typically non-repetitive, and hence an organization would often recruit specialized personnel to meet the needs of a new project. Towards the end of the project, these $R \& D$ personnel would then be reassigned to other projects where each one of them has to perform a completely different task. In contrast, in construction organizations the same personnel may comprise project teams across many different projects.

- Project Scheduling/Plans: Owing to their inherent predictability, construction execution activities are more amenable to scheduling as compared to $R \& D$ execution activities. While scheduling is not important to an R\&D team during 
execution, scheduling of project transfer during termination stage, being controllable, is of prime concern to them.

- Evaluative Feedback: The evaluative feedback of the team members is directly linked to their commitment to established schedules and budget. Being comparatively less routine in nature, $R \& D$ projects often have a higher susceptibility to face budget overruns and schedule delays, and hence result in a negative feedback of the team members. It shall be noted that failure to honor commitments may not necessarily be because of the inefficiency of $R \& D$ professional and may have arisen because of the complex nature of their research; the understandably unavoidable breaches in commitment by the $R \& D$ professionals, reported to the top management as their evaluation, may hence adversely affect the creativity that their profession needs so badly. With regard to construction projects, any breach in commitment by a team member may be rightly attributed to his/her inefficiency and hence reporting it to the top management should not create negative feelings against the team leader.

- Top Management Support: Top management of construction projects can easily predict the resources needed to accomplish the goals; hence, they are aware of "what they are getting into at the beginning of the project and are likely to maintain their initial commitment." On the other hand, top management of R\&D projects have a very vague idea of the needs of their project, they cannot accurately measure its current status against established goals, and are hence more likely to withdraw the support that is essential for the success of an ongoing project.

\subsubsection{Conclusions}

This study shows that though identification of a set of general critical success factors has some benefits for both academics and practitioners, strict adherence to them would not necessarily ensure project success. It is proved that every project type offers its own set of problems, and hence the characteristic difference in the perception of what is critical for the implementation of construction and R\&D projects. "Theoreticians must descend from the broad 
level of generalizations to take into account the peculiarities of various classes of projects [Pinto and Covin 1989]."

Furthermore, the study reveals that while some factors are more important during an early lifecycle stage, others are more important in later stages of a project. In other words, the CSFs for any one lifecycle stage of a project are markedly different from the CSFs for another stage of a project's lifecycle. The chances of success can be enhanced if managers were to give due importance to the CSFs in a stage-wise fashion. 


\subsection{Work by Ashley et al.}

The following two subsections describe and summarize the research published by D.B. Ashley, C.S. Lurie, and E.J. Jaselskis (1987) entitled "Determinants of construction project success." The study constitutes the phase 1 (Pilot Study Phase) of the last author's [Jaselskis 1988] PhD research at the University of Texas, Austin. The subsections touch upon the study so as to give the reader a brief insight into yet another methodology (other than those mentioned in detail in Section 4.1 and 4.3) adopted by CSF researchers.

The research indicates that "much of success or failure of construction project rests on the shoulders of the management organization as opposed to other participants associated with the project [Jaselskis 1988]." Hence the study viewed project success from the project manager's perspective for the owner and contractor organizations he works for, and did not take into consideration the viewpoint of other professionals working for owner, contractor and consultant organizations.

\subsubsection{Methodology}

A list of approximately 2000 factors perceived to be important for success of construction projects was extracted from literature and consultation with knowledgeable construction professionals. Thorough examination by the researcher trimmed the list to a total of 46 potential factors. The reduced list of potential factors was presented to construction professionals from owner and contractor organizations. The experts were asked to rate the potential factors on a scale of 1 (no significance) to 5 (high significance).

After the ranking of potential factors was obtained in accordance with mean of ratings by the two types of professionals (Figure 4.1), they were divided into five categories: (1) Management, organization and communication, (2) Scope and planning, (3) Control, (4) Environmental, economic, social and political, and (5) Technical. Two highly ranked factors were selected from each category in addition to the third highly ranked management factor making a list of 11 factors (Table 4.3). Additional data related to the list of 11 factors was obtained from 16 projects: 8 of these were "Average Projects" and 8 were "Outstanding projects". Hypothesis testing was used to identify factors exhibiting strong statistical difference between the "Average Projects" and "Outstanding Projects." 


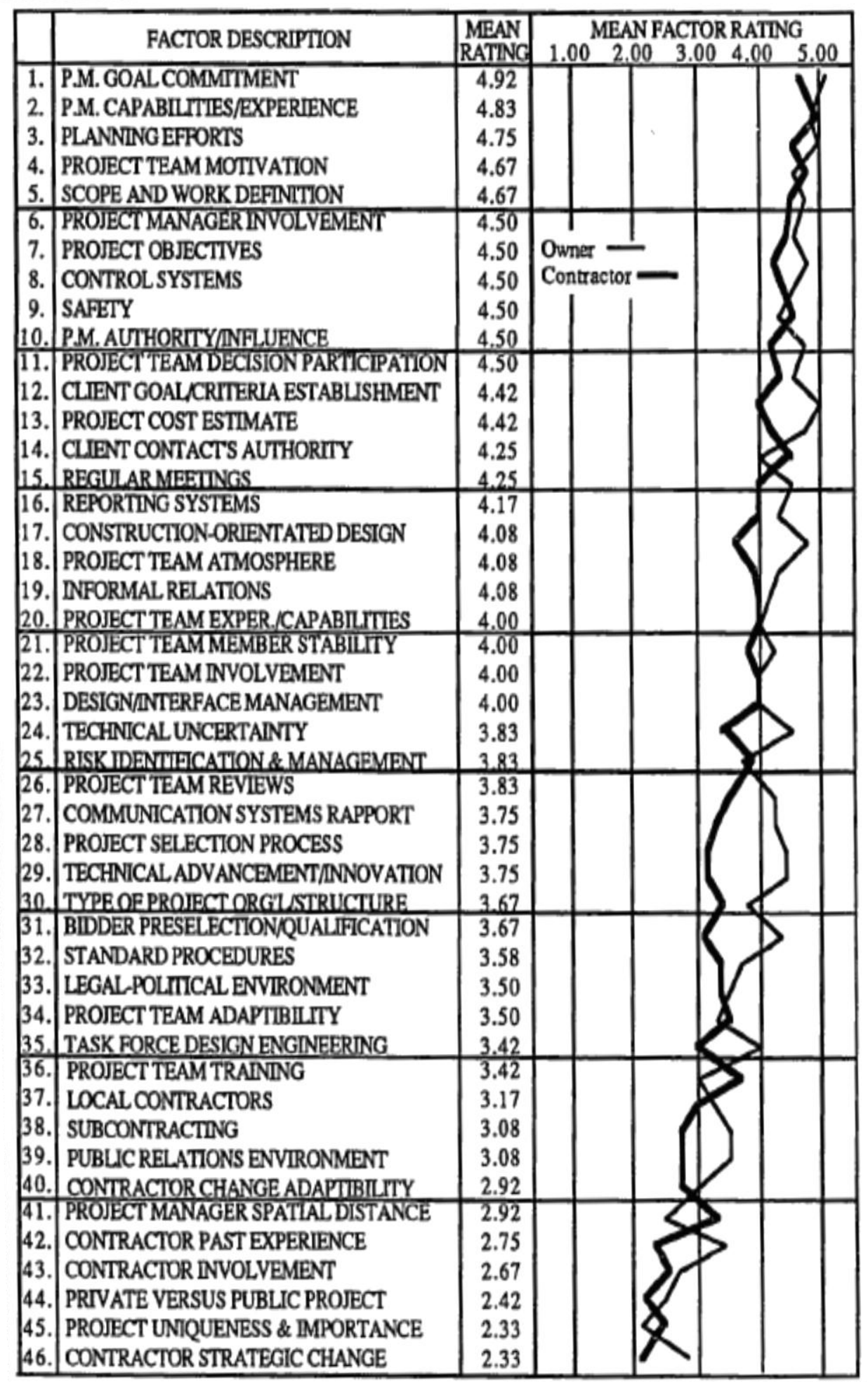

Figure 4.1 Subjective Factor Rating by Owner and Contractor PMs [Jaselskis 1988] 
Table 4.3 Selected Major Success Factors [Jaselskis 1988]

\begin{tabular}{|l|l|}
\hline SELECTED MAJOR FACTORS DESCRIPTION & RANK/MEAN RATING \\
\hline MANAGEMENT, ORGANIZATION AND COMMUNICATION & \\
1. PM Goal Commitment & $1 / 4.92$ \\
2. PM Capabilities and Experience & $2 / 4.83$ \\
3. Project Team Motivation and Goal Orientation & $4 / 4.67$ \\
\hline SCOPE AND PLANNING & \\
4. Planning Efforts & $3 / 4.75$ \\
5. Scope and Work Definitions & $5 / 4.67$ \\
\hline CONTROL & \\
6. Control Systems & $8 / 4.5$ \\
7. Safety & $9 / 4.5$ \\
\hline ENVIRONMENTAL, ECONOMIC, SOCIAL AND POLITICAL & \\
8. Risk Identification and Management & $25 / 3.83$ \\
9. Legal-Political Environment & $32 / 3.58$ \\
\hline TECHNICAL & \\
10. Design/Interface Management & $23 / 4.00$ \\
11. Technical Uncertainty. & $24 / 3.83$ \\
\hline
\end{tabular}

\subsubsection{Results \& Conclusions}

Figure 4.1 shows the mean of factor-ratings by the two types of professionals; in addition it also demonstrates how each factor was rated separately by the two types of professionals. The following projections are obvious from the ratings and resulting rankings:

- Owner PMs (project managers) usually rated the factors higher than contractor PMs.

- Among the 46 factors, most of the highest ranked factors correspond to PM. These include PM goal commitment (at rank 1), PM capabilities/experience (at rank 2), PM involvement (at rank 6), PM authority/influence (at rank 10).

- The 10 highest rank factors also include project planning efforts (at rank 3) and control systems (at rank 8).

Table 4.3 shows the most highly ranked factors in each of the five categories. Additional subjective and objective data was obtained on these factors from 8 average and 8 outstanding projects. Hypothesis testing was then employed to find those factors that made strong statistical difference while going from average to outstanding projects. Results of hypothesis testing demonstrates that statistically significant differences existed between average and outstanding projects with regard to the factors of planning efforts (construction and design), project manager 
goal commitment, project team motivation, project manager technical capabilities, scope and work definition, and control systems (Figure 4.2).

It is generally believed that better than expected cost, schedule, quality and safety performance are the criteria that can sufficiently measures success. Rather than strictly adhering to this pet definition of success, hypothesis testing was used to identify the criteria that exhibited strong statistical difference between the average projects and outstanding projects. It was determined that budget performance, schedule performance, project manager satisfaction, client satisfaction, contractor satisfaction, and functionality were most appropriate for measuring construction project success.

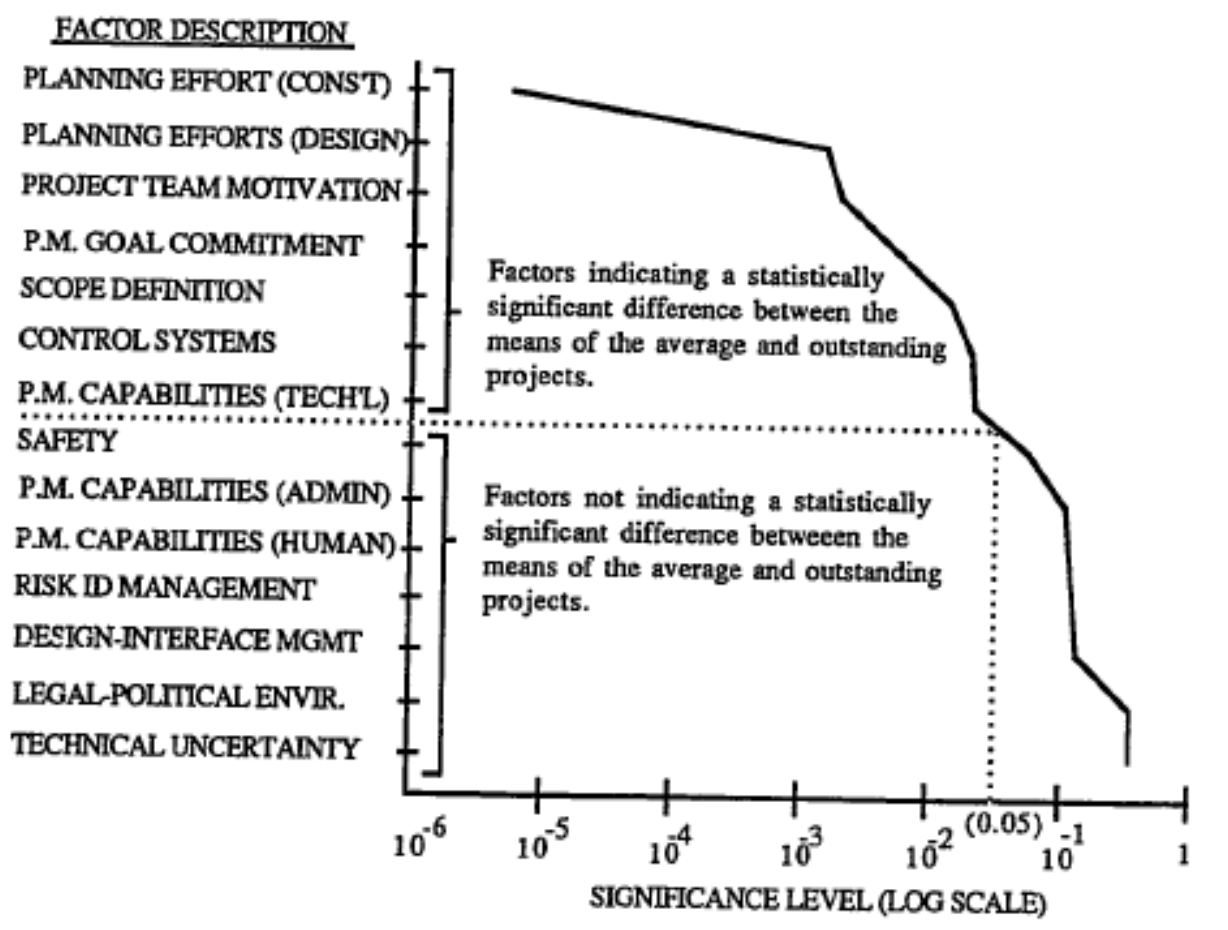

Figure 4.2 Factor Significance Level for Average versus Outstanding Projects [Ashley et al. 1988] 


\subsection{Work by Kog and Loh.}

Y.C. Kog and colleagues applied neural networking approach on data from 75 construction projects for determining CSFs for budget performance [Chua et al 1997]. In a later research, Kog and colleagues used neural networking approach for extracting CSFs for schedule performance [Kog et al. 1999]. Since the neural networking technique is only applicable to tangible factors, subsequent research contributions by Kog that employed intangible factors utilized the Analytical Hierarchy Process (AHP). Kog and colleagues used the AHP for distinguishing CSFs for different project objectives [Chua et al. 1999]. A yet to be published research by Kog and Loh (2011) uses the AHP for differentiating the CSFs based on objectives as well as components of construction projects. The research entitled "Critical success factors for different components of construction projects", being the most exclusive of Kog's contributions, is considered here for a detailed review.

\subsubsection{Research Objectives}

None of the research conducted before 2011 attempted to study any possible dissimilarity between CSFs pertaining to different components of construction projects-Civil works, architectural works, and mechanical and electrical works. It cannot be ruled out that the outcomes of the earlier studies were less illustrative for those components which had a comparatively lower representation in the surveys.

The difference in academic backgrounds and job descriptions of professionals involved in construction can be expected to shape their divergent views on CSFs. The divergence in views of the professionals may also be caused by the different frames of time that they mostly work in. While a major portion of civil and structural works would be undertaken in early project-life, mechanical and electrical works, and architectural works would be initiated later in the project's life. In order to check the validity of these stated expectations Kog and Loh (2011) studied the CSFs of construction projects separately for the following four categories:

- Civil and structural works

- Architectural works

- Mechanical and electrical works

- Quantity surveying 
Until 2011 no efforts were undertaken to check if the reliability of a respondent's opinion depended on the possessed level of experience. It would not be unfair to claim a possible influence of a respondent's expertise on molding his/her judgment capabilities. A preliminary feature of the subject study was to find the authenticity of the stated claim.

\subsubsection{Research Methodology}

The subject study is a continuation of the work of Chua et al. (1999). The survey questionnaire consisted of 67 potential factors (Table B.1) that were previously reported in the literature: Ashley and Jaselskis (1991), Murphy et al. (1983), Construction (1991), Diekmann and Girard (1995), Gordon (1994), Loh (2000), Macomber (1989), and Might and Fisher (1985). The relative importance of the potential factors for 3 different objectives, and for overall project success was to be determined profession wise-The AHP (See Chapter 2 of this report) that uses pairwise comparisons of experts was utilized for this purpose. The objectives or the criteria for which the relative importance of the factors was to be determined were: (1) schedule performance, (2) quality performance, and (3) budget performance.

The 67 factors pertained to four typical aspects of construction projects: (1) project characteristics, (2) contractual arrangements (3) project participants, and (4) interactive processes. However, before the factors could be assigned to their respective aspects, the former (except for contractual arrangements) were divided into two or more sub-aspects. This was done in lieu of aiding the AHP and is shown below:

- Project characteristics: Internal and external.

- Contractual arrangements: Undivided aspect.

- Project Participants: PM, client, contractor, consultant, subcontractors, and suppliers.

- Interactive processes: Communication, planning, monitoring and control, and project organization.

The AHP model for the study is shown in Figure 4.3. The goal of 'construction project success' occupies level-1, followed by the three objectives (criteria) of schedule, quality and budget at level-2, followed by the four main project aspects at level-3. As shown in Figure 4.4 to Figure 4.7 each of the factors occupies the lowest level of the subhierarchy corresponding to the four project aspects. 


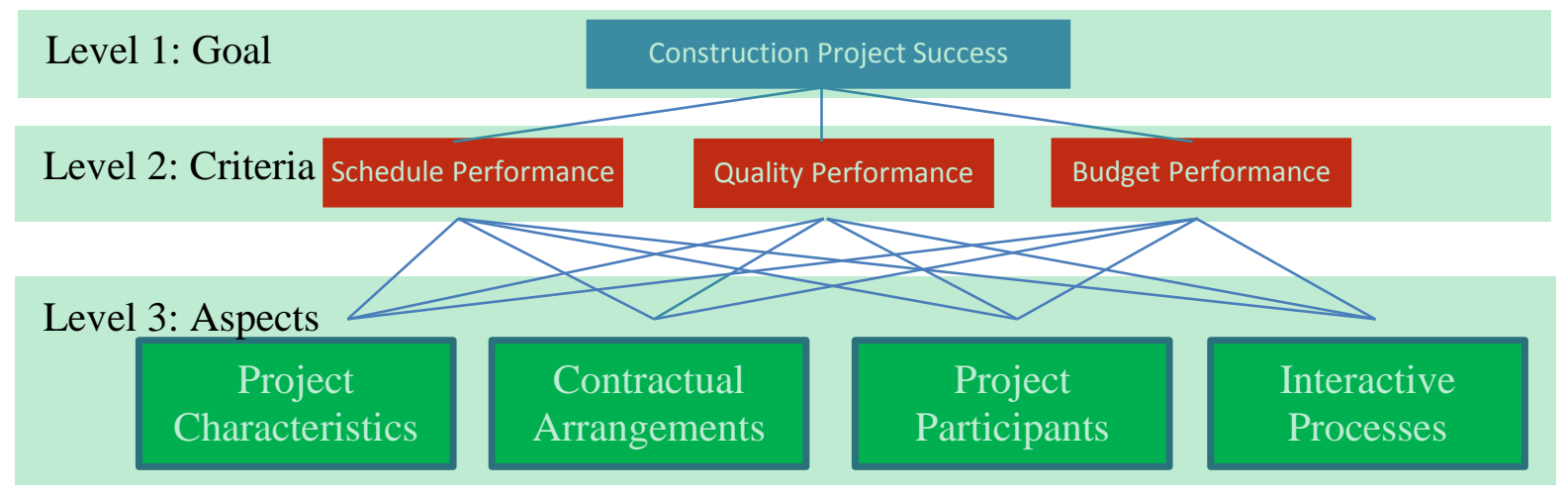

Figure 4.3 AHP Model for Construction Project Success [Chua et al. 1999]

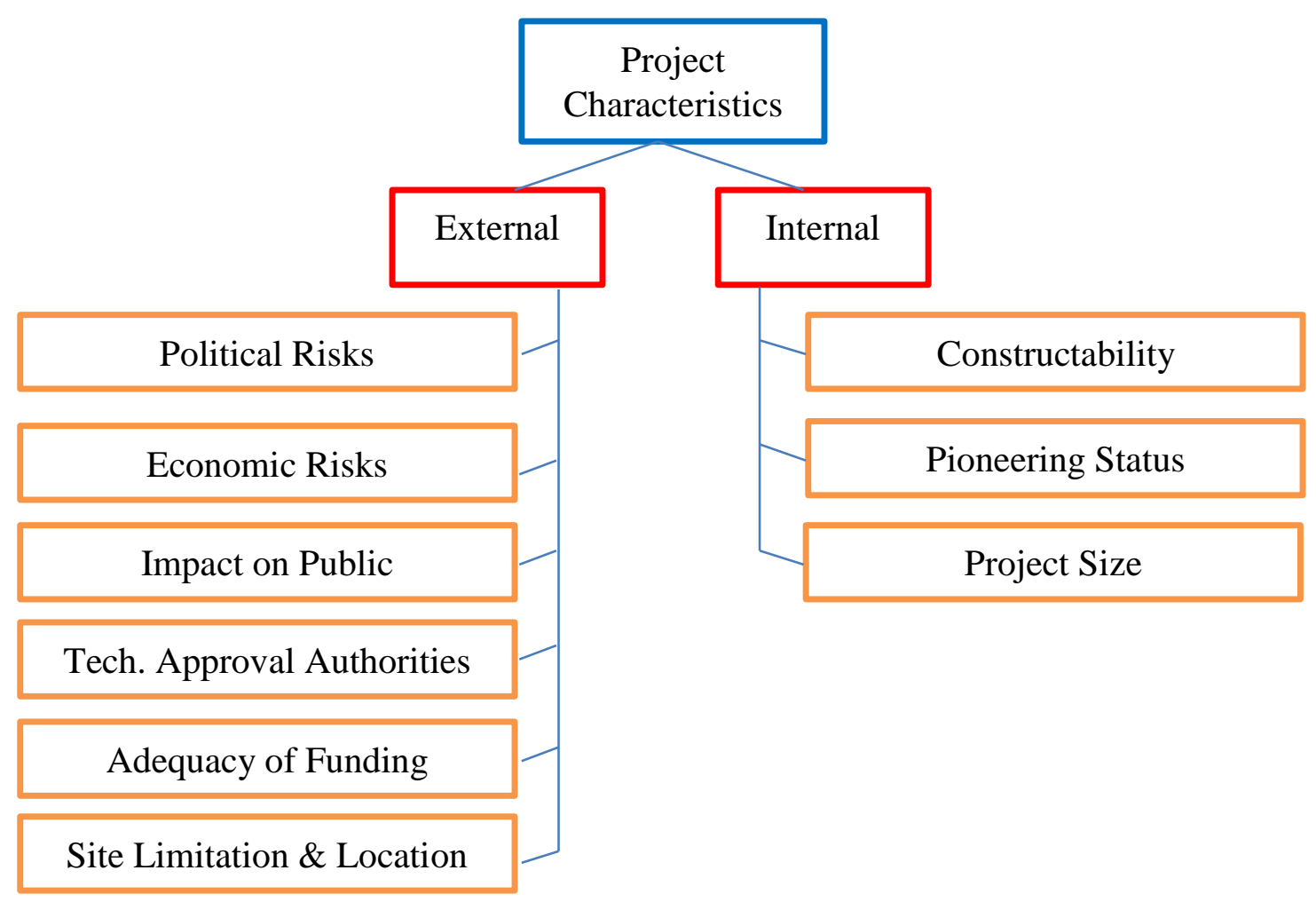

Figure 4.4 Subhierarchy for Project Characteristics [Chua et al. 1999] 


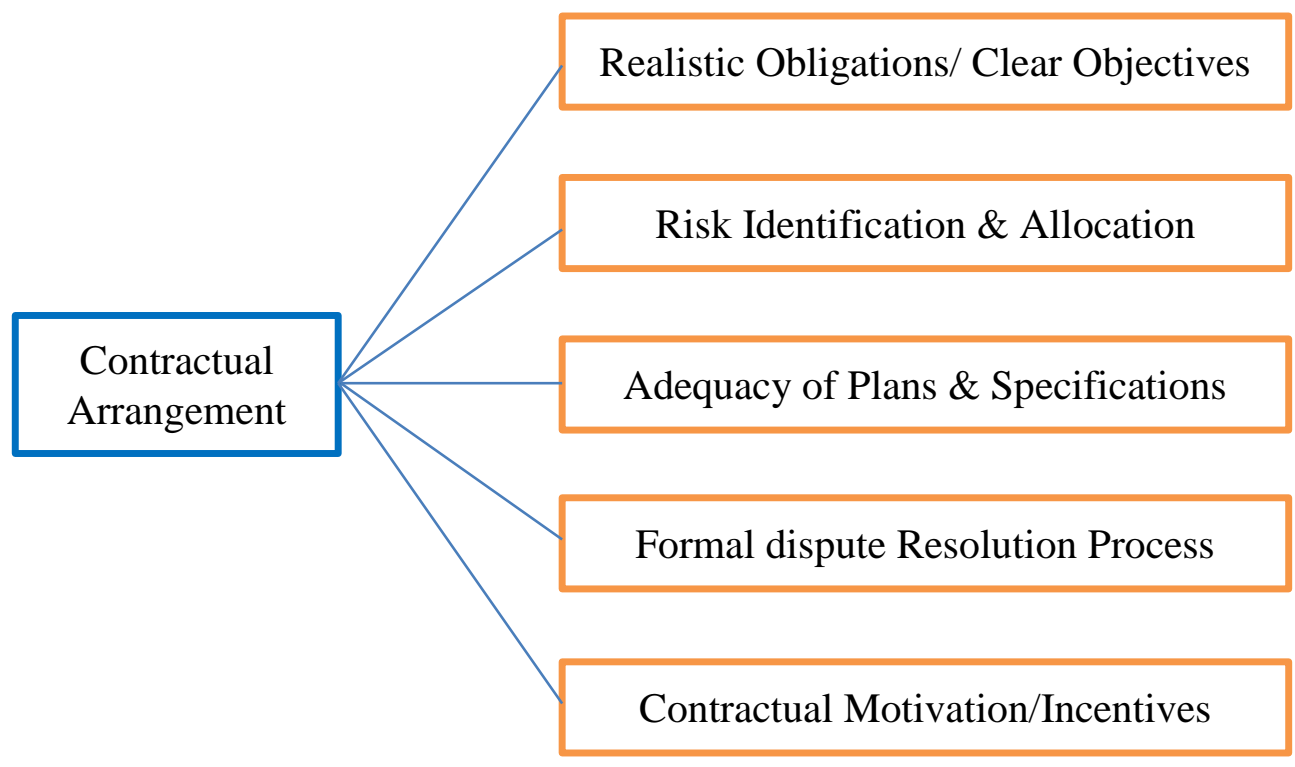

Figure 4.5 Subhierarchy for Contractual Arrangements [Chua et al. 1999]

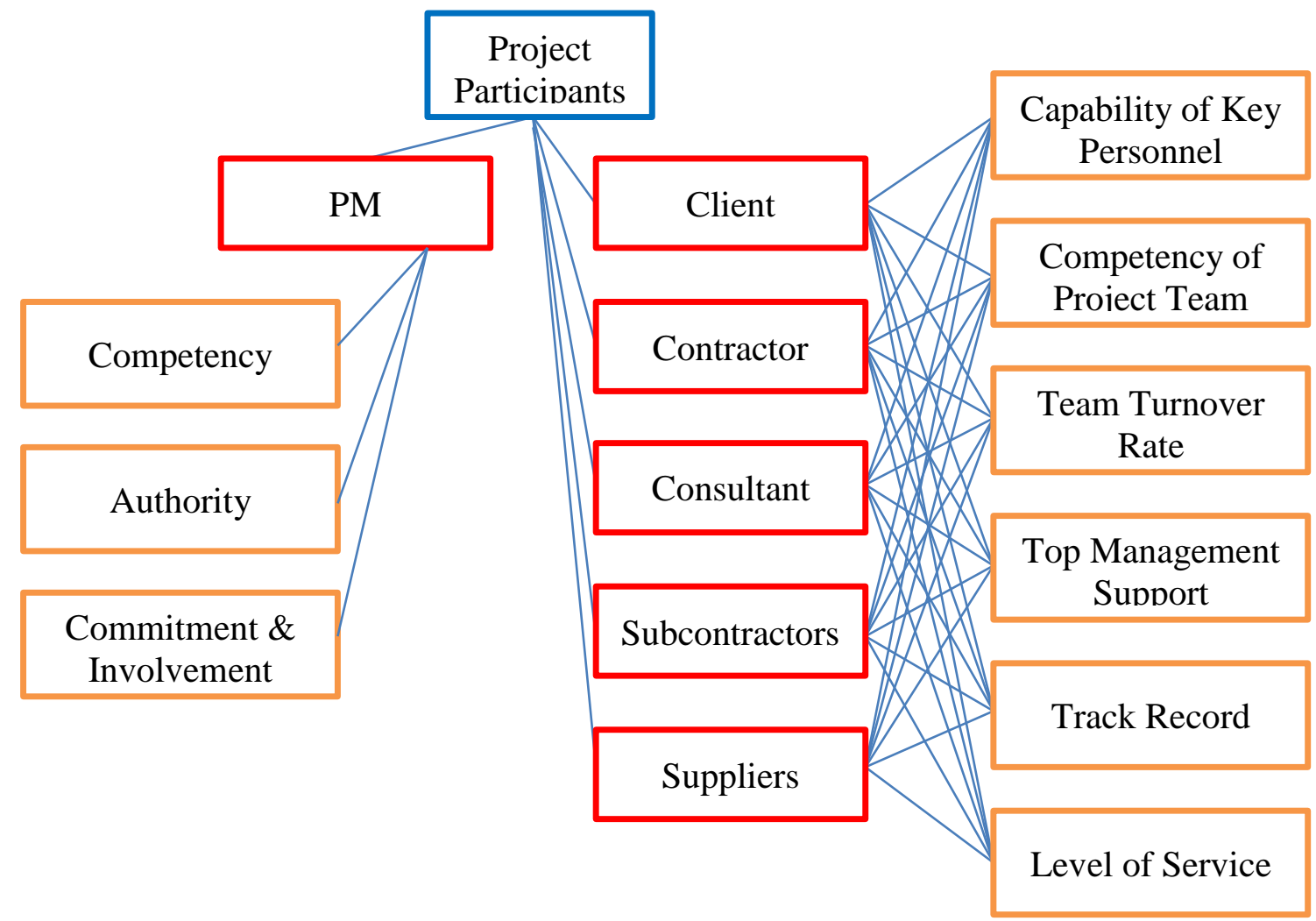

Figure 4.6 Subhierarchy for Project Participants [Chua et al. 1999] 


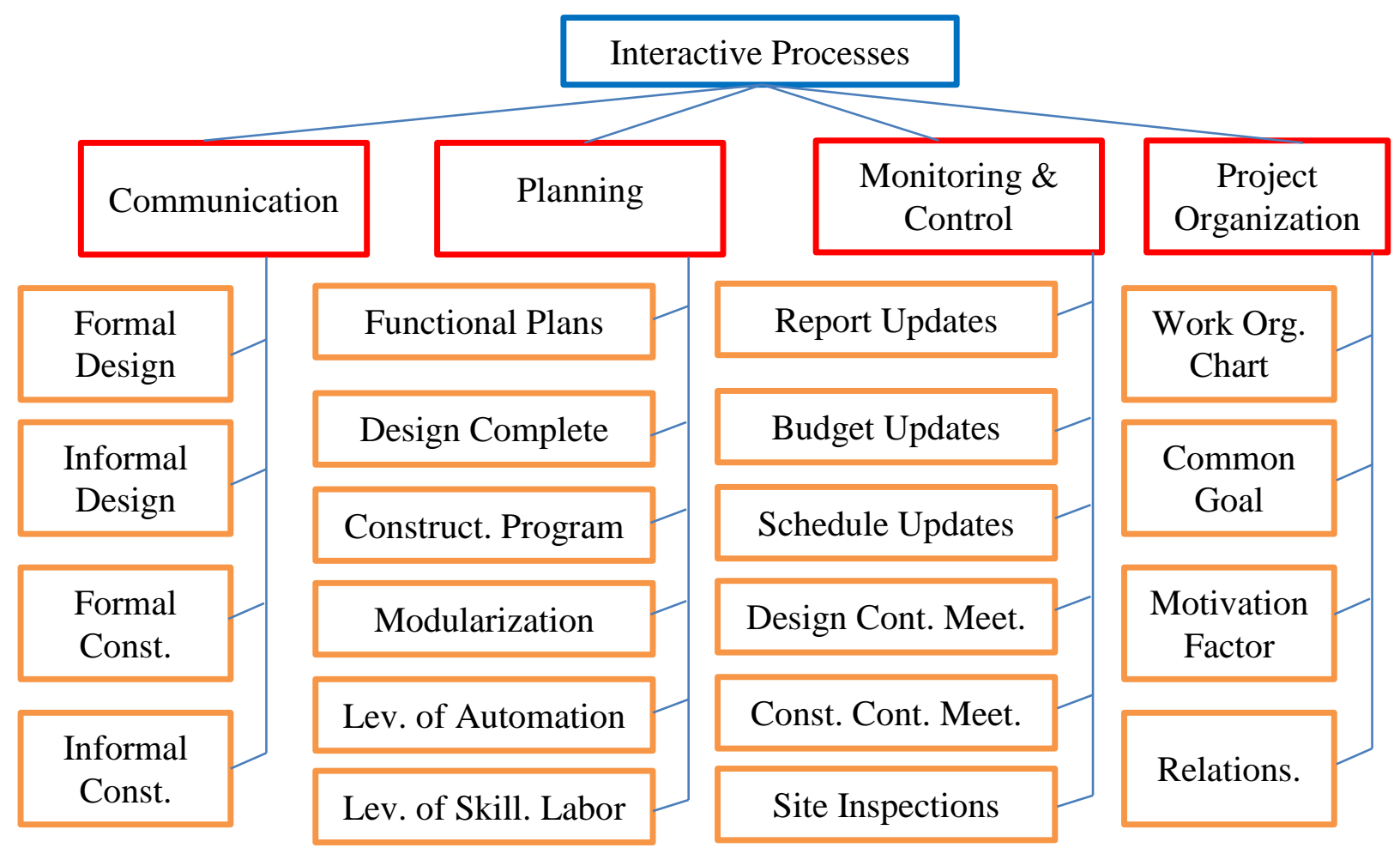

Figure 4.7 Subhierarchy for Interactive Processes [Chua et al. 1999]

In order to ensure higher quality of sampling the services of only those professionals were availed who occupied very senior positions and had work-experience in more than three countries. This strict definition of 'expert' attributed to a smaller number of respondents (total of 33). The number of experts to whom the survey was presented comprised of the following:

- Civil and structural (C\&S) engineers: 15 .

- Architects: 6.

- Mechanical and electrical (M\&E) engineers: 5.

- Quantity Surveyors: 7.

The professionals had worked in organizations of consultants, contractors, clients or project management consultants. Their countries of experience included:

- United Kingdom

- Australia

- Singapore

- Hong Kong 
- Malaysia

- Vietnam

- Seychelles

- Middle East

\subsubsection{Preliminary Findings (Initial Results and Conclusions)}

27 of these 33 respondents had more than 15 years of experience. An extra feature of the study was to see if reliability of respondents' judgments depended on their level of experience. This was achieved by adopting two of the statistical techniques presented in chapter 3 . Prior to this, a consistency check (explained in Chapter 2) on the 33 questionnaires revealed that the overall consistency ratio of 6 individuals with less than 15 years of experience was unsatisfactorily much above $10 \%$.

The AHP, for each individual, reveals the relative importance of factors with respect to the three objectives and the overall project success (goal). The experience-brackets considered in the study were:

- Less than 10 years of experience

- 10-15 years of experience

- 15-20 years of experience

- More than 20 years of experience.

For individuals within the same experience bracket, the relative importance of each factor was averaged out. The averaging process was repeated separately for schedule, quality, budget and overall project success. The rankings of the factors for each objective for each experience bracket was determined as explained in Chapter 2. This was followed by determining the Spearman Coefficient of rank concordance $\left(r_{s}\right)$ values for rankings between all possible pairs of experience brackets-The process being repeated for each of the objectives and the goal.

The $r_{s}$ values for the objectives of schedule performance, budget performance, quality performance and overall performance are shown in Table 4.4 to Table 4.7 , respectively. It turned out that for all the three objectives and the goal, the $r_{s}$ values (4 in all) between 'the subgroup having 15-20 years of experience' and 'the subgroup having more than 20 years of experience' were more than 0.7, indicating a high level of consistency of rankings between respondents having more than 15 years of experience. Conversely for all the objectives and the goal, the $r_{s}$ 
Table 4.4 $r_{s}$ Between Different Expertise Level (Schedule Performance) [Kog and Loh 2011]

\begin{tabular}{|c|c|c|c|c|}
\hline \multicolumn{4}{|c|}{$\mathrm{r}_{\mathrm{s}}$ between groups of respondents with different years of experience- Schedule Performance } \\
\hline & $>20$ years & $15-20$ years & $10-15$ years & $<10$ years \\
\hline$>20$ years & - & & & \\
\hline $15-20$ years & 0.84 & - & & \\
\hline $10-15$ years & 0.32 & 0.35 & - & \\
\hline$<10$ years & 0.58 & 0.74 & 0.26 & - \\
\hline
\end{tabular}

Table 4.5 $r_{s}$ Between Different Expertise Level (Budget Performance) [Kog and Loh 2011]

\begin{tabular}{|c|c|c|c|c|}
\hline \multicolumn{5}{|c|}{$\mathrm{r}_{\mathrm{s}}$ between groups of respondents with different years of experience- Budget Performance } \\
\hline & $>20$ years & $15-20$ years & $10-15$ years & $<10$ years \\
\hline$>20$ years & - & & & \\
\hline $15-20$ years & 0.78 & - & & \\
\hline $10-15$ years & 0.69 & 0.56 & - & \\
\hline$<10$ years & 0.56 & 0.65 & 0.40 & - \\
\hline
\end{tabular}

Table 4.6 $r_{s}$ Between Different Expertise Level (Quality Performance) [Kog and Loh 2011]

\begin{tabular}{|c|c|c|c|c|}
\hline \multicolumn{5}{|c|}{$r_{s}$ between groups of respondents with different years of experience- Quality Performance } \\
\hline & $>20$ years & $15-20$ years & $10-15$ years & $<10$ years \\
\hline$>20$ years & - & & & \\
\hline $15-20$ years & 0.76 & - & & \\
\hline $10-15$ years & 0.48 & 0.35 & - & \\
\hline$<10$ years & 0.68 & 0.58 & 0.40 & - \\
\hline
\end{tabular}

Table 4.7 $r_{s}$ Between Different Expertise Level (Overall Performance) [Kog and Loh 2011]

\begin{tabular}{|c|c|c|c|c|}
\hline \multicolumn{5}{|c|}{$r_{s}$ between groups of respondents with different years of experience- Overall Performance } \\
\hline & $>20$ years & $15-20$ years & $10-15$ years & $<10$ years \\
\hline$>20$ years & - & & & \\
\hline $15-20$ years & 0.72 & - & & \\
\hline $10-15$ years & 0.53 & 0.36 & - & \\
\hline$<10$ years & 0.58 & 0.66 & 0.28 & - \\
\hline
\end{tabular}


values ( 4 in all) of rankings between 'the subgroup having less than 10 years of experience' and 'the subgroup having 10-15 years of experience' were less than or equal to 0.4 , indicating a low level of consistency between respondents having less than 15 years of experience. This indicates that, as compared to respondents with more than 15 years of experience, participants with less than 15 years of experience do not hold a consistent opinion of what comprises the CSFs for Schedule Performance, Budget Performance, Quality Performance and Overall Performance for construction projects.

Moreover, 4 of the $16 r_{s}$ values of rankings between 'the two subgroups having less than 15 years of experience' and 'the two subgroups having more than 15 years of experience' were less than 0.4; looking at it from a different critical perspective tells us that 15 of the $16 r_{s}$ values were less than 0.7. This merely indicates the existence of an inconsistency of opinion between the group above (two upper subgroups) and the group below (two lower subgroups) the border limit of 15 years of experience-The higher consistency of opinion between the two upper subgroups, and the lower consistency between the two lower subgroups is actually explained in the preceding paragraph.

Kendall's test was performed to determine the internal agreement between members of each experience-bracket, the whole process being repeated for each of the four objectives. Explaining further, this time the averaging of relative importance was not resorted to as the aim was to seek an intra-group correlation rather than an inter-group one; The rankings were rather determined separately for each member of the experience-bracket. As the number of factors was more than 7, the test was approximated using $\chi^{2}$ test of independence as explained in Section 3.2.1.

It was found that for respondents with less than 10 years of experience, the $\chi^{2}$ values were less than the critical value at $95 \%$ level of confidence, and that this observation held true for each of the three objectives and the goal. This meant that there was no clear evidence of any association between the members of the group with less than 10 years of experience: putting it another way, there was a clear evidence of no association between the members of the group with less than 10 years of experience. The same outcomes held true for members of group with 10-15 years of experience. Together for the two groups, it can be stated that the judgments of respondents with less than 15 years of experience were not good enough. 
It was concluded that studies in existing literature which includes the opinion of respondents having less than 15 years of experience should be read with caution. Moreover, subsequent analysis of this particular survey was claimed to be carried out after rejecting the 6 questionnaires corresponding to respondents with less than 15 years of experience leading to the following composition of respondents:

- $\quad$ Civil and structural (C\&S) engineers: 13.

- Architects: 4.

- Mechanical and electrical (M\&E) engineers: 4.

- Quantity Surveyors: 6.

\subsubsection{Final Findings (Final Results and Conclusions)}

For respondents with a common profession (analogous to consideration of common experience bracket in Section 4.3.2.1), considering one objective at a time, the relative importance of each factor can be averaged out-The averaging process had to be repeated separately for schedule, quality, budget and overall project success. The resulting ranking of factors for the $C \& S$ engineers, $M \& E$ engineers, architects, and quantity surveyors are compiled in Table B.2 to Table B.5. Re-grouping of the same results based on the objectives of schedule, quality, budget, and overall performance is shown in Table B.6 to Table B.9.

\subsubsection{Results: Grouping Based on Components}

For the $\mathrm{C} \& \mathrm{~S}$ engineers the factors of adequacy of plans and specifications, realistic obligations, PM competency and constructability forms the four common CSFs for all the objectives and the goal (Table B.2). Similarly, for the M\&E engineers the factors of adequacy of plans and specifications, PM competency, and PM commitment and involvement forms the three common CSFs for all objectives and the goal (Table B.3). For the architects, the five identical CSFs for all the objectives and the goal were adequacy of plans and specifications, realistic objectives, PM competency, constructability, and consultant team turnover rate (Table B.4).

It is important though to mention that the views of quantity surveyors cannot be expected to be shaped by their experience in any particular component of construction projects. This is because rather than designing or supervising a specific component of construction works, they deal with payment matters of C\&S engineers and architects - Views of QS are most likely to be 
formed by construction projects as a whole except M\&E works. The QS considers the five factors of adequacy of plans and specifications, realistic objectives, PM competency, PM authority, and constructability to commonly control the overall project success and the three stated objectives (Table B.5).

\subsubsection{Results: Grouping Based on Objectives}

The results of the survey, grouped on the basis of objectives, are shown in Table B.6 to Table B.9. Schedule performance was seen to be commonly determined by the CSFs of adequacy of plans and specifications, PM competency, and constructability by professionals related to all the three components (Table B.6). Together the C\&S engineers and M\&E engineers ranked the factors of technical approval authorities, construction control meetings, and schedule updates as highly important for determining the schedule performance. The architects alone judged the factors of capability of contractor key personnel, contractor team competency, and formal construction communication as key determinants of schedule performance.

Quality performance was seen to be commonly determined by the CSFs of adequacy of plans and specifications, realistic obligations, PM competency, and constructability by professionals related to all the three components (Table B.7). The factors of PM commitment and involvement, site inspections, construction control meetings, and contractor team turnover rate were considered as crucial for schedule performance by the $C \& S$ engineers and $M \& E$ engineers but not by the architects. The architects alone considered capability of contractor key personnel, capability of consultant key personnel, consultant team competency, and consultant team turnover rate as highly important for determining schedule performance.

Budget performance was seen to be commonly determined by the CSFs of adequacy of plans and specifications, realistic obligations, PM competency, and adequacy of funding by professionals related to all the three components (Table B.8). Both the C\&S engineers and M\&E engineers rank the factors of economic risks, budget updates and risk identification and allocation as highly important for determining budget performance. The architects alone counted on capability of contractor key personnel, consultant team turnover rate, and client top management support as being the factors that are critical for schedule performance.

Overall performance was seen to be commonly determined by the CSFs of adequacy of plans and specifications, realistic obligations, PM competency, and constructability by professionals related to all the three components (Table B.9). The factors of PM commitment and 
involvement, and contractual motivation/incentives were considered as crucial for overall performance by the $C \& S$ engineers and $M \& E$ engineers but not by the architects. The architects alone deemed capability of consultant key personnel, consultant team competency, consultant team turnover rate, and client top management support as key determinants for overall performance.

\subsubsection{Conclusions and Discussion}

The study shows that considering any of the objectives, the CSFs are not the same for all components of construction projects (Table B.5 to Table B.9); the non-similarity in judgments by the professionals related to these components is rightly attributable to the difference in their specific roles. It goes without saying that conclusions of CSF studies reported in existing literature would be highly biased if due consideration is not given to the professional backgrounds of survey respondents.

For architectural works, 50\% of the top ten CSFs are among the project participant attributes, particularly those of the contractor and consultant, whether the goal or any of the three objectives is taken into consideration (Table B.4). One possible reason for this trend is that architectural works are not so well defined in contractual documents and hence need additional human interactions between the architect and contractor.

For both the $\mathrm{C} \& S$ and $M \& E$ works, factors pertaining to control and monitoring form a major portion of CSFs for the goal as well as the three objectives; least contribution to CSFs is seen from the factors grouped under project participant attributes (Table B.2 and Table B.3). This may be because of a feeling that C\&S and M\&E works are by default well-defined in contract documents, so further improvement in attaining objectives would require effective implementation of control and monitoring mechanisms.

The correlations of views between the professional groups for the goal and for the three objectives are shown in Table 4.8 to Table 4.11. For the three components of construction projects ( $C \& S, M \& E$ and architectural works), it can be seen that considering the goal or any of the three objectives, the highest correlation of views exists between the $C \& S$ and $M \& E$, followed by that between the $C \& S$ and architect. Of the correlations between the three components, the lowest is always that between the M\&E and the architect. Possible reasons for the lowest correlation between the $\mathrm{M} \& \mathrm{E}$ and the architect is the substantial difference between them regarding the following: 
- Design phase: Architectural design is the first to be initiated among the designs of the three components; The M\&E design (being the last) is initiated normally when all issues pertaining to architectural and civil designing have been sorted out.

- Construction phase: It was previously stated (Section 4.3.1) that both M\&E and architectural works follows the civil/structural works later in the construction phase; In fact, while the M\&E works may directly follow the C\&S works, the architectural works are normally left for the final stages of construction phase.

- Scope of work: Architects are involved in construction projects right from conceptualization until project completion; M\&E engineers have a very limited role in construction projects "except for building projects with high content of M\&E inputs such as intelligent buildings, hospitals and heavy industry mills." 
Table 4.8 $r_{s}$ Between Different Professions (Schedule Performance) [Kog and Loh 2011]

\begin{tabular}{|c|c|c|c|c|}
\hline \multicolumn{5}{|c|}{$r_{\mathrm{s}}$ between groups of respondents of Different Professions- Schedule Performance } \\
\hline & C\&S & M\&E & QS & Architect \\
\hline C\&S & - & & & \\
\hline M\&E & 0.67 & - & & \\
\hline QS & 0.73 & 0.48 & - & \\
\hline Architect & 0.60 & 0.41 & 0.62 & - \\
\hline
\end{tabular}

Table 4.9 $r_{s}$ Between Different Professions (Budget Performance) [Kog and Loh 2011]

\begin{tabular}{|c|c|c|c|c|}
\hline \multicolumn{5}{|c|}{$\mathrm{r}_{\mathrm{s}}$ between groups of respondents of Different Professions- Budget Performance } \\
\hline & $\mathrm{C} \& \mathrm{~S}$ & $\mathrm{M} \& \mathrm{E}$ & QS & Architect \\
\hline $\mathrm{C} \& \mathrm{~S}$ & - & & & \\
\hline $\mathrm{M} \& \mathrm{E}$ & 0.64 & - & & \\
\hline $\mathrm{QS}$ & 0.82 & 0.58 & - & \\
\hline Architect & 0.52 & 0.32 & 0.70 & - \\
\hline
\end{tabular}

Table 4.10 $r_{s}$ Between Different Professions (Quality Performance) [Kog and Loh 2011]

\begin{tabular}{|c|c|c|c|c|}
\hline \multicolumn{5}{|c|}{$\mathrm{r}_{\mathrm{s}}$ between groups of respondents of Different Professions- Quality Performance } \\
\hline & $\mathrm{C} \& \mathrm{~S}$ & $\mathrm{M} \& \mathrm{E}$ & QS & Architect \\
\hline $\mathrm{C} \& \mathrm{~S}$ & - & & & \\
\hline $\mathrm{M} \& \mathrm{E}$ & 0.63 & - & & \\
\hline QS & 0.74 & 0.54 & - & \\
\hline Architect & 0.63 & 0.41 & 0.50 & - \\
\hline
\end{tabular}

Table 4.11 $r_{s}$ Between Different Professions (Overall Performance) [Kog and Loh 2011]

\begin{tabular}{|c|c|c|c|c|}
\hline \multicolumn{5}{|c|}{$\mathrm{r}_{\mathrm{s}}$ between groups of respondents of Different Professions- Overall Performance } \\
\hline & $\mathrm{C} \& \mathrm{~S}$ & M\&E & QS & Architect \\
\hline C\&S & - & & & \\
\hline M\&E & 0.70 & - & & \\
\hline QS & 0.78 & 0.54 & - & \\
\hline Architect & 0.43 & 0.24 & 0.64 & - \\
\hline
\end{tabular}




\subsection{Comparative Discussion}

For ease of comprehension, in this section the goal and the three objectives used in Kog and Loh (2011) are collectively referred to as 'the four objectives.' Besides 'adequacy of plans and specifications', 'PM competence' was a factor that was considered crucially important by all the four types of professionals for all the four objectives. 'Constructability' was ranked as a CSF by the C\&S engineers, architects and QS irrespective of the consideration of any of the objectives; the M\&E ranked 'constructability' as a CSF for all objectives except for budget performance.

Similarly, 'realistic obligations/clear objectives' was ranked as a CSF by the C\&S engineers, architects and QS irrespective of the type of objective under consideration; the M\&E ranked 'realistic obligations' as a CSF for all objectives except for schedule performance. This

finding is in total agreement with that of Pinto and Covin (1989) who found 'mission/initial clarity of goals' to be the only factor crucial to the success of all the four stages of construction projects (see Section 4.1.3).

Quite understandably, 'adequacy of funding' was considered to be crucially important by all the four types of professionals for budget performance; for the remaining three objectives it was not considered as being crucially important by any of the four professions with just one exception being the architects deeming it important for overall performance.

Pinto and Covin (1989) claimed that construction workers are used to the general routine nature of construction projects (undertaken by their particular organization), and hence an exceptionally innovative construction project is more susceptible to failure. Perhaps for similar reasons professionals related to the two key components of construction projects, namely the $\mathrm{C} \& S$ engineers and architects, attached a very high importance to the factor of 'pioneering status.' Whereas 'pioneering status' was considered as crucial by the $\mathrm{C} \& \mathrm{~S}$ for the objectives of quality and budget performance (Table B.2), it was considered as crucial by the architects for the objectives of quality and overall performance (Table B.4). However, it is important to mention that, including the passive construction professions of $M \& E$ and $Q S$, the $C \& S$ engineers and architects did not consider 'pioneering status' as a highly important factor for the objective of schedule performance (Table B.6).

The factor 'characteristics of project team leader' used by Pinto and Covin (1989) was explained as: a combination of PM authority and PM competency. Stepwise regression analysis 
showed that this factor could not appear relatively important during any of the four phases of construction. Kog and Loh (2011) rather tested 'PM authority' and 'PM competency' as two distinct factors. 'PM competency' (besides adequacy of plans and specifications) was a factor that was considered crucially important by all the four types of professionals irrespective of the type of stated objective. On the other hand, 'PM authority' was ranked as a CSF for only 5 of the 16 possible combinations of objectives and professions: four by QS (Table B.5), and one by the architects (Table B.4).

J.J. Tuman, a mechanical engineer by profession, and program manager for several aerospace R\&D projects [PMH 1983] referred to the presence of an inverse relation between the effectiveness of project management to the size of the project. The same trend was witnessed with regard to M\&E engineers in building construction projects-They considered the factor of 'project size' as critically important for the objectives of schedule and quality performance (Table B.3). However, the factor of 'project size' seemed to be less important the C\&S engineers, architects and QS with respect to all the four objectives (Table B.2, Table B.4 and Table B.5). 


\title{
Chapter 5 - Research Component
}

\author{
CRITICAL SUCCESS FACTORS FOR DIFFERENT ORGANIZATIONS IN \\ CONSTRUCTION PROJECTS
}

\subsection{Introduction.}

Progress in search of success factors is impulsively evident from a rich treasure of resources on construction projects. State-of-the-art contributions on success studies by various researchers, discussed at length in the Chapter 4 , have been a source of inspiration for this research.

Chua et al. (1999) researched the CSFs for different objectives of construction projects: schedule, budget, and quality performance. The research, though very briefly, also attempted to distinguish between CSFs for different organizations involved in construction projects. Because the survey sample was quite small, the researchers referred to their findings regarding organization-based CSFs as inconclusive. It was suggested that further research be conducted in this regard. Using a different methodology, the present study aims at differentiating the CSFs based on organizational backgrounds of project participants: Contractor organization personnel, project management organization personnel, and consultant organization (design) personnel.

Like this study, Hwang and Lim (2012) is also grounded on the recommendations of Chua et al. (1999). Interestingly, most of the 53 factors of this study as well as the 32 factors of Hwang and Lim (2012) were extracted from the 67 factors of Chua et al. (1999) after discarding the factors pertaining to subcontractors, suppliers, and project organization. The two studies, however, differ in the following ways: (1) this study surveyed 39 contractor, consultant, and project management organization personnel from 7 countries; Hwang and Lim (2012) surveyed 12 contractor, consultant, and owner personnel from Singapore alone, and (2) this study uses the absolute judgment mode of the AHP; Hwang and Lim (2012) uses the comparative judgment mode of the AHP. 


\subsection{Methodology}

\subsubsection{Survey and Respondents}

A survey was offered to construction professionals to rank a list of 53 potential factors (Table C.1: see Appendix C). The list includes, in addition to important factors of Chua et al. (1999), potential-factors that were shortlisted after in-depth interviews of experts who have worked in both developed and developing countries. The nomenclature of some of the factors is explained in Table C.2, the others being self-explanatory. The professionals include civil/structural engineers, architects, mechanical engineers, electrical engineers and quantity surveyors having work experiences in consultant firms (design firms), contractor firms, and project manager organizations (construction management firms) in the construction industry. The survey was offered to professionals having experience both in developed countries like Canada, UK and USA, and developing countries namely Libya, Pakistan, Saudi Arabia, and UAE.

\subsubsection{Conversion of Classificatory Data to Absolute Form}

Because of the subjective nature of the data, this study chooses the Analytical Hierarchy Process (AHP) to analyze the completed questionnaires. Depending on the circumstances, the AHP can be used for analyzing comparative judgments or absolute judgments. In the comparative judgment procedure, the AHP uses absolute scale numbers (Table 5.1) for judgments of factors and returns the absolute values for priorities. Alternately, it is possible to solicit from experts an absolute judgments/ratings of factors on an intensity level, conduct a pairwise comparison of intensity levels (rather than factors), and assign the resulting priority values to the absolute judgments. In both methods the priorities ultimately becomes relative upon normalization or idealization (Saaty 2006).

Rather than asking the experts to conduct a pairwise comparison of factors, they were requested to rate the factors based on their ability to determine schedule, budget and quality performances. A five-level intensity scale was to be employed by the experts: Excellent, above average, average, below average, and poor. 
Table 5.1 Fundamental Pairwise Comparison Scale [Saaty 2006]

\begin{tabular}{|c|l|l|}
\hline $\begin{array}{c}\text { Level of } \\
\text { Importance }\end{array}$ & \multicolumn{1}{|c|}{ Definition } & \multicolumn{1}{c|}{ Explanation } \\
\hline 1 & Equal importance & The two nodes contribute equally to the parent \\
\hline 3 & Moderate importance & Judgment moderately favors the strong over the weak \\
\hline 5 & Strong importance & Judgment strongly favors the strong over the weak \\
\hline 7 & $\begin{array}{l}\text { Very strong demonstrated } \\
\text { importance }\end{array}$ & $\begin{array}{l}\text { The stronger node's importance over the weaker is } \\
\text { demonstrated very strongly in practice. }\end{array}$ \\
\hline 9 & $\begin{array}{l}\text { Extremely strong } \\
\text { demonstrated importance }\end{array}$ & $\begin{array}{l}\text { Extremely strong evidence exists for favoring the } \\
\text { stronger over the weaker node. }\end{array}$ \\
\hline \multicolumn{2}{|l}{ Values 2,4,6,8 can be used for intermediate intensities between above-stated levels of importance } \\
\hline
\end{tabular}

Pairwise comparison matrix and the resulting idealized priority vector for the 5-levels of intensity are computed as below:

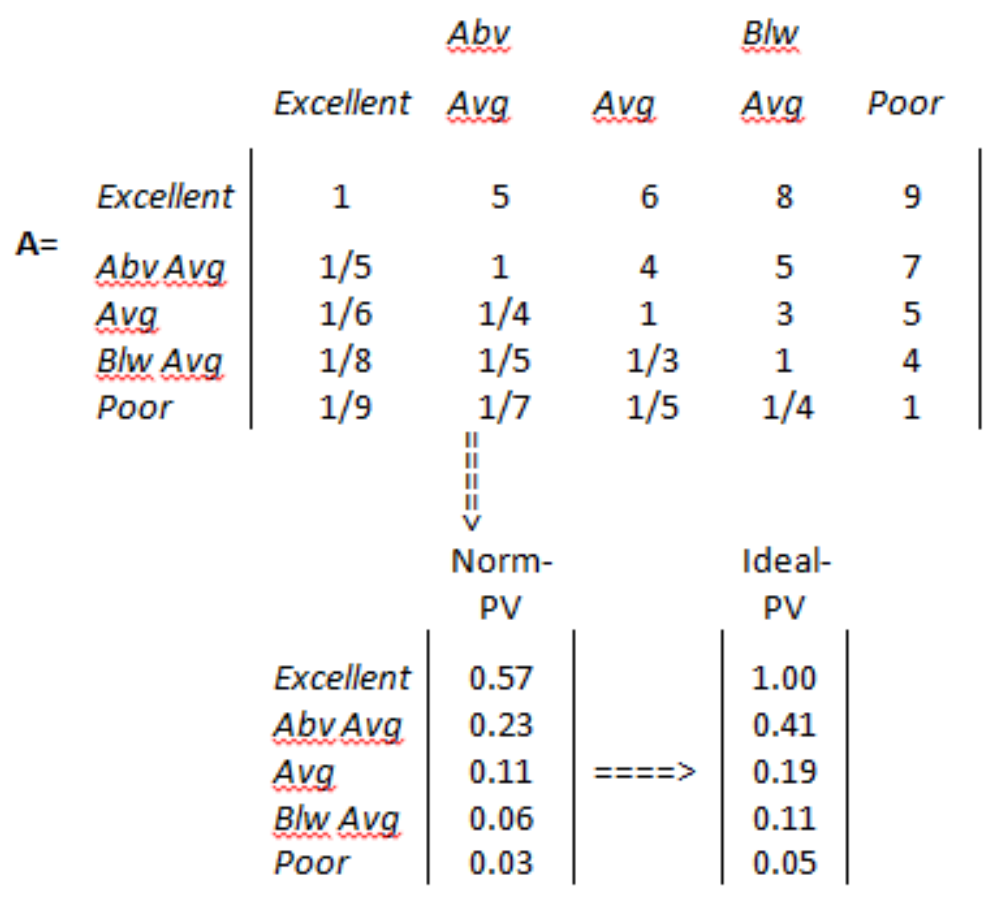

\subsubsection{Determining Objective-wise Performance}

Considering one organization-type at a time, hypothesis testing is employed to determine the factors that have a significant impact on each of schedule performance (s), budget 
performance (b), and quality performance (q). Spearman rank correlation coefficient $\left(\mathrm{r}_{\mathrm{s}}\right)$ is used to test the null hypothesis, $\mathrm{H}_{\mathrm{o}}\left(\mu_{1}=\mu_{2}\right)$ : objective (Schedule, Budget, or Quality) is independent of factor $\left(f_{1}\right.$ to $f_{53}$ ), is tested against the alternate hypothesis, $H_{A}$ : objective (Schedule, Budget, or Quality) is positively correlated to factor $\left(f_{1}\right.$ to $\left.f_{53}\right)$. The alternate hypothesis would be accepted if the calculated p-value is less than 0.05. This implies that for the alternate hypothesis to be accepted, the following conditions must be satisfied:

- Contractor organization (21 professionals): $r_{\mathrm{s}} \geq 0.368$

- Consultant organization (9 professionals): $r_{s} \geq 0.600$

- Project Management Organization (14 professionals): $r_{\mathrm{s}} \geq 0.456$

\subsubsection{Determining Overall Project Performance}

The idealized priority values were assigned to the intensity levels of the 53 factors for the objectives of budget, schedule and quality performance as assessed by each expert. This was followed by determining the priority values and rankings for overall project success. $\chi^{2}$ values for the of rankings were calculated to ascertain the level of association between experts hailing from the same organizational background. Priority values of experts from the same type of organization were only averaged if calculated value of $\chi^{2}$ was more than the relevant critical value at $95 \%$ level of confidence.

\subsection{Results}

\subsubsection{Contractor Organization}

Factors satisfying the alternate hypothesis for an objective (schedule, budget or quality) imply that they have a capacity to significantly determine the particular objective. Table 5.2 shows significant factors for schedule performance, budget performance, and quality performance for the contractor organizations. The factors of realistic obligations/clear objectives, adequacy of plans and specifications, capability of contractor key personnel, construction control meetings, and site inspections were seen to be commonly significant for all the three objectives. The factors of technical approval authorities, site access limitation, and latent site conditions were commonly significant for schedule and budget performance. The factors of economics risks, capability of consultant key personnel, competency of consultant proposed team, design 
Table 5.2 Contractor Organization Significant Factors

\begin{tabular}{|c|c|c|c|c|c|c|}
\hline \multirow{3}{*}{ Potential Factor } & \multicolumn{6}{|c|}{ Significant at $5 \%$ for Contractor Personnel } \\
\hline & \multicolumn{2}{|c|}{ Schedule } & \multicolumn{2}{|c|}{ Budget } & \multicolumn{2}{|c|}{ Quality } \\
\hline & $\mathrm{r}_{\mathrm{s}}$ & $p$-val & $\mathrm{r}_{\mathrm{s}}$ & $p$-val & $r_{\mathrm{s}}$ & $p$-val \\
\hline Realistic Obligations & 0.45 & 0.020 & 0.55 & 0.004 & 0.42 & 0.026 \\
\hline Adequacy of Plans \& Specifications & 0.49 & 0.012 & 0.61 & 0.002 & 0.38 & 0.044 \\
\hline Capability of Contractor Key Personnel & 0.40 & 0.037 & 0.49 & 0.012 & 0.44 & 0.024 \\
\hline Construction Control Meetings & 0.62 & 0.001 & 0.37 & 0.049 & 0.47 & 0.015 \\
\hline Site Inspections & 0.60 & 0.002 & 0.55 & 0.005 & 0.43 & 0.026 \\
\hline Technical Approval authorities & 0.41 & 0.032 & 0.56 & 0.004 & & \\
\hline Site Access Limitation & 0.39 & 0.040 & 0.41 & 0.032 & & \\
\hline Latent Site Conditions & 0.43 & 0.025 & 0.43 & 0.026 & & \\
\hline Economics Risks & & & 0.43 & 0.025 & 0.41 & 0.032 \\
\hline Capability of Consultant Key Personnel & & & 0.47 & 0.016 & 0.38 & 0.044 \\
\hline Competency of Consultant Team & & & 0.49 & 0.011 & 0.62 & 0.001 \\
\hline Design Complete & & & 0.50 & 0.010 & 0.42 & 0.028 \\
\hline Level of Automation & & & 0.55 & 0.005 & 0.68 & 0.0003 \\
\hline Transparency in work award & & & 0.42 & 0.030 & 0.66 & 0.0005 \\
\hline Adequacy of Funding & 0.48 & 0.014 & & & & \\
\hline Contractual Motivation & 0.43 & 0.027 & & & & \\
\hline Informal Construction Communication & 0.49 & 0.012 & & & & \\
\hline Schedule Updates & 0.45 & 0.020 & & & & \\
\hline Bureaucratic Involvement & 0.42 & 0.040 & & & & \\
\hline Functional Plan & & & 0.52 & 0.007 & & \\
\hline General Tolerance to Corruption & & & 0.42 & 0.029 & & \\
\hline Absence of Litigations & & & 0.40 & 0.034 & & \\
\hline Constructability & & & & & 0.56 & 0.004 \\
\hline Pioneering Status & & & & & 0.64 & 0.001 \\
\hline Project Size & & & & & 0.58 & 0.003 \\
\hline PM Competency & & & & & 0.43 & 0.025 \\
\hline PM Authority & & & & & 0.43 & 0.025 \\
\hline PM Commitment and Involvement & & & & & 0.53 & 0.006 \\
\hline Competency of Contractor Team & & & & & 0.37 & 0.047 \\
\hline Level of Skill Labor Required & & & & & 0.66 & 0.0006 \\
\hline
\end{tabular}


complete at construction start, level of automation, and transparency in awarding of work were seen to be commonly significant for budget and quality performance.

The factors that were significant for schedule but not for budget and quality performance were: adequacy of funding, contractual motivation/incentives, informal construction communication, schedule updates, and bureaucratic involvement. The factors that significantly contributed only to budget performance were functional plan, general tolerance to corruption, and absence of litigations/claims. The factors that significantly contributed only to quality performance were constructability, pioneering status, project size, PM competency, PM authority, PM commitment and involvement, competency of contractor proposed team, and level of skill labor required.

\subsubsection{Project Management Organization}

Table 5.3 shows significant factors for schedule performance, budget performance, and quality performance for the project management organizations. Of the 53 factors, 20 were significant contributors to schedule performance, 12 were significant contributors to budget performance, and 20 were significant contributors to quality performance. The factors of capability of contractor key personnel, capability of consultant key personnel, level of skill labor required, and site access limitation were seen to be commonly significant for all the three objectives. Capability of client key personnel, recruitment and training procedures, and latent site conditions were commonly significant for schedule and budget performance. Economics risks, adequacy of plans and specifications, pioneering status, project size, realistic obligations, level of modularization, construction control meetings, and schedule updates were commonly significant for schedule and quality performance. The factor of functional plan was commonly significant for budget and quality performance.

The factors that were significant for schedule but not for budget and quality performance were constructability, informal construction communication, design complete at construction start, level of automation, and transparency in awarding of work. The factors that significantly contributed only to budget performance were budget updates, general tolerance to corruption, competent authority discretionary powers, and absence of litigations. The factors that significantly contributed only to quality performance were PM competency, PM authority, PM 
Table 5.3 PM Organization Significant Factors.

\begin{tabular}{|c|c|c|c|c|c|c|}
\hline \multirow{3}{*}{ Potential Factor } & \multicolumn{6}{|c|}{ Significant at 5\% for PMO: } \\
\hline & \multicolumn{2}{|c|}{ Schedule } & \multicolumn{2}{|c|}{ Budget } & \multicolumn{2}{|c|}{ Quality } \\
\hline & $\mathrm{r}_{\mathrm{s}}$ & $p$-val & $r_{s}$ & $p-v a l$ & $\mathrm{r}_{\mathrm{s}}$ & $p-v a l$ \\
\hline Site Access Limitation & 0.77 & 0.001 & 0.53 & 0.026 & 0.49 & 0.044 \\
\hline Capability of Contractor Key Personnel & 0.47 & 0.044 & 0.47 & 0.044 & 0.67 & 0.004 \\
\hline Capability of Consultant Key Personnel & 0.68 & 0.004 & 0.82 & 0.000 & 0.48 & 0.040 \\
\hline Level of Skill Labor Required & 0.84 & 0.000 & 0.65 & 0.005 & 0.60 & 0.012 \\
\hline Capability of Client Key Personnel & 0.47 & 0.044 & 0.47 & 0.044 & & \\
\hline Recruitment and Training & 0.56 & 0.018 & 0.47 & 0.044 & & \\
\hline Latent Site Conditions & 0.53 & 0.026 & 0.50 & 0.034 & & \\
\hline Economics Risks & 0.79 & 0.0004 & & & 0.71 & 0.002 \\
\hline Adequacy of Plans \& Specifications & 0.47 & 0.044 & & & 0.48 & 0.044 \\
\hline Pioneering Status & 0.51 & 0.031 & & & 0.77 & 0.001 \\
\hline Project Size & 0.60 & 0.011 & & & 0.47 & 0.045 \\
\hline Level of Modularization & 1.00 & 0.000 & & & 0.67 & 0.004 \\
\hline Construction Control Meetings & 0.82 & 0.0002 & & & 0.67 & 0.004 \\
\hline Schedule Updates & 0.68 & 0.004 & & & 0.48 & 0.040 \\
\hline Functional Plan & & & 0.82 & 0.0001 & 0.84 & 0.000 \\
\hline Constructability & 0.63 & 0.008 & & & & \\
\hline Informal Construction Communication & 0.58 & 0.015 & & & & \\
\hline Design Complete & 0.52 & 0.029 & & & & \\
\hline Level of Automation & 0.59 & 0.013 & & & & \\
\hline Transparency in Work Award & 0.59 & 0.013 & & & & \\
\hline Budget Updates & & & 0.62 & 0.009 & & \\
\hline General Tolerance to Corruption & & & 0.47 & 0.044 & & \\
\hline Competent Authority Discretionary Powers & & & 0.74 & 0.001 & & \\
\hline Absence of Litigations & & & 0.62 & 0.009 & & \\
\hline Realistic Obligations & 0.47 & 0.044 & & & 0.60 & 0.012 \\
\hline PM Competency & & & & & 0.48 & 0.040 \\
\hline PM Authority & & & & & 0.67 & 0.004 \\
\hline PM Commitment and Involvement & & & & & 0.47 & 0.043 \\
\hline Competency of Client Team & & & & & 0.73 & 0.001 \\
\hline Competency of Contractor Team & & & & & 0.67 & 0.004 \\
\hline Competency of Consultant Team & & & & & 0.79 & 0.0004 \\
\hline Site Inspections & & & & & 0.47 & 0.040 \\
\hline
\end{tabular}


commitment and involvement, competency of client proposed team, competency of contractor proposed team, competency of consultant proposed team, and site inspections.

\subsubsection{Consultant Organization}

The term consultant organization refers to design firms. Table 5.4 shows significant factors for schedule performance, budget performance, and quality performance for the consultant organizations. Of the 53 factors, 6 were significant contributors to schedule performance, 7 were significant contributors to budget performance, and 12 were significant contributors to quality performance. The factors of capability of contractor key personnel, and adequacy of plans and specifications were seen to be commonly significant for all the three objectives. Level of skill labor required, and latent site conditions were commonly significant for schedule and budget performance.

Table 5.4 Consultant Organization Significant Factors.

\begin{tabular}{|l|c|c|c|c|c|c|}
\hline \multirow{2}{*}{ Potential Factor } & \multicolumn{5}{|c|}{ Significant at 5\% for conslt: } \\
\cline { 2 - 7 } & \multicolumn{2}{|c|}{ schedule } & \multicolumn{2}{|c|}{ budget } & \multicolumn{2}{c|}{ quality } \\
\cline { 2 - 8 } & $\mathrm{r}_{\mathrm{s}}$ & $p$-val & $\mathrm{r}_{\mathrm{s}}$ & $p$-val & $\mathrm{r}_{\mathrm{s}}$ & $p$-val \\
\hline Adequacy of Plans and Specifications & 0.80 & 0.005 & 0.67 & 0.024 & 0.86 & 0.001 \\
\hline Capability of Contractor Key Personnel & 0.68 & 0.022 & 0.80 & 0.005 & 0.62 & 0.036 \\
\hline Level of Skill Labor Required & 0.61 & 0.040 & 0.61 & 0.040 & & \\
\hline Latent Site Conditions & 0.71 & 0.015 & 0.63 & 0.034 & & \\
\hline Adequacy of Funding & 0.60 & 0.043 & & & & \\
\hline Contractual Motivation/Incentives & 0.75 & 0.010 & & & & \\
\hline Formal Dispute Resolution Process & & & 0.75 & 0.010 & & \\
\hline Capability of Consultant Key Personnel & & & 0.82 & 0.003 & & \\
\hline Formal Design Communication & & & 0.67 & 0.025 & & \\
\hline Pioneering Status & & & & & 0.72 & 0.014 \\
\hline Project Size & & & & & 0.69 & 0.020 \\
\hline Competency of Contractor Proposed Team & & & & & 0.70 & 0.018 \\
\hline Competency of Consultant Proposed Team & & & & & 0.71 & 0.015 \\
\hline Functional Plan & & & & & 0.67 & 0.025 \\
\hline Level of Modularization & & & & & 0.66 & 0.025 \\
\hline Design Control Meetings & & & & & 0.65 & 0.028 \\
\hline Construction Control Meetings & & & & & 0.69 & 0.018 \\
\hline Site Inspections & & & & & 0.65 & 0.030 \\
\hline Force Majour & & & & & 0.74 & 0.012 \\
\hline
\end{tabular}


The factors that were significant for schedule but not for budget and quality performance were adequacy of funding, and contractual motivation/incentives. The factors that significantly contributed only to budget performance were formal dispute resolution process, capability of consultant key personnel, and formal design communication. The factors that significantly contributed only to quality performance were pioneering status, project size, competency of contractor proposed team, competency of consultant proposed team, functional plan, level of modularization, design control meetings, construction control meetings, site inspections, and force majour.

\subsubsection{Overall Project Performance}

Table 5.5 shows that out of the total of 53 factors, only 40 were significant for at least one of schedule, budget or quality performances for any of the three professionals: contractors, managers, or consultants. This finding allowed for eliminating the 13 factors which could not satisfy the minimum significance criteria. Hence, subsequent analysis for overall project performance for each of the three professionals was conducted by considering only the 40 significant factors.

Table 5.6 shows the top ten CSFs for overall project performance for each of contractor personnel, managers, and consultants. It can be seen that for overall project performance the managers and the contractor personnel shared the same 6 CSFs: technical approval authorities, adequacy of funding, realistic obligations/clear objectives, adequacy of plans and specifications, level of skill labor required, and site inspections. Similarly, for overall project performance the managers and the consultants shared the same 5 CSFs: PM competency, capability of contractor key personnel, functional plan, design complete at construction start, and level of skill labor required. However, the contractor personnel and the consultants had only 1 common CSF: level of skill labor required. 
Table 5.5 List of 40 Significant factors.

\begin{tabular}{|c|c|c|c|c|c|c|c|c|c|}
\hline \multirow[t]{3}{*}{ Significant Factor } & \multicolumn{9}{|c|}{ Significant* at 5\% for: } \\
\hline & \multicolumn{3}{|c|}{$\begin{array}{l}\text { Contractor } \\
\text { Personnel }\end{array}$} & \multicolumn{3}{|c|}{ Managers } & \multicolumn{3}{|c|}{ Consultants } \\
\hline & $S$ & B & Q & $S$ & B & Q & $S$ & B & Q \\
\hline Economics Risks & & $*$ & $*$ & $*$ & & $*$ & & & \\
\hline Technical Approval authorities & $*$ & $*$ & & & & & & & \\
\hline Adequacy of Funding & $*$ & & & & & & $*$ & & \\
\hline Site Access Limitation & $*$ & $*$ & & $*$ & * & $*$ & & & \\
\hline Constructability & & & $*$ & $*$ & & & & & \\
\hline Pioneering Status & & & $*$ & $*$ & & $*$ & & & $*$ \\
\hline Project Size & & & * & * & & $*$ & & & $*$ \\
\hline Realistic Obligations/Clear Objectives & $*$ & $*$ & $*$ & & & $*$ & & & \\
\hline Adequacy of Plans and Specifications & $*$ & $*$ & $*$ & $*$ & & $*$ & $*$ & $*$ & $*$ \\
\hline Formal Dispute Resolution Process & & & & & & & & $*$ & \\
\hline Contractual Motivation/Incentives & $*$ & & & & & & $*$ & & \\
\hline PM Competency & & & $*$ & & & $*$ & & & \\
\hline PM Authority & & & $*$ & & & $*$ & & & \\
\hline PM Commitment and Involvement & & & * & & & $*$ & & & \\
\hline Capability of Client Key Personnel & & & & * & * & & & & \\
\hline Competency of Client Team & & & & & & $*$ & & & \\
\hline Capability of Contractor Key Personnel & $*$ & $*$ & $*$ & $*$ & $*$ & $*$ & $*$ & $*$ & $*$ \\
\hline Competency of Contractor Team & & & $*$ & & & $*$ & & & * \\
\hline Capability of Consultant Key Personnel & & $*$ & $*$ & * & $*$ & $*$ & & $*$ & \\
\hline Competency of Consultant Team & & $*$ & $*$ & & & $*$ & & & $*$ \\
\hline Formal Design Communication & & & & & & & & $*$ & \\
\hline Informal Construction Communication & $*$ & & & $*$ & & & & & \\
\hline Functional Plan & & $*$ & & & $*$ & $*$ & & & $*$ \\
\hline Design Complete at Construction Start & & $*$ & $*$ & $*$ & & & & & \\
\hline Level of Modularization & & & & $*$ & & $*$ & & & $*$ \\
\hline Level of Automation & & $*$ & * & * & & & & & \\
\hline Level of Skill Labor Required & & & $*$ & $*$ & $*$ & $*$ & $*$ & $*$ & \\
\hline Budget Updates & & & & & * & & & & \\
\hline Schedule Updates & $*$ & & & $*$ & & $*$ & & & \\
\hline Design Control Meetings & & & & & & & & & $*$ \\
\hline Construction Control Meetings & $*$ & $*$ & $*$ & $*$ & & $*$ & & & $*$ \\
\hline Site Inspections & $*$ & $*$ & $*$ & & & $*$ & & & $*$ \\
\hline General Tolerance Corruption & & $*$ & & & * & & & & \\
\hline
\end{tabular}

(Table Continued on next page) 
(Table Continued from last page)

\begin{tabular}{|c|c|c|c|c|c|c|c|c|c|}
\hline \multirow[t]{3}{*}{ Significant Factor } & \multicolumn{9}{|c|}{ Significant* at $5 \%$ for: } \\
\hline & \multicolumn{3}{|c|}{$\begin{array}{l}\text { Contractor } \\
\text { Personnel }\end{array}$} & \multicolumn{3}{|c|}{ Managers } & \multicolumn{3}{|c|}{ Consultants } \\
\hline & $S$ & B & Q & $S$ & B & Q & $S$ & B & Q \\
\hline Bureaucratic involvement & $*$ & & & & & & & & \\
\hline Transparency in work award & & $*$ & $*$ & $*$ & & & & & \\
\hline Competent Authority Powers & & & & & $*$ & & & & \\
\hline Recruitment and Training & & & & $*$ & * & & & & \\
\hline Absence of Litigations & & $*$ & & & $*$ & & & & \\
\hline Force Majour & & & & & & & & & $*$ \\
\hline Latent Site Conditions & $*$ & $*$ & & $*$ & $*$ & & $*$ & $*$ & \\
\hline S: Sche & udg & $t, 0$ & : Qua & lity & & & & & \\
\hline
\end{tabular}

Table 5.6 CSFs for Overall Project Success.

\begin{tabular}{|l|c|c|c|}
\hline Critical Success Factor & $\begin{array}{c}\text { Contractor } \\
\text { Personnel }\end{array}$ & Managers & Consultants \\
\hline Technical Approval authorities & 4 & 9 & - \\
\hline Adequacy of Funding & 2 & 8 & - \\
\hline Site Access Limitation & 6 & - & - \\
\hline Project Size & 5 & - & - \\
\hline Realistic Obligations/Clear Objectives & 9 & 5 & - \\
\hline Adequacy of Plans and Specifications & 10 & 7 & - \\
\hline PM Competency & - & 4 & 6 \\
\hline Capability of Contractor Key Personnel & - & 10 & 5 \\
\hline Competency of Contractor Proposed & & & 4 \\
\hline Team & - & - & 10 \\
\hline Capability of Consultant Key Personnel & - & - & 1 \\
\hline Competency of Consultant Proposed Team & - & - & 2 \\
\hline Functional Plan & - & 1 & 3 \\
\hline Design Complete at Construction Start & - & 3 & 8 \\
\hline Level of Modularization & - & - & 9 \\
\hline Level of Skill Labor Required & 3 & 6 & - \\
\hline Design Control Meetings & - & - & - \\
\hline Construction Control Meetings & 8 & - & - \\
\hline Site Inspections & 7 & 2 & - \\
\hline Transparency in awarding of work & 1 & - & - \\
\hline
\end{tabular}




\subsection{Discussion}

Interestingly for the contractor personnel, while schedule updates was significant for schedule performance, budget updates could not prove significant for budget performance. However, for the project management personnel (managers), while budget updates was significant for budget performance, schedule updates proved as significant for both schedule and quality performances. For the consultants, neither of budget or schedule updates proved as significant for any objective.

It is also interesting to note that, as against previous research findings (Chua et al. 1999), site inspection was considered by contractor personnel to have significant contribution not only for quality performance but also for budget and schedule performances. The managers and the consultants, on the other hand, held site inspection as significant only for quality performance.

A somewhat varying trend between contractor personnel, managers, and consultants was witnessed with regard to factors that have a finance related background. Adequacy of funding was held as significant at $5 \%$ level of confidence for schedule performance by the contractor personnel and the consultants, but not by the managers. Whereas the consultants did not hold economic risks as a significant factor for any objective, the contractor personnel considered it significant for budget and quality performances, and the managers held the factor as significant for schedule and quality performances.

Networking techniques such as Critical Path Method (CPM) and Program Evaluation Review Technique (PERT) are generally considered being synonymous with project management. A combined previous research on construction, research and development (R\&D), and manufacturing projects (Murphy et al. 1983) suggested that overuse of networking techniques, rather than being helpful is detrimental to successful implementation of projects. The particular finding had been justified by quoting the case study of a satellite program whose complex and time consuming network actually hampered its initial success. The factor 'overuse of networking techniques' was retested in this study by particularly presenting it to the respondents as 'initial overuse of CPM/PERT.' This was done for two reasons: (1) the said earlier research comprised construction projects only as a part of the whole study, and (2) with the advent of computerization, complexity of CPM/PERT may not be an issue in today's timeframe. Though the second reason may seem to have sufficient anecdotal evidence, it still needed to be researched empirically. Remarkably, the factor of 'initial overuse of CPM/PERT' 
could not prove as significant for any of the three professionals- Surprisingly, this held true for schedule as well as budget performance. While this finding clearly testifies that contractors, managers, and consultants do not consider early overuse of CPM/PERT as a significant determinant of construction project success, it does not essentially down play importance attached with sensible and continued use of networking techniques.

A comparative study by Pinto and Covin (1989) had shown that as opposed to R\&D projects, construction projects did not hold significance for the factor of 'project team personnel.' It was claimed that as compared to R\&D projects, construction projects are more routine and less innovative, and hence the need of trainings for construction personnel does not essentially arise. With regard to an increase in the complexity of construction projects over time, this study deemed it necessary to retest the factor by presenting it to the respondents as 'recruitment and training.' It revealed that though the factor was not significant for the contractor personnel and the consultants, it did hold significance for the managers for both schedule and budget performance.

It is comprehendible as to how schedule performance for contractors lies at the mercy of adequacy of funding and site inspections. The factor 'adequacy of funding' refers to timely provision of monitory resources by the owner to the contractor as an acceptance of the work done by the later. In the event that regular inspections are not conducted by the consultant to witness the completed work, and certify its required conformity to the plans and specifications that the consultant had framed in the contract documents, the contractor's ability to finance upcoming construction activities would be adversely affected. Delayed 'site inspections' by the consultant are bound to trigger a reduced 'adequacy of funding' for the contractor, which in turn negatively affects the schedule performance of the project.

Analogous to the dependence of schedule performance on site inspections, as seen by the contractor's personnel, is the explanation of the dependence of budget performance and quality performance on site inspections, capability of consultant key personnel, and competency of consultant proposed team. Timely observations of consultant during site inspections act as a blessing in disguise for the contractors. Late intimation about divergence from plans and specifications would magnify the cost that the contractor would have to incur on redoing rejected work. 
The factor of economic risks refers to changes in prices of labor, materials and equipment. While a deflation is rare to occur, inflation in the economy affects an investor's profit margin drastically. The higher the investment, the more is the risk associated with inflations. Compared to PMOs and consultants, contractors have a much bigger financial stake involved in construction projects, and are hence at the higher risk of inflation. The evil of inflation spares no type of contract- for lump sum and guaranteed maximum contracts, it causes a reduced profit (to say the least) on investment of the contractor; for cost plus fixed fee contracts, though the contractor would receive a larger sum as a profit but with a reduced purchasing power. Unless contract agreement allows compensation for escalations, the contractor's ability to ensure project quality would undoubtedly deteriorate. No wonder why economic risks demonstrated a strong significance for the contractor organizations regarding quality and budgetary performance.

Formal construction communications requires that all correspondences between the contractor and owner, or those between the contractor and designer (architect/engineer) be routed through the field representative of the owner, designer or the construction manager firm. Such a designated field representative is commonly referred to as the Resident Project Representative (RPR). Inheriting authority from his/her employer, the RPR is responsible for a wide range of subjects- scheduling, cost control, quality control through field inspections, ensuring work done according to established plans and specifications, reviewing contractor payment requests, verifying contractor claims, and project coordination. The RPR's authority by far is limited, as for instance the contractor's demand for a change of specification, if justifiable, can only be accorded by the project manager (located at the home office and overseeing an array of projects); the RPR merely communicates the contractor's demand to the PM, receives the PM's decision, and communicates it back to the contractor. As field situations often require, oral communication (of course to be followed by paper work) provides for the quickest mode of decision making, and hence prevents avoidable delays. The contractor personnel's and managers' desire of informal construction communication for schedule performance originates from this very principal.

\subsection{Conclusions}

Some useful unique inferences for the organization types were observed. For instance, while contractor personnel are aware of the importance of site inspections for quality performance, they also deem it essential for maintaining their cash flows (budget performance) 
which in turn affects their productivity (schedule performance). Another unique inference is the managers' attachment of significance to training for schedule and budget performances that indicates that construction management is not a set of routine activities as it had been previously thought of- It is innovative and complex in nature. Also, contractor personnel's attachment of a high significance to bureaucratic involvement and technical approval authorities for schedule performance emanates from the reality that the responsibility of obtaining technical approvals primarily lays on their shoulders.

Some interesting commonalities of results between the organization types are worth mentioning. The fact that contractor personnel, managers, and consultants hold latent site conditions as critical for schedule and budget performances indicates that no amount of initial investigations and surveys can eliminate the possibility of unforeseen site conditions. The finding that contractor personnel, managers and consultants hold capability of contractor key personnel as significant for all the three objectives testifies that project success without able leaders in contractor team is nothing but wishful thinking.

Similarly, both managers and contractor personnel are in agreement over the role that the three PM related factors play in ensuring quality performance. The importance of Informal construction communications shall not be underestimated as both the managers and contractors value it as an asset for good schedule performance. Furthermore, unless contract agreement allows compensation for escalations, the contractor's ability to ensure project quality would undoubtedly deteriorate; No wonder why economic risks demonstrated a strong significance for the managers and contractor personnel regarding quality performance. Lastly, as would be expected both the managers and contractor personnel testify the significant impact of absence of litigations and general tolerance to corruption on budget performance.

Spearman's test on rankings of the 40 significant factors (Table 5.5) for overall project performance results in a highest level of correlation between the managers and contractor personnel ( $\mathrm{rs}=0.54)$, followed by that between the managers and the consultants $(\mathrm{rs}=0.50)$, and a least correlation between the contractor personnel and the consultants ( $r s=0.19$ ). Managers not only maintain a significant presence on the site with the contractors, but also coordinate with the consultants regarding any design-construction issues that arise more than often during project execution: No wonder why their pivotal position helps the managers to establish a higher understanding with both contractor personnel and consultants. The lowest correlation of views 
between the contractor personnel and the consultants arise from the spot on difference between their workspace environments. Whereas the contractor personnel operate in the field, the consultants are mostly restricted to their design offices. 


\section{References}

1. Ashley, D.B., Lurie, C.S., and Jaselskis, E.J. (1987). "Determinants of construction project success.” Project Management Journal, 18(2), 69-79.

2. Ashley, D.B., and Jaselsky, E.J. (1991). "Optimal allocation of project management resources for achieving success." Journal of Construction Engineering and Management, ASCE, 117(2), 321-340.

3. Boynton, A.C., and Zmund, R.W. (1984). "An assessment of critical success factors." Sloan Management Review, 25(4), 17-27.

4. Chan, D.W.M., and Kumaraswamy, M.M. (1997). "A comparative study of causes of overruns in Hong Kong construction projects." International Journal of Project Management, 15(1), 55-63.

5. Chua, D.K.H., Kog,Y.C., and Loh, P.K. (1999). "Critical Success Factors for different project objectives." Journal of Construction Engineering and Management, ASCE, 125(3), 142-150.

6. Cleland, D.I. (1986). "Measuring success: The owner's viewpoint.” Proc., Project Management Institute, Montreal, Canada, 1986, 6-12.

7. Construction Management Committee of the ASCE Construction Division. (1991). "Constructability and constructability programs: White Paper." Journal of Construction Engineering and Management, ASCE, 117(1), 67-89.

8. de Wit, A. (1986). "Measuring project success: an illusion.” Proc., Project Management Institute, Montreal, Canada, 1986, 69-79.

9. Diekmann, J.E., and Girard, M.J. (1995). “Are contract disputes predictable?” Journal of Construction Engineering and Management, ASCE, 121(4), 335-363.

10. Gordon, C.M. (1994). “Choosing appropriate construction contracting method.” Journal of Construction Engineering and Management, ASCE, 118(1), 94-111.

11. Hwang, B., and Lim, E.J. (2012). "Critical success factors for key project players and objectives: case study of Singapore." Journal of Construction Engineering and Management, ASCE, doi: 10.1061/(ASCE)CO.1943-7862.0000597. 
12. Jaselskis, E. J. (1988). Achieving construction project success through prediction discrete choice model, Ph.D thesis, University of Texas at Austin.

13. Kog, Y.C., and Loh, P.K. (posted ahead of print August 10, 2011.). "Critical Success Factors for different components of construction projects." Journal of Construction Engineering and Management, ASCE, doi: 10.1061/(ASCE)CO.1943-7862.0000464.

14. Loh, P. K. (2000). Critical success factors in computer-based construction project management, Ph.D thesis, The National University of Singapore, 291p.

15. Macomber, J.D. (1989). "You can manage construction risk." Harvard Business Review, 67(2), 155-165.

16. Might, R.J., and Fisher, W.A. (1985). "The role of structural factors in determining project management success.” IEEE Transactions on Engineering Management, 32(2), $71-77$.

17. Morris, P.W.G. (1983). "Managing project interfaces-key points for project success." Project management handbook, D.I. Cleland and W.R. King, eds., Van Nostrand Reinhold, New York, 1983, 3-36.

18. Murphy, D.C., Baker, B.N., and Fisher, D. (1974). "Determinants of project success." National Technical Information Service, USDC, Springfield, VA. 22151.

19. Murphy, D.C., Baker, B.N., and Fisher, D., (1983). "Factors affecting project success." Project management handbook, D.I. Cleland and W.R. King, eds., Van Nostrand Reinhold, New York, 1983, 669-685.

20. Narasimhan, R., and Schroeder, R.G, (1979). "An empirical investigation of implementation as a change process." In: Doktor, R., Schultz, R.L., and Slevin, D.P., The Implementation of Management Science, North-Holland, Amsterdam, 63-84.

21. Pinto, J.K., and Covin, J.G. (1989). "Critical factors in project implementation: a comparison of construction and R\&D projects." Technovation, 9(1), 49-62.

22. Pinto, J.K., and Mantel, S.J. (1990). "The causes of project failure." IEEE Transactions on Engineering Management, 37(4), 269-276.

23. Pinto, J.K., and Slevin, D.P. (1987). "Critical factors in successful project implementation." IEEE Transactions on Engineering Management, 34(1), 22-27.

24. Pinto, J.K., and Slevin, D.P. (1986). "The project implementation profile: new tool for project managers." Project Management Journal, XVIII(4), 57-71. 
25. Project Management Handbook (1983), 2nd edition, D. I. Cleland and W. R. King, eds, Van Nostrand Reinhold, New York, 479-512.

26. Saaty, T.L. (2006). "Rank from comparisons and from ratings in the analytical hierarchy/network processes.” European Journal of Operational Research, 168, 557-570.

27. Saaty, T.L. (1980), The Analytical Hierarchy Process: planning, priority setting, resource allocation, McGraw-Hill Inc.

28. Sanvido, V., Parfitt, K., Grobler, F., Guvenis, M. and Coyle, M. (1992). "Critical success factors for construction projects." Journal of Construction Engineering and Management, $A S C E$, 118(1), 94-111.

29. Tuman, J.J. (1986). "Success modeling: A technique for building a winning project team.” Proc., Project Management Institute, Montreal, Canada, pp.94-108.

30. Yeomans, K.A. (1979), Statistics for the social scientist 2: Applied Statistics, Penguin Education, England. 


\section{Appendix A - Outcomes of Murphy et al. (1974)}

Table A.1 Strong Failure Factors [Murphy et al. 1974]

1. Insufficient use of status/progress reports.

2. Use of superficial status/progress reports.

3. Inadequate PM administrative skills.

4. Inadequate PM human skills.

5. Inadequate PM technical skills.

6. Inadequate PM influence.

7. Inadequate PM authority.

8. Insufficient client influence.

9. Poor coordination with client.

10. Lack of rapport with client.

11. Client disinterest in budget criteria.

12. Lack of project team participation in decision making.

13. Lack of project team participation in major problem solving.

14. Excessive structuring within the project team.

15. Job insecurity within the project team.

16. Lack of team spirit and sense of mission within project team.

17. Parent organization stable, non-dynamic, lacking strategic change.

18. Poor coordination with parent organization.

19. Lack of rapport with parent organization.

20. Poor relations within the parent organization.

21. New type of project.

22. Project more complex than the parent has completed previously.

23. Initial underfunding.

24. Inability to freeze design early.

25. Inability to close-out the effort.

26. Unrealistic project schedules.

27. Inadequate change procedures.

28. Poor relations with public officials.

29. Unfavorable public opinion. 
Table A.2 Strong Success Factors [Murphy et al. 1974]

1. Frequent feedback from parent organization.

2. Frequent feedback from the client.

3. Judicious use of networking techniques.

4. Availability of backup strategies.

5. Organization structure suited to the project team.

6. Adequate control procedures, especially for dealing with changes.

7. Project team participation in determining schedules and budgets.

8. Flexible parent organization.

9. Parent organization commitment to established schedules.

10. Parent organization enthusiasm.

11. Parent organization commitment to established budget.

12. Parent organization commitment to technical performance goals.

13. Parent organization desire to build-up internal capabilities.

14. PM commitment to established schedules.

15. PM commitment to established budget.

16. PM commitment to technical performance goals.

17. Client commitment to established schedules.

18. Client commitment to established budget.

19. Client commitment to technical performance goals.

20. Enthusiastic public support.

21. Lack of legal encumbrances.

22. Lack of excessive government red tape.

23. Minimized number of public/government agencies involved. 
Table A.3 Strong Common Factors [Murphy et al. 1974]

1. Goal commitment to project team

2. Accurate initial cost estimates.

3. Adequate project team capability.

4. Adequate funding to completion.

5. Adequate planning and control techniques.

6. Minimal start-up difficulties.

7. Task (vs. social) orientation.

8. Absence of bureaucracy.

9. On-site project manager.

10. Clearly established success criteria. 


\section{Appendix B - Inputs and Results of Kog and Loh (2011)}

Table B.1 List of 67 Potential Factors Considered in the Study [Kog and Loh 2011]

\begin{tabular}{|c|c|}
\hline $\begin{array}{c}\text { Project } \\
\text { Characteristics }\end{array}$ & $\begin{array}{l}\text { Political Risks, Economics Risks, Impact on Public, Technical Approval } \\
\text { Authorities, Adequacy of Funding, Site Limitation and location, Constructability, } \\
\text { Pioneering Status, Project Size. }\end{array}$ \\
\hline $\begin{array}{l}\text { Contractual } \\
\text { Arrangement }\end{array}$ & $\begin{array}{l}\text { Realistic Obligations/Clear Objectives, Risk Identification and allocation, } \\
\text { Adequacy of Plans and Specifications, Formal Dispute Resolution Process, } \\
\text { Contractual Motivation/Incentives }\end{array}$ \\
\hline $\begin{array}{c}\text { Project } \\
\text { Participants }\end{array}$ & $\begin{array}{l}\text { PM Competency, PM Authority, PM Commitment and Involvement, Capability of } \\
\text { Client Key Personnel, Competency of Client Proposed Team, Client Team } \\
\text { Turnover Rate, Client Top Management Support, Client Track Record, Client Level } \\
\text { of Service, Capability of Contractor Key Personnel, Competency of Contractor } \\
\text { Proposed Team, Contractor Team Turnover Rate, Contractor Top Management } \\
\text { Support, Contractor Track Record, Contractor Level of Service, Capability of } \\
\text { Consultant Key Personnel, Competency of Consultant Proposed Team, Consultant } \\
\text { Team Turnover Rate, Consultant Top Management Support, Consultant Track } \\
\text { Record, Consultant Level of Service, Capability of Subcontractors' Key Personnel, } \\
\text { Competency of Subcontractors' Proposed Team, Subcontractors' Team Turnover } \\
\text { Rate, Subcontractors' Top Management Support, Subcontractors' Track Record, } \\
\text { Subcontractors' Level of Service, Capability of Suppliers Key Personnel, } \\
\text { Competency of Suppliers Proposed Team, Suppliers Team Turnover Rate, } \\
\text { Suppliers Top Management Support, Suppliers Track Record, Suppliers Level of } \\
\text { Service. }\end{array}$ \\
\hline $\begin{array}{l}\text { Interactive } \\
\text { Process }\end{array}$ & $\begin{array}{l}\text { Formal Design Communication, Informal Design Communication, Formal } \\
\text { Construction Communication, Informal Construction Communication, Functional } \\
\text { Plan, Design Complete at Construction Start, Constructability Program, Level of } \\
\text { Modularization, Level of Automation, Level of Skill Labor Required, Report } \\
\text { Updates, Budget Updates, Schedule Updates, Design Control Meetings, } \\
\text { Construction Control Meetings, Site Inspections, Work Organization Chart, } \\
\text { Common Goal, Motivational Factor, Relationships. }\end{array}$ \\
\hline
\end{tabular}


Table B.2 Ranking of CSFs for C\&S Works [Kog and Loh 2011]

\begin{tabular}{|l|c|c|c|c|}
\hline Potential Factor & Schedule & Budget & Quality & Overall \\
\hline Constructability & 1 & 1 & 2 & 1 \\
\hline Adequacy of plans and specifications & 2 & 3 & 1 & 2 \\
\hline Realistic obligations/clear objectives & 3 & 4 & 3 & 3 \\
\hline Economic risks & 8 & 2 & - & 4 \\
\hline PM Competency & 4 & 5 & 5 & 5 \\
\hline PM Commitment and involvement & - & - & 8 & 6 \\
\hline Contractual motivation/incentive & 5 & - & 7 & 7 \\
\hline Technical approval authorities & 7 & - & - & 8 \\
\hline Construction control meetings & 9 & - & 9 & 9 \\
\hline Pioneering status & - & 9 & 6 & 10 \\
\hline Schedule updates & 6 & - & - & - \\
\hline Site limitation and location & 10 & 10 & - & - \\
\hline Adequacy of funding & - & 6 & - & - \\
\hline Budget updates & - & 7 & - & - \\
\hline Risk identification and allocation & - & 8 & - & - \\
\hline Site inspection & - & - & 4 & - \\
\hline Contractor team turnover rate & - & - & 10 & - \\
\hline
\end{tabular}

Table B.3 Ranking of CSFs for M\&E Works [Kog and Loh 2011]

\begin{tabular}{|l|c|c|c|c|}
\hline Potential Factor & Schedule & Budget & Quality & Overall \\
\hline PM Competency & 1 & 2 & 2 & 1 \\
\hline Adequacy of plans and specifications & 3 & 1 & 5 & 2 \\
\hline Constructability & 2 & - & 1 & 3 \\
\hline Realistic obligations/clear objectives & - & 3 & 8 & 4 \\
\hline PM commitment and involvement & 4 & 7 & 7 & 5 \\
\hline Construction control meetings & 5 & - & 4 & 6 \\
\hline Contractual motivation/incentive & - & 5 & - & 7 \\
\hline Technical approval authorities & 7 & - & - & 8 \\
\hline Constructability Program & 6 & 10 & - & 9 \\
\hline Modularization & - & - & 9 & 10 \\
\hline Schedule updates & 8 & - & - & - \\
\hline Site inspection & - & - & 3 & - \\
\hline Project size & 9 & - & 6 & - \\
\hline Contractor team turnover rate & 10 & - & 10 & - \\
\hline Adequacy of funding & - & 4 & - & - \\
\hline Risk identification and allocation & - & 6 & - & - \\
\hline Economic risks & - & 8 & - & - \\
\hline Budget updates & - & 9 & - & - \\
\hline
\end{tabular}


Table B.4 Ranking of CSFs for Architectural Works [Kog and Loh 2011]

\begin{tabular}{|l|c|c|c|c|}
\hline Potential Factor & Schedule & Budget & Quality & Overall \\
\hline Adequacy of plans and specifications & 2 & 1 & 1 & 1 \\
\hline Realistic obligations/clear objectives & 4 & 2 & 7 & 2 \\
\hline PM Competency & 1 & 5 & 10 & 3 \\
\hline Adequacy of funding & - & 4 & - & 4 \\
\hline $\begin{array}{l}\text { Capability of consultant key } \\
\text { personnel }\end{array}$ & - & - & 2 & 5 \\
\hline Pioneering status & - & - & 3 & 6 \\
\hline Consultant team turn-over rate & 10 & 10 & 4 & 7 \\
\hline Constructability & 5 & 9 & 9 & 8 \\
\hline Client top management support & - & 3 & - & 9 \\
\hline Consultant team competency & - & - & 5 & 10 \\
\hline Formal construction communication & 3 & - & - & - \\
\hline PM Commitment and involvement & 6 & - & - & - \\
\hline Contractual motivation/incentive & 7 & 7 & - & - \\
\hline PM Authority & - & 6 & - & - \\
\hline $\begin{array}{l}\text { Capability of contractor key } \\
\text { personnel }\end{array}$ & 8 & 8 & 6 & - \\
\hline Contractor team competency & 9 & - & 8 & - \\
\hline
\end{tabular}

Table B.5 Ranking of CSFs for QS Works [Kog and Loh 2011]

\begin{tabular}{|l|c|c|c|c|}
\hline Potential Factor & Schedule & Budget & Quality & Overall \\
\hline Adequacy of plans and specifications & 2 & 2 & 1 & 2 \\
\hline PM Competency & 6 & 5 & 9 & 5 \\
\hline Constructability & 1 & 9 & 5 & 1 \\
\hline Realistic obligations/clear objectives & 3 & 6 & 7 & 4 \\
\hline Contractual motivation/incentive & 8 & - & 10 & 9 \\
\hline Site limitation and location & 5 & - & - & 8 \\
\hline PM Commitment and involvement & 4 & 3 & 6 & 3 \\
\hline Schedule updates & 10 & - & - & - \\
\hline PM Authority & 7 & 8 & 8 & 6 \\
\hline Formal Construction communication & 9 & - & - & - \\
\hline Economic risks & - & 1 & 4 & 7 \\
\hline Adequacy of funding & - & 7 & 3 & 10 \\
\hline Budget updates & - & 10 & - & - \\
\hline Risk identification and allocation & - & 4 & - & - \\
\hline site inspection & - & - & 2 & - \\
\hline
\end{tabular}


Table B.6 Ranking of CSFs for Schedule Performance [Kog and Loh 2011]

\begin{tabular}{|l|c|c|c|c|}
\hline Potential Factor & C\&S & M\&E & Arch & QS \\
\hline Adequacy of plans and specifications & 2 & 3 & 2 & 2 \\
\hline PM Competency & 4 & 1 & 1 & 6 \\
\hline Constructability & 1 & 2 & 5 & 1 \\
\hline Technical approval authorities & 7 & 7 & - & - \\
\hline Construction control meetings & 9 & 5 & - & - \\
\hline Schedule updates & 6 & 8 & - & 10 \\
\hline Economic risks & 8 & - & - & - \\
\hline Site limitation and location & 10 & - & - & 5 \\
\hline Contractor team turnover rate & - & 10 & - & - \\
\hline Project size & - & 9 & - & - \\
\hline Constructability Program & - & 6 & - & - \\
\hline Capability of contractor key personnel & - & - & 8 & - \\
\hline Contractor team competency & - & - & 9 & - \\
\hline Consultant team turn-over rate & - & - & 10 & - \\
\hline Formal construction communication & - & - & 3 & 9 \\
\hline Realistic obligations/clear objectives & 3 & - & 4 & 3 \\
\hline Contractual motivation/incentive & 5 & - & 7 & 8 \\
\hline PM Commitment and involvement & - & 4 & 6 & 4 \\
\hline
\end{tabular}


Table B.7 Ranking of CSFs for Quality Performance [Kog and Loh 2011]

\begin{tabular}{|l|c|c|c|c|}
\hline Potential Factor & C\&S & M\&E & Arch & QS \\
\hline $\begin{array}{l}\text { Adequacy of plans and } \\
\text { specifications }\end{array}$ & 1 & 5 & 1 & 1 \\
\hline $\begin{array}{l}\text { Realistic obligations/clear } \\
\text { objectives }\end{array}$ & 3 & 8 & 7 & 7 \\
\hline PM competency & 5 & 2 & 10 & 9 \\
\hline Constructability & 2 & 1 & 9 & 5 \\
\hline PM commitment and involvement & 8 & 7 & - & 6 \\
\hline Site inspection & 4 & 3 & - & 2 \\
\hline Construction control meetings & 9 & 4 & - & - \\
\hline Contractor team turnover rate & 10 & 10 & - & - \\
\hline Contractual motivation/incentive & 7 & - & - & 10 \\
\hline Project size & - & 6 & - & - \\
\hline Modularization & - & 9 & - & - \\
\hline $\begin{array}{l}\text { Capability of consultant key } \\
\text { personnel }\end{array}$ & - & - & 2 & - \\
\hline Consultant team competency & - & - & 5 & - \\
\hline $\begin{array}{l}\text { Capability of contractor key } \\
\text { personnel }\end{array}$ & - & - & 6 & - \\
\hline Contractor team competency & - & - & 8 & - \\
\hline Consultant team turn-over rate & - & - & 4 & - \\
\hline Economic risks & - & - & - & 4 \\
\hline PM authority & - & - & - & 8 \\
\hline Adequacy of funding & - & - & - & 3 \\
\hline Pioneering status & 6 & - & 3 & - \\
\hline
\end{tabular}


Table B.8 Ranking of CSFs for Budget Performance [Kog and Loh 2011]

\begin{tabular}{|l|c|c|c|c|}
\hline \multicolumn{1}{|c|}{ Potential Factor } & C\&S & M\&E & Arch & QS \\
\hline Adequacy of plans and specifications & 3 & 1 & 1 & 2 \\
\hline Realistic obligations/clear objectives & 4 & 3 & 2 & 6 \\
\hline PM competency & 5 & 2 & 5 & 5 \\
\hline Adequacy of funding & 6 & 4 & 4 & 7 \\
\hline Economic risks & 2 & 8 & - & 1 \\
\hline Budget updates & 7 & 9 & - & 10 \\
\hline Risk identification and allocation & 8 & 6 & - & 4 \\
\hline Pioneering status & 9 & - & - & - \\
\hline Site limitation and location & 10 & - & - & - \\
\hline Constructability program & - & 10 & - & - \\
\hline PM commitment and involvement & - & 7 & - & 3 \\
\hline Client top management support & - & - & 3 & - \\
\hline $\begin{array}{l}\text { Contractor capability of key } \\
\text { personnel }\end{array}$ & - & - & 8 & - \\
\hline Consultant team turnover rate & & & 10 & \\
\hline PM authority & - & - & 6 & 8 \\
\hline Constructability & 1 & - & 9 & 9 \\
\hline Contractual motivation/incentives & - & 5 & 7 & - \\
\hline
\end{tabular}


Table B.9 Ranking of CSFs for Overall Performance [Kog and Loh 2011]

\begin{tabular}{|l|c|c|c|c|}
\hline Potential Factor & C\&S & M\&E & Arch & QS \\
\hline Constructability & 1 & 3 & 8 & 1 \\
\hline Adequacy of plans and specifications & 2 & 2 & 1 & 2 \\
\hline PM competency & 5 & 1 & 3 & 5 \\
\hline Realistic obligations/clear objectives & 3 & 4 & 2 & 4 \\
\hline Construction control meetings & 9 & 6 & - & - \\
\hline Technical approval authorities & 8 & 8 & - & - \\
\hline PM commitment and involvement & 6 & 5 & - & 3 \\
\hline Contractual motivation/incentive & 7 & 7 & - & 9 \\
\hline Economic risks & 4 & - & - & 7 \\
\hline Constructability Program & - & 9 & - & - \\
\hline Modularization & - & 10 & - & - \\
\hline Client top management support & - & - & 9 & - \\
\hline Capability of consultant key & & & & \\
\hline personnel & - & - & 5 & - \\
\hline Consultant team turn-over rate & - & - & 7 & - \\
\hline Consultant team competency & - & - & 10 & - \\
\hline Adequacy of funding & - & - & 4 & 10 \\
\hline PM authority & - & - & - & 6 \\
\hline Site limitation and location & - & - & - & 8 \\
\hline Pioneering status & 10 & - & 6 & - \\
\hline
\end{tabular}




\section{Appendix C - Research Component}

Table C.1 List of 53 Potential Factors Considered in the Study.

\begin{tabular}{|c|c|}
\hline $\begin{array}{c}\text { Project } \\
\text { Characteristics }\end{array}$ & $\begin{array}{l}\text { Political Risks, Economics Risks, Public Opinion, Technical Approval Authorities, } \\
\text { Adequacy of Funding, Site Access Limitation, Constructability, Pioneering Status, } \\
\text { Project Size. }\end{array}$ \\
\hline $\begin{array}{l}\text { Contractual } \\
\text { Arrangement }\end{array}$ & $\begin{array}{l}\text { Realistic Obligations/Clear Objectives, Adequacy of Plans and Specifications, } \\
\text { Formal Dispute Resolution Process, Contractual Motivation/Incentives. }\end{array}$ \\
\hline $\begin{array}{c}\text { Project } \\
\text { Participants }\end{array}$ & $\begin{array}{l}\text { PM Competency, PM Authority, PM Commitment and Involvement, Capability of } \\
\text { Client Key Personnel, Competency of Client Proposed Team, Client Top } \\
\text { Management Support, Client Track Record, Capability of Contractor Key } \\
\text { Personnel, Competency of Contractor Proposed Team, Contractor Top Management } \\
\text { Support, Contractor Track Record, Capability of Consultant Key Personnel, } \\
\text { Competency of Consultant Proposed Team, Consultant Top Management Support, } \\
\text { Consultant Track Record. }\end{array}$ \\
\hline $\begin{array}{l}\text { Interactive } \\
\text { Process }\end{array}$ & $\begin{array}{l}\text { Formal Design Communication, Informal Design Communication, Formal } \\
\text { Construction Communication, Informal Construction Communication, Functional } \\
\text { Plan, Design Complete at Construction Start, Constructability Program, Level of } \\
\text { Modularization, Level of Automation, Level of Skill Labor Required, Budget } \\
\text { Updates, Schedule Updates, Design Control Meetings, Construction Control } \\
\text { Meetings, Site Inspections. }\end{array}$ \\
\hline Miscellaneous & $\begin{array}{l}\text { General Tolerance to Corruption, Bureaucratic Involvement, Transparency in } \\
\text { Awarding of Work, Post-award Impartiality, Competent Authority Discretionary } \\
\text { Powers, Recruitment and Training Procedures. Absence of Litigations/Claims, } \\
\text { Initial Overuse of CPM/PERT, Force Majour, Latent Site Conditions. }\end{array}$ \\
\hline
\end{tabular}


Table C.2 Explanation of Important Factors.

\begin{tabular}{|l|l|}
\hline Factor & Explanation \\
\hline Economic Risks & Refers to changes in prices of labor, materials and equipment. \\
\hline Technical Approval Authorities & Refers to Bureaucratic involvement. \\
\hline Public Opinion & Refers to involvement of public primarily in public projects. \\
\hline Pioneering Status & $\begin{array}{l}\text { The extent of familiarity of project team to new methodology used } \\
\text { in the project. A project is of pioneering status if methodology used } \\
\text { in the project is new to the project team. }\end{array}$ \\
\hline Realistic Obligations & $\begin{array}{l}\text { Expecting a productivity level (from project team members) which } \\
\text { is within achievable limits. }\end{array}$ \\
\hline PM Competency & $\begin{array}{l}\text { Refers to Administrative, technical and interpersonal skills of the } \\
\text { PM. }\end{array}$ \\
\hline Top-management Support & $\begin{array}{l}\text { Willing of top management to provide necessary resources and } \\
\text { authority to lower staff for effective performance of their tasks. (In a } \\
\text { project management organization, the top management includes all } \\
\text { the hierarchy above the level of project managers. The same analogy } \\
\text { applies to client organization, consultant organization and contractor } \\
\text { organization). }\end{array}$ \\
\hline Functional Plan & $\begin{array}{l}\text { Detailed plans for schedule, budget and resource allocation. } \\
\text { Level of Modularity }\end{array}$ \\
$\begin{array}{l}\text { Refers to the construction of an object by joining together } \\
\text { standardized units to form larger compositions. }\end{array}$ \\
\hline
\end{tabular}

